University of Louisville

ThinkIR: The University of Louisville's Institutional Repository

Electronic Theses and Dissertations

$5-2011$

\title{
Examining the mismatch between the training and assessment of band and orchestra conductors in Michigan.
}

Eric A. Becher

University of Louisville

Follow this and additional works at: https://ir.library.louisville.edu/etd

\section{Recommended Citation}

Becher, Eric A., "Examining the mismatch between the training and assessment of band and orchestra conductors in Michigan." (2011). Electronic Theses and Dissertations. Paper 91.

https://doi.org/10.18297/etd/91

This Doctoral Dissertation is brought to you for free and open access by ThinkIR: The University of Louisville's Institutional Repository. It has been accepted for inclusion in Electronic Theses and Dissertations by an authorized administrator of ThinkIR: The University of Louisville's Institutional Repository. This title appears here courtesy of the author, who has retained all other copyrights. For more information, please contact thinkir@louisville.edu. 


\title{
EXAMINING THE MISMATCH BETWEEN THE TRAINING AND ASSESSMENT OF BAND AND ORCHESTRA CONDUCTORS IN MICHIGAN
}

\author{
By \\ Eric A. Becher \\ B.M., The University of Michigan, 1978 \\ M.M., The University of Michigan, 1980 \\ A Dissertation \\ Submitted to the Faculty of the \\ Graduate School of the University of Louisville \\ In Partial Fulfillment of the Requirements \\ For the Degree of \\ Doctor of Philosophy \\ Higher Education \\ Department of Educational Leadership, Foundations and Human Resource Education \\ University of Louisville \\ Louisville, Kentucky
}

May 2011 
Copyright 2011 by Eric A. Becher

All rights reserved 



\section{EXAMINING THE MISMATCH BETWEEN THE TRAINING AND ASSESSMENT OF BAND AND ORCHESTRA CONDUCTORS IN MICHIGAN}

\section{By}

Eric A. Becher

B.M., The University of Michigan, 1978

M.M., The University of Michigan, 1980

A Dissertation Approved on

May 11, 2011

By the following Dissertation Committee

Dr. John Keedy, Dissertation Director

Dr. Albert Ly gets

Dr. Frederick $\$$ peck

Dr. Jason Winffee 


\section{DEDICATION}

This dissertation is dedicated to my parents

Dr. William D. and Helen N. Becher 


\section{ACKNOWLEDGEMENTS}

I would like to thank my dissertation director, Dr. John L. Keedy, for his assistance throughout my doctoral studies and in preparation of all phases of this dissertation. His advice, expertise, and patience in all aspects of this dissertation process has been invaluable to this process. I would also like to thank my other committee members, Dr. Frederick Speck, Dr. Albert Lyons, and Dr. Jason Winfree for their comments, suggestions, and encouragement. Special thanks is given to Dr. Nancy Becker Johnson for her tireless work in proof reading this dissertation through many revisions. Finally, a lifetime of thanks to my parents William and Helen Becher for their love, support, kindness, and patience in all aspects of my education and personal growth. 


\title{
ABSTRACT \\ EXAMINING THE MISMATCH BETWEEN THE TRAINING AND ASSESSMENT OF BAND AND ORCHESTRA CONDUCTORS IN MICHIGAN
}

\author{
Eric A. Becher
}

May 11, 2011

The dissertation builds on the research literature studying conductor training and the musical attributes requisite for adequate conducting skill and musical performance. The study also provides evidence that effective tools for evaluation of band and orchestra conductors are prevalent throughout the music education literature. Public school administrators, however, are generally unaware of that literature and often lack adequate assessment instruments to measure conductor effectiveness in rehearsal settings.

Conductors have been teaching in the public schools for almost a century, however, many still undergo assessment procedures as if they were in an academic classroom. The study was assisted by the Michigan School Band and Orchestra Association (MSBOA) who provided a clean set of respondents representing middle school and high school conductors from the State of Michigan.

Three research questions framed the study. The first research question identified to what extent the conductors' formal training matched up with the musical attributes requisite for adequate conducting skill and musical performance. The literature review provided the context for a comparison of these training attributes based on the frequency 
of those attributes found in the research studies. The survey results from the study respondents provided a compilation of the means and standard deviations of the conductors' formal training as compared with the musical attributes requisite to adequate conducting skill and musical performance. The second research question investigated whether the conductors perceived that their review process evaluated these same musical attributes. The researcher used a Pearson-Product Moment correlation analysis to compare the means of those musical skills received in their studies with the assessment criteria used by administrators. This method measured the strength of the relationship between the training and the assessment instruments used by administrators in the public schools.

For the third research question, the study determined to what extent the review process contributed to their job satisfaction. The researcher used a regression analysis to compare overall job satisfaction with the evaluative process and with specific variables that correlated to job satisfaction or dissatisfaction. A regression analysis instrument measured the difference for each factor to determine the statistical association that assessment variables had with job satisfaction.

The final chapter summarizes the study's implications for conductor assessment and provides a possible framework for use in Michigan public schools for administrators to effectively evaluate conductors. This proposed assessment instrument aligns the formal musical training attributes found in the literature with those of successful musical performance practices and offers opportunities for growth and continued development of the conductor. 


\section{TABLE OF CONTENTS}

PAGE

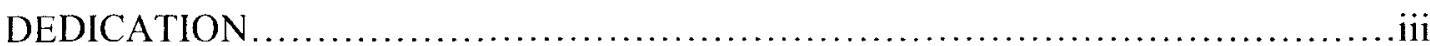

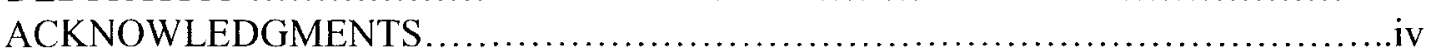

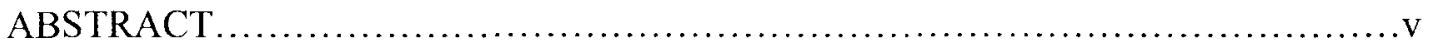

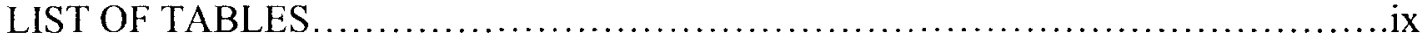

\section{CHAPTER}

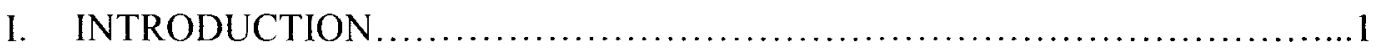

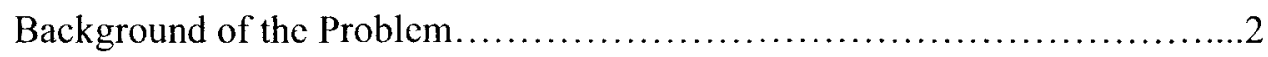

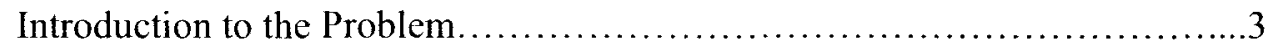

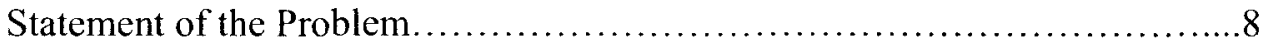

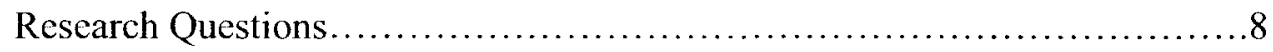

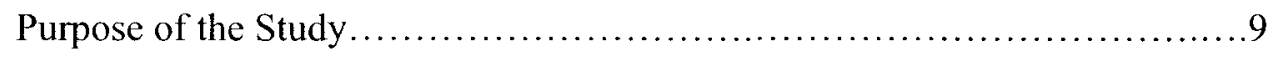

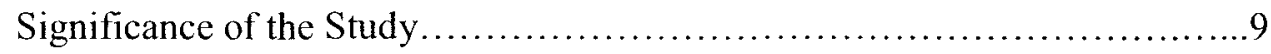

Definition of Terms....................................................... 10

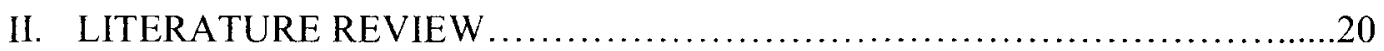

General Music Education Research....................................21

Concert and Marching Band Research................................43

Choral and String Ensemble Research....................................70

Applied Music Research................................................92

Elementary Music Instruction Research...................................100

Conducting Gesture Research.........................................110 
Research on Score Study and Evaluation of Students

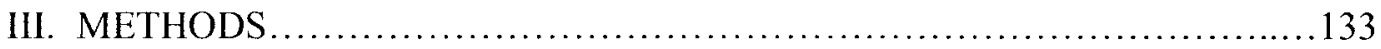

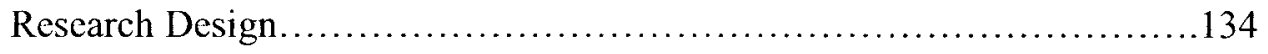

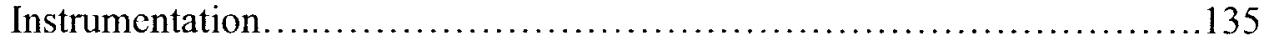

Participants......................................................... 136

Data Collection .................................................... 136

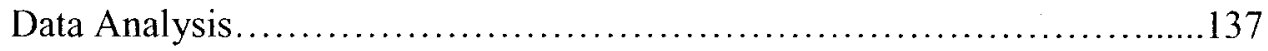

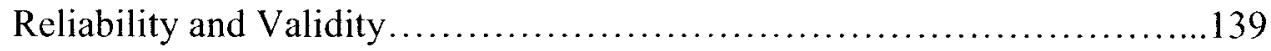

Limitations of Study ............................................ 140

Matrix from the Literature Review.................................. 142

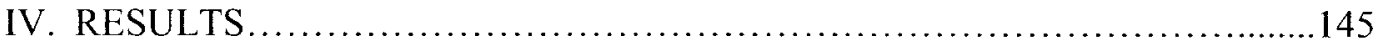

Power of the Survey Results........................................ 145

V. SUMMARY, DISCUSSION, AND CONCLUSIONS .......................... 160

Summary ...................................................... 160

Discussion.................................................. 162

A Recommended Framework for Public School Administrators.............167

Conclusions by the Researcher........................................175

Final Recommendations........................................... 177

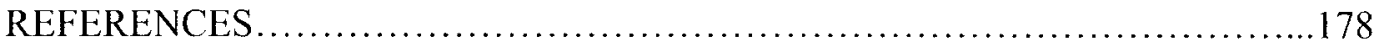

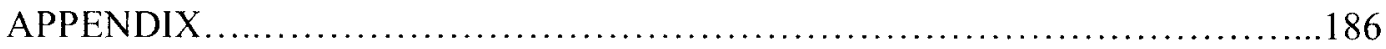

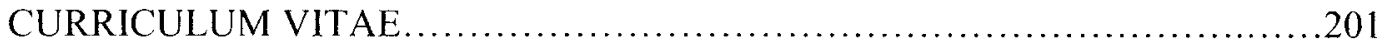




\section{LIST OF TABLES}

TABLE

PAGE

1. Musical Training Attributes from the Literature Review....................... 143

2. Musical Attributes Related to Successful Musical Performance..................... 148

3. Musical Training Compared to Assessment Instruments....................... 152

4. Evaluation Related to Job Satisfaction...................................... 157

5. Conductor Evaluation Schedule.......................................... 172

6. Music Conductor Evaluation Worksheet.................................... 174 


\section{CHAPTER I}

\section{INTRODUCTION}

Researchers studying conductor evaluation provide evidence that effective tools for evaluation of band and orchestra conductors are prevalent throughout the music education literature. Public school administrators, however, are generally unaware of that literature and often lack adequate assessment instruments to measure conductor effectiveness in rehearsal settings. Given the specialized training that music teachers must complete in order to achieve certification, it is unfair to expect administrators to evaluate music teachers without having the requisite knowledge of assessment guidelines associated with those teachers' daily teaching responsibilities. Evaluation instruments used by public school administrators, typically designed for classroom teaching evaluation, offer little or no relevance specific to music instruction and delivery indigenous to the performance medium.

This chapter has seven sections: (a) Background of the Problem, (b) Introduction to the Problem, (c) Statement of the Problem, (d) Research Questions, (e) Purposes of the Study, (f) Significance of the Study, and (g) Definition of Terms. 


\section{Background of the Problem}

According to Paul Lichau (personal communication, June 25, 2010), Executive Director of the Michigan School Band and Orchestra Association (MSBOA), "Assessment instruments utilized by public school administrators to evaluate musical conductors often bear little resemblance to the formal training they received in music school. There is a disconnect between the skills assessed by their evaluators and the training these conductors received. This may also have an adverse effect on conductor job satisfaction." Musical conductors have been teaching in the public schools for almost a century and the popularity of school ensembles remains strong. Conductors, however, still undergo assessment procedures as if they were in an academic classroom. In the state of Michigan, effective assessment outcomes, largely based on the level of music knowledge that a particular administrator may have, can influence the teaching assignments offered to the conductor.

MSBOA, founded in 1934, serves as a guiding force in the development and support for band and orchestral education in the state. The work of MSBOA includes performance oriented activities in band, orchestra, and jazz, solo and ensemble activities, teacher clinics, and mentoring.

To improve the return rate of the study, MSBOA agreed to a mutually beneficial collaboration. In return for the cooperation offered by MSBOA by identifying the participant pool, Lichau hopes to offer possible alternatives to existing public school assessment instruments and to provide a framework for young conductors as they prepare for annual reviews, contract renewals, and tenured appointments. 
Introduction to the Problem

The literature is replete with examples of attributes used to assess conductors. Keely (1997) noted the effect of nonverbal physical conducting gestures on beginning band students related to basic performance variables such rhythm, articulation, phrasing, and dynamics. The author suggested that bands exposed to conductors with greater training improved at a faster rate than those ensembles where the conductor had less formal training.

Hamann, Baker, McAllister, and Bauer (2000) studied the effect of classroom delivery skills and lesson content on the assessment of lesson or teacher appeal compared to the amount of formal training of the conductors. Delivery skills focused on posture, eye contact, gestures, facial expression, and vocal inflection. They found good delivery/good content from advanced student conductors more appealing to the participants viewing the rehearsals than those rehearsed by conductors who did not display these characteristics.

Johnson, Fredrickson, Achey, and Gentry (2003) examined the relationships between nonverbal conducting techniques (physical gestures) with the assessment of student and professional (experienced) conductors. Similarly to Hamann et al., the authors concluded that several of the physical movements evaluated, including facial expression and eye contact, were consistent attributes of more experienced conductors compared to less experienced conductors.

Although conductors may have extensive training in these attributes listed above, as well as other areas, the question remains whether the evaluative instruments used in the public schools consider formal conductor training when measuring teaching 
effectiveness. Specific criteria related to their formal training in conducting are not standardized across assessment instruments. Evaluations of music teachers related to conducting skills and techniques typically focus on the work done by conductors on the podium during band, choral, or orchestra rehearsals.

Finding the common threads of assessment instruments for general or elementary music teachers, in contrast to band conductors continues to evolve in the literature. Taebel (1980) developed a list of music teaching competencies and distributed a survey to music teachers for ranking and comparison among general, choral, and instrumental teachers. As a result of the study, the author recommended that music educators needed (a) stronger training in aural skills, (b) more training in sight-reading and improvisational skills, and (c) that music education programs should be structured to incorporate . differences for general, choral, and instrumental preparation. Music teacher evaluations should reflect the skills listed above as part of any regular assessment.

Standley and Madsen (1991) tackled the problem of identifying what they called "good teaching." The purpose of their study was to develop a procedure that would differentiate levels of teaching expertise and whether expertise was independent of years of experience. The authors offered proof that experience and effective teaching practices were related independent variables and should be part of assessment models for conductor evaluation.

Several authors focused on specific areas of assessment as part of their research on marching band or concert band instruction. Ramsey (1979) developed a program designed to train music education students to detect errors in rehearsal and designed a test to measure effectiveness in this area. The seven areas of assessment were: (a) 
determining typical errors; (b) selecting repertoire; (c) assigning errors to the score; (d) recording the mistakes; (e) validation of the program items; (f) establishing degrees of difficulty; and $(\mathrm{g})$ constructing three program sequences.

Goolsby (1999) studied experienced and novice teachers to determine characteristics that were common to effective band directors. He examined differences between experienced and novice conductors in their use of rehearsal time and verbal instruction. Much as Dickey (1991) reported, the author found that experienced conductors spent significantly more time employing nonverbal modeling/demonstration techniques than did their novice counterparts.

Goolsby compared the rehearsal effects of working with four different ensembles comparing working with (a) their regular conductor, (b) a conductor with high magnitude characteristics, and (c) one with low magnitude characteristics. He used similar variables as did some of the instrumental studies to measure eye contact, closeness, volume and modulation of voice, gestures, facial expressions, and rehearsal pace. Once again, experienced teachers demonstrated higher levels of achievement in study characteristics reinforcing a need for adequate assessment in these areas.

Hendel (1995) found that nonverbal teaching techniques such as eye contact, speaking patterns, conducting gestures, and facial expressions were common attributes of effective teachers. The high level of nonverbal teaching techniques is not typical of most general classroom environments. While special education and physical education teachers also rely on high levels of nonverbal teaching techniques, administrators have little experience with these, or with the conducting gestures and physical movement skills that are expected of conductors. Similarly, assessing score study regimen and application is a 
difficult task for most administrators. Yarbrough and Price (1981) studied issues related to aspects of instructional delivery, particularly conductor-student eye contact.

Skadsem (1997) suggested that effective communication was one of the most important facets to consider when examining conductor effectiveness. The author compared verbal instruction with nonverbal or gestural instruction. The author recommended that conductors should receive training (and then the appropriate assessment) to lead performers gradually away from markings in the music or verbal instructions and eventually rely more on conducting gestures as a more efficient method of communication.

Rutgers (1998) determined rehearsal behaviors and evaluated performance achievement with respect to rehearsal preparation. The author found that verbal instruction decreased and nonverbal conducting gesture communication increased as performance ratings increased. The author proposed that absent proper training rubrics for administrators, recognizing this nonverbal form of instruction may be difficult to evaluate without the requisite training. Similarly, Yarbrough and Henley (1999) suggested that there was often an apparent lack of communication between conductor and performer, which would also be difficult for administrators to ascertain without training on these evaluation rubrics.

The studies above provide a sample of the issues and commonalities considered regarding conductor assessment. These issues certainly affect the assessment of the conductor and should raise concerns among administrators who lack appropriate training regarding music education attributes. 
Administrators typically do not use evaluation criteria instruments that take into consideration the many aspects of conductors' educational training. An assessment ideally should not only evaluate conductor ability but should also recommend appropriate courses of remediation when necessary.

Middle school and high school music ensemble directors are often at a distinct disadvantage regarding evaluation procedures that determine promotion and tenure issues. Administrators often have little or no training in music or other specialized areas such as the physical education, special education, or visual arts; and yet must assess the abilities of these teachers on an annual or semi-annual basis.

Evaluations of teachers often focus on the concert band portion of the school year in a rehearsal setting. The concert band segment of instruction, however, is only one part of a total band program. Interwoven into these programs is instruction in jazz repertoire, improvisation, small ensembles repertoire, and private instruction - all of which require unique types of evaluation tools.

In addition to classroom concert band rehearsal evaluation processes, high school band directors confront yet another challenging aspect as part of their evaluation. Within a typical high school band program, the marching band season occupies at least a third (or more) of the school year and is the most visible component of the band program. Marching band instruction often begins during the summer months and continues into November when concert band rehearsals begin. Because it is the most visible component, the marching band portion of a band director's responsibility often receives a considerable amount of administrative scrutiny. Without proper training as to the nuances of marching band instruction, proper assessment by administrators can be difficult. 


\section{Statement of the Problem}

Many school and district administrators do not use adequate evaluation instruments to assess teaching effectiveness accurately in public middle school and high school music classes, particularly in rehearsal settings. This creates a mismatch between the training the conductors received and the areas of assessment used by administrators.

There is a lack of connection between evaluative instruments and conductors' formal training. In discussions with music educators and administrators from the Michigan School Band and Orchestra Association (MSBOA), a topic of concern is the absence of a direct correlation between the formal training that conductors receive and the assessment instruments used by their administrators. The assessment instruments currently used in Michigan public middle school and high schools influence promotion and tenure decisions and are of critical importance to the conductors. Employee evaluations have been identified as sources of friction in conductor/administrator relations. Such friction can lead to varying degrees of job satisfaction, especially when conductors suspect that their evaluations are not as carefully crafted as those used by administrators for general classroom teachers.

\section{Research Questions}

Three research questions frame this study:

RQ1. To what extent did the conductors' formal training match up with the musical attributes requisite for adequate conducting skill and musical performance?

RQ2. Did the conductors perceive that their review process evaluated these same musical attributes? 
RQ3. To what extent did the review process contribute to their job satisfaction?

Purpose of the Study

This study has three purposes. The first purpose grounds the first research question above by exploring the potential gap between conductors' training and the identified musical attributes requisite for adequate conducting skill and musical performance. The researcher's literature review (see Chapter II) establishes common musical skill assessment attributes for conducting and other types of musical instruction. These attributes, grouped into themes, form the basis for the survey. The findings of the study will offer a framework for future evaluative instruments to be used by public school administrators.

The second purpose is to compare these reoccurring assessment themes with the musical skills learned as part of conductor training, to determine the correlation between formal training and with current assessment practices used in the public schools. Results of the study will provide insights for public school administrators as they assess the specialized area of instruction, specifically conducting. The third purpose of the study is to provide feedback on whether the present evaluation instruments contribute to or detract from employee satisfaction, on how they might lower conductor turnover, and, ultimately, on how proper evaluations can create stronger programs.

\section{Significance of the Study}

Thorough review of the literature and a survey of middle school and high school conductors suggests a possible future assessment model for use by administrators. The 
analysis of musical assessment literature provides a framework comparing the existing research on evaluative instruments with the specific musical skills examined in previous studies. A matrix in Chapter III quantifies the frequency of criteria across the literature.

\section{Definition of Terms}

To clarify the terminology described throughout the literature study, the following definitions of terms provide insights into these attributes. The first subsection, Musical Skills, pertains to different types or groupings of musical performers and types of instruction. As part of their formal training, conductors learn various attributes that they should incorporate into their daily teaching routines. Certain skills, which are considered a subset of attributes, should be achieved at a mastery level and should be a learning goal or outcome for their students at different stages of their musical development. Musical Skills

Accompanying skills. In smaller ensemble settings, or when a large ensemble is not available, conductors often play piano reductions of the original score. These score reductions give performers a sense of the overall scope of the music.

Ancillary music programs. Major ensembles often subdivide into small ensembles of groups of similar or like instruments.

Applied music. Applied music instruction refers to one-on-one instruction between teacher and student. This type to teaching or training is also referred to as private lesson instruction.

Arranging. Writing adaptations of existing musical themes or settings is a skill often needed by conductors. Occasionally, existing ensemble membership does not 
reflect what is called for in a musical score and conductors need to rearrange existing parts or rewrite the entire setting. Other times, conductors need to rewrite an existing piece into a new arrangement of the original material.

Aural skills. Conductors and music teachers need aural discrimination skills to ascertain student performance abilities and internalize musical information prior to rehearsals.

Composition skills. Composition in a musical sense relates to creating and writing new music based on original themes.

Ear-to-hand skills. The ability to hear sounds and then reproduce those same sounds on an instrument defines this musical skill. This skill is especially important for improvisatory purposes as it frees the mind to compose without worrying about what note to produce physically on an instrument.

Ear training. Exercises that increase a musician's aural skills are part of musical training. This training increases sight singing and ear-to-hand skills.

General music class. For young students, general music classes offer an opportunity to learn musical concepts and basic performance skills. Basic vocal performance or rudimentary percussion instruments serve as the performance medium for exploring musical concepts.

Improvisation. Music that is performed entirely as spontaneous performance without notation is referred to as improvisation and has many applications in various musical styles and formats.

Music modeling. Conductors often rely on performing short segments of music to communicate specific musical ideas to student performers. Modeling techniques enables 
conductors to demonstrate nuances in the music that otherwise are difficult for young students to understand.

Musical ensembles. Any gathering of instrumentalists or vocalists is referred to as an ensemble.

Music theory. Music theory is the study of structure in music and relates to notation including melodic, chordal, form, and other specifics of music notation and analysis. This is the foundation of music; at times music germinates from the theory and other times theory attempts to explain the music.

Rehearsal pacing. Constructing a rehearsal that flows and does not inordinately dwell on certain sections of the music at the expense of some members who are not involved is one part of effective rehearsal pacing. The ability to carry out an effective rehearsal, one that moves the development of an ensemble forward in an engaging fashion, is a goal of effective conductors.

Sight-reading. The ability to read and perform music with fluency on first reading is an indicator of musical ability. Music festivals often include sight-reading as a part of the overall performance measurements.

Sight singing. The ability to sing a selection of music without assistance or use of another instrument is a technique used in rehearsals or in individual teaching sessions.

Small ensembles. Subsets of larger ensembles that feature fewer performers per part or one per part offer performers an opportunity for increased musical independence and expressiveness.

Solo and ensemble contests. These festivals or contests encourage performers to learn solo or small group repertoire in order to expand their musical vocabulary. 
Conductors often encourage this type of performance for young students to develop their expressive and interpretive skills and musical independence.

Vocal skills. This refers to a performer's skills as represented through singing abilities, both technical and musical in nature.

The next subsection provides definitions of musical concepts and skills regularly taught by conductors. These skills and concepts should play a major and regular part in the development of young musicians, both in theory and in practice. As part of conductors' formal training, these skills become a focus of their rehearsal planning, teaching goals, and performance objectives. Terms and concepts outlined in this section appear throughout the literature review and form the basis of some of the existing topics of study.

Music Concepts and Skills

Articulation. The manner by which notes are begun or started provides stylistic considerations that inform the music.

Balance. The ability to adjust the various sounds in an ensemble setting is an important consideration for any conductor. If some parts are too prominent they cover up other musical lines that are important to the overall effect of the musical score.

Blend. Blend is different from balance in the sense that there is an art to how sounds go together not only in terms of relative volume, but also related to the timbre or the tone quality. Scores rely on the premise that given a certain blend of instruments and scoring techniques, a specific or intentioned sound will emanate from the ensemble. Imbalance of any part can obscure the complexion of any musical selection. 
Body percussion. Similar to echo clapping, music teachers often have students perform rhythmic body pats in response to teacher examples to internalize complex rhythms.

Bowing. In string literature, markings for bowing are important to the final interpretation of the music. Distinctive sounds are produced by up bowing or down bowing on a string instrument and are important considerations when preparing and rehearsing string repertoire. Orchestral conductors spend considerable time communicating proper bowing markings to students either by making notations in the music or communicating those notations verbally.

Diction. In singing lessons and in choral performance, diction or the clarity of pronunciation or enunciation is important to capture not only the texture of the music but also has stylistic implications.

Dynamics. Dynamics refer to the relative volume of musical sounds. Dynamics run the full range from quieter sounds to very loud sounds, depending on the musical score.

Echo clapping. This refers to the practice of internalizing rhythms by clapping segments and having students echo back the same rhythm. Teachers will often teach students a specific rhythm first by echoing and then show them the corresponding notation.

Expressive nuance. An expressive nuance is a smaller segment of music whereas a phrase is a longer musical statement or sentence. This type of nuance can occur in any segment of a melodic line, accompaniment, or texture. 
Fermata. A fermata is a marking in music that indicates a prolonging of a particular note for dramatic purposes. The duration and style of the held note has a profound effect on the interpretation of the musical line.

Form. Form in music refers to the structural parameters in musical compositions. Many forms in music are indigenous to different periods of music or stylistic frameworks.

Harmony. A sonority created when two or more notes are struck simultaneously as a chord or a harmony of the original tone. Chords or harmonies are generally thought of as being a sound that is agreeable but many harmonies provide a purposeful dissonance or tension in the music.

Intonation. The ability to match pitch with other performers is an ongoing issue in all ensemble settings and can be especially challenging for younger students.

Legato. This is a musical term that denotes a musical segment that is to be played in a smooth or connected style.

Melody. The main thematic material in a composition is generally the melody, from which variations, harmonies, and counterpoint emanate. It is often defined as an agreeable succession of sounds. Some forms of music, however, will not have a recognizable melody that is clearly identifiable. Instead, music can be more textural in nature and not possess a single line that stands out within the composition.

Musical interpretation. How a performer or conductor interprets what a composer indicated in a score is the art of musical interpretation. Even though a composer may have placed specific markings in their score to produce the sound that they hear in their 
head, conductors and performers still have or take considerable liberties in their individual interpretations, much to the delight or chagrin of an audience.

Musicianship. Musicianship is a subjective term to describe an individual's sum total of all musical skills as a conductor or as a performer. This measure includes accuracy of performance, interpretive, expressive, and stylistic skills.

Phrasing. The style of expression through the grouping of notes into musical ideas or thoughts is described by the term phrasing. It is important in ensemble settings, for conductors to coordinate the style of phrasing music lines among multiple performers for purposes of agreement and creating the proper interpretation.

Slurring. When two of more notes are connected together without articulation or break, they are described as a slurred passage.

Staccato. This notation indicates a detached style in music, often confused by young conductors as always indicating notes that are short in length.

Tenuto. Notes that are marked with a tenuto indication suggest a brief holding or hesitation of a note. This is used for indicating phrasing or specific musical nuances. It also affects the manner by which a note is released, thereby affecting the interpretation of the musical segment.

Tempo. Commonly referred to as the speed that a musical selection should be played by performers, as indicated in the score. This speed or tempo is an important consideration in music-making, as performing a piece much too slowly or too quickly can affect the final outcome or interpretation of the piece significantly.

Timbre. Timbre refers to the idiosyncratic color or type of sound. Each instrument type has an inherent timbre. Certain types of music, for example, may call for a mellow 
sound whereas other compositions will call for a more forceful approach to the desired sound.

Tone quality. The characteristic sound produced is the one of the most basic skills for all levels of musicians. Much like the concept of timbre, tone quality refers to the type of sound produced by an instrumentalist or vocalist.

The following conducting terms and skills related to conducting movement and gestures appear throughout the literature study. These skills are an integral part of conductors' formal training. Movement and Gestures (subsets of attributes)

Conducting gestures. Conducting gestures communicate nonverbal information that indicates a spectrum of musical ideas. These gestures encompass left and right hand movement or signals, facial expression, and body movement.

Conducting patterns. Conducting patterns communicate information to performers indicating meter, style, and other interpretive information through physical gestures. Experienced conductors use conducting patterns as a secondary physical gesture to reinforce stylistic considerations that are readily apparent in the musical notation. This allows the experienced conductor to communicate more specific musical nuances and phrasing.

Cueing. The art of cueing performers is an important function for conductors as it provides valuable information from the podium. It not only serves to remind individuals or sections when to commence or finish performing a particular section of music, it also provides valuable musical and interpretive information to the performers. 
Ictus. The ictus is the point where the conductor's motion moves from the preparatory gesture to the specific downbeat plane that indicates when the beat begins. This plane should generally stay in relatively the same place, so conductors do not confuse performers about when to begin notes or the overall tempo of a segment of music.

Mirrored conducting gestures. Many novice conductors get in the habit of mirroring information in both hands instead of relaying different musical information from both hands. This is often a common trait of young conductors who have not developed a repertoire of gestures for both arms and hands, independent of one another.

Podium. The term refers not only to the physical structure upon which a conductor stands but also as the figurative location from which musical information and direction emanates.

Preparatory beat. A preparatory gesture is the movement that serves as an important clue as to the speed, style, and dynamics of the downbeat gesture. This gesture allows the performer an opportunity to breathe or physically prepare for an upcoming note before it begins.

Release gestures. This gesture indicates the time and style of how to stop or let go of a note.

Repertoire. The body of work for a particular type of ensemble is referred to as the repertoire. Conductors select from this body of work to teach musical concepts and prepare concert programs. Their knowledge of the repertoire is an important skill set that conductors continue to develop for teaching purposes and for their audiences. 
Score study. Conductors prepare for rehearsals by studying musical scores that contain individual music for members of the particular ensemble.

To understand the development of music evaluation processes, it is necessary to study both existing research on evaluation in general and those studies focused on music instruction. Research concerning classroom teacher effectiveness provides a useful beginning framework for studies relating to music instruction. The primary goal of the literature review is to ascertain trends in music teacher evaluation from previous research highlighting specific teaching skills and concepts. 


\section{CHAPTER II}

\section{LITERATURE REVIEW}

The goal of this literature review is to ascertain trends in music conductor evaluation from previous research. Thorough research of the literature and a survey of middle school and high school conductors might suggest a possible assessment model for administrators. These guidelines would assist administrators in their assessment of conductors and offer insights into revisions of music education curriculums. Music education programs affecting these changes could have a profound effect on the training of music education students who currently join the workforce without a clear sense of how they will be evaluated.

Studies presented in the literature review divide into seven topic headings. The first section, General Music Education Research, examines research pertaining to the effects of teacher behavior on student achievement in typical classroom settings and identifies research pertaining to music teacher training at the undergraduate and graduate levels. The second section, Concert and Marching Band Research, examines studies that focus on concert marching band rehearsals as the primary medium. Marching band research is limited in scope but does examine the effects of competition on music cducation and student learning. The third section, Choral and String Ensemble Research, looks at research using choirs and orchestras as the performance medium. 
The fourth section, Applied Music Research, examines situations where there is one-on-one musical training occurring. The fifth section, Elementary Music Instruction Research, looks at the elementary general music class as the source of study. The sixth section, Conducting Gesture Research, relates to physical movement as a means of communicating musical thought. The final section, Score Study and Evaluation of Students Research, relates to the study aspect of rehearsal preparation. This final section examines score study, evaluation, and grading of students research and looks at assessment factors in music classes.

\section{General Music Education Research}

As a starting point in the evolution of assessment in the classroom, it is necessary to examine research on the subject of general classroom teacher assessment studies. Several of the earlier studies listed in the following pages found no significance for teacher attitudes or skills affecting student achievement. As the research on teacher assessment progressed, however, teacher attributes were found to be increasingly more influential on student learning and achievement.

Marchand (1975) studied whether students could learn expressive performance. He studied which one of two instructional methods was more effective - discovery or expository - and if previous musical experience had a positive effect on achievement. The researchers divided the sample of college music students $(N=89)$ into three treatment groups. The author divided the students into approximate equal distributions: discovery (teacher leads students to learning), expository (didactic learning through repetition), and the control group. Four pretests - aural, music facts, vocal skills, and 
music experience inventory and four posttests - expressive performance, aural achievement, music facts, and vocal skill tests framed the study.

A two-way analysis of variance at the $p>.05$ level served as the indicator of significance for all tests. A Scheffé test for paired means indicated significant difference between the two treatment and control groups. Music experience had a positive relationship with expressive performance $(F=17.69, p>.01)$. The author suggested that: (a) expressive performance can be learned; (b) technical skills are enhanced when expression is of greater focus; (c) both treatment groups, discovery and expository, had similar effects on scores related to aural achievement, music fact knowledge, and vocal skills; and (d) students with more experience benefited from the expository approach, while less experienced students fared better using a discovery approach.

Tacbel (1980) developed a list of music teaching competencies and distributed a survey to music teachers for ranking and comparison among general, choral, and instrumental teachers. The music competency list, generated through informal interviews with music teachers, consultants, members of the music education faculty at Georgia State University, and a comparison with the state of Georgia list, served as the final version for the survey. Competencies were rated on a zero to five scale, with zero indicating that the individual did not use the competency. A score of one indicated that the respondent seldom used the competency and a score of five indicated the competency was essential to student learning.

Competencies, divided into categories - musical or teaching - framed the two sections of the study. Fifty-one musical competencies fell into the following subheadings: (a) aural skills; (b) conducting skills; (c) vocal skills; (d) analytic and composition skills; 
(e) knowledge of history, literature, and teaching materials; (f) skills in dance and movement; (g) principal performance medium skills; and (h) accompanying skills. The 59 teaching competencies were divided into the following categories: (a) planning, (b) methods and techniques, (c) instructional materials and equipment, (d) classroom climate, (e) communication skills, (f) pupil evaluation and feedback, (g) program and teacher evaluation, (h) professional responsibilities, and (i) control and management skills. The survey yielded a $74 \%$ return rate among 201 teachers with $81 \%$ of the respondents indicating they would be willing to participate in further research. A mean ranking for each competency ranked the competencies from highest to lowest. Under musical competencies, understanding elements of music and error detection abilities were at the high end of the table with accompanying with guitar, recorder, or ukulele occupying the bottom layer of the list. Cooperation, professional traits, and enthusiasm ranked 1,2, and 3 out of the 59 for teaching competencies. Standardized testing and use of specialized instructional approaches were last in this area. Taebel (1980) recommended that music educators needed: (a) stronger training in aural skills, (b) more training in sight-reading and improvisational skills, and (c) music education programs should be structured to incorporate differences for general, choral, and instrumental preparation.

De Nicola (1990) investigated the historical aspects of instructional language to define an evaluation instrument for preservice elementary and music education majors. The subjects for the study included juniors and seniors $(N=143)$ enrolled in a required elementary music education course from two geographically different universities (Midwest and Southeast). Research of the literature considering language behavior 
framed the study and included such areas as: subject-matter vocabulary, clarity, fluency, grammar, and articulation. Studies of this nature revealed that students subjected to teachers displaying these positive language characteristics generally did better in school and had a positive disposition for their teachers. Studies utilizing elements of positive and negative teacher feedback, student guidance, instruction, and elements of student participation produced higher music performance gains and generally more positive student evaluations of their teaching.

Drawing upon the noted education treatises of Quintilianus, Erasmus, and Herbart, a list of eight language variables emerged. The eight independent variables employed in the study were: (a) eloquence, (b) modeling, (c) pronunciation and articulation, (d) organization/clarity, (e) subject matter, (f) delivery, (g) positive interaction, and $(\mathrm{h})$ grammar.

Each participant in the study taught a music mini-lesson to the rest of class on a musical concept. The mean percentage variable distribution indicated that elementary education majors had higher percentage scores in positive verbal interaction, subjectmatter vocabulary use, variable voice pitch and higher levels of articulation. The music education students, however, received higher scores for proper vocabulary use and steady speech speed. (The score data of these categories did not accompany the findings.)

The study provided an appropriate instrument for evaluating teacher effectiveness as related to language skill and contended that because effective teaching (elementary and music education) requires appropriate language skills, these skills should appear early in the educational preparation of future teachers. 
Wolfe and Jellison (1990) delineated the differences between the actual and perceived differences in teaching styles that contribute to learning in music. Teaching strategies, referred to as "style", provided the focus of the study. Previous research, using videotaped examples directed at the teacher, often exaggerated the amount of negative feedback given by the teacher. Untrained observers frequently viewed feedback as being less positive than did evaluators trained in approval/disapproval techniques. The purpose of the study was to observe differences in perception of three different teaching styles contrasted with the individuals' own perceptions.

The topic of the study related to the concept of textures in music repertoire. The first teaching style was in a traditional lecture style featuring definitions and examples of music concepts. The second style employed the use of questions designed to generate student response while still using the lecture format. The final style used positive feedback to student responses to questions and the lecture format from the previous styles.

Participants were 188 elementary education and 99 music students enrolled in music education, therapy, pedagogy, or applied study (the entire population) divided into two experimental groups. Each group analyzed the effectiveness of the three teaching styles or scripts using a music evaluation form from a previous study. The return rate was $100 \%$ as all of the students responded. The evaluation instrument included the following 10 categories: lesson organization; clarity of teacher's presentation; questioning effectiveness; teacher's attitude toward students; reinforcement effectiveness; quality of instruction; student participation; sincerity of teacher; communication with students; and overall effectiveness of lesson. "Quality of instruction" and "overall teaching 
effectiveness" were not used as independent variables to provide the most favorable comparison across the three teaching styles. The order of the scripts changed between evaluators.

The authors used stepwise discriminant analysis to compare participant responses between education and music major experimental groups. Based on the standardized discriminant function coefficients, the first group of education majors rated student participation (Wilks' lambda $=.317, p<.0001$ ) and reinforcement effectiveness the most significant (Wilks' lambda $=.257, p<.0001$ ). The second group of music students found greater significance for student participation (Wilks' lambda $=.249, p<.0001$ ), reinforcement effectiveness (Wilks' lambda $=.179, p<.0001$ ), and lesson organization (Wilks' lambda $=.166, p<.0001$ ). Both groups of students rated positive feedback as the most favorable teaching style. Individuals from both groups rated verbal teacher approval highest when considering their own personal teaching style or script.

Duke and Blackman (1991) used four teaching evaluation variables from an appraisal document used in the Texas public schools for purposes of the study. The four variables used on the observation form were: (a) reinforces correct responses; (b) gives corrective feedback, or none needed; (c) reinforces appropriate behavior; and (d) gives corrective social feedback. The subjects employed in the study were music education majors and non-music $(n=100)$, cducation majors enrolled at the University of Texas at Austin.

Before each subject evaluated a 12-minute videotape of a fifth-grade general music class, he or she received one of four different forms for the observation. The first version asked the subjects $(n=50)$ to record the number of approvals and disapprovals 
given by the teacher during the class. Version 2 directed the subjects $(n=50)$ to record the number of approvals and disapprovals and then total the two together. The third version asked subjects $(n=50)$ to record the number of times that the teacher obtained a musical or verbal response from the students. The fourth version asked the subjects to record any information they thought was important. After the observation period, the subjects all rated the teacher performance using the four evaluation variables described above using a 6-point rating scale.

The ratings provided by the non-music majors were significantly higher than those reported by the music education students $(p<.002)$. There was no significant difference among the four variables. Duke and Blackman (1991) found that instructing subjects to perform different tasks while observing a general music class did not affect the mean ratings of the teachers in the study. They suggested further research to define specific methods of evaluating music tcachers, such as describing attributes of good teaching, and summarizing these results, thus connecting these factors into the overall rating of teacher performance in music.

Standley and Madsen (1991) tackled the problem of identifying what they called "good teaching". The purpose of their study was to develop a procedure that would differentiate levels of teaching expertise and whether it was independent of years of experience. Researchers asked the music teachers and students $(N=150)$ to observe, analyze and write narratives about 20 videotaped excerpts of music rehearsals. The subjects, divided into five equal groups ( $n=30)$, included freshmen, juniors, novices, experienced teachers and experts. All subjects were enrolled at Florida State University, 
were teaching in the Tallahassee area, or were music education faculty members at Florida State. (The study did not indicate how the students were chosen.)

Freshmen subjects indicated an intent to study music education; junior subjects had completed two years of college courses and also intended to major in music education; novice teachers were those students awaiting a student teacher assignment; experienced music teachers had the requisite degree and from 1 to 10 years of teaching experience; and expert teachers had the required degree, identified as having taught for more than ten years, and had received awards from colleagues for outstanding levels of teaching success.

The observation tape contained 20 examples of one-minute excerpts including special education interactions $(N=9)$, and general, choral or instrumental groups at the elementary, middle, and high school levels. The tape also included a professional music performance of a piano concerto with orchestra and a violin concerto with piano accompaniment. The subjects wrote narratives about what they observed and were given positive points for accurate, descriptive answers and had points deducted for errors.

Raters were members of music education faculties with more than ten years of teaching experience. The $98 \%$ agreement among raters generated study reliability. Mean scores, score ranges, and standard deviations computed for all five populations had gradually higher mean scores and range scores moving from the results of the freshmen population through the expert population. A one-way ANOVA test demonstrated that all groups were significantly different from one another $(F=57.45, p<.001)$. This gave the authors further proof that experience and effective teaching practices were related independent variables and should be part of assessment models for conductor evaluation. 
Grant and Drafall (1991) examined research regarding teaching effectiveness in general music education. Researchers selected successful music teachers for purposes of the study as those who had significant numbers of students selected for All-State (musical performance opportunities), received superior ratings at District and State musical festivals, and/or received invitations to perform at state, regional, or national conferences. The authors performed a meta-analysis combining the results of several studies and found that research had six similar characteristics: (a) studies were performed in normal school settings; (b) studies usually lasted a year; (c) relationship between teacher instruction and effectiveness of learning by students; (d) focus of each study is on the teacher only; (e) teacher effectiveness is measured in student gains on standardized tests; and (f) low-interference measures were used with a tally system rather than an assessment of quality.

Results from these types of process-product studies indicate that teachers do make a difference in the learning levels of their students with certain teaching behaviors affecting learning more than others do. Two overreaching themes arise in all of the studies. First, the amount of time students are engaged in appropriate academic activities affects learning. Second, student learning increases when their teachers relate current material to past learning information.

Several concerns emerged throughout the above studies concerning the use of standardized testing to measure increases in student learning indicating teaching effectiveness. Studies are often correlational in nature and may not indicate other teaching factors affecting increased learning. The authors also concluded that musicteaching assessment was too complex to reduce the components into a single process. 
Most music education studies are descriptive in nature when studying processproduct effects. Music education studies fall into three categories: (a) identifying personal, musical, and professional attributes of music teachers, (b) prioritizing teaching competencies deemed successful, and (c) studying successful musical teachers to determine common teaching skill traits. Common teaching skill criteria included: enthusiasm of the teacher, caring for students, strong and consistent discipline, student enjoyment factors, confidence, and preparation. Results indicated no significant relationship between creativity and teaching effectiveness and no relationship between creativity and teaching style. There was a consistent correlation between teaching effectiveness and teaching style.

Grant \& Drafall (1991) also examined teaching compctencies across the studies. The three most common areas of music competencies were performance, analysis and composition. Specifically, the highest-ranked competencies were sight singing, accompanying, analysis of musical form, arranging, aural error detection skills, conducting skill, and vocal skill in modeling. Time usage studies of choral directors indicated that successful music teachers used $65 \%$ of the time conducting and used verbal instruction $35 \%$ of the time. Of the $35 \%$ verbal instruction, $16 \%$ of the time was nonmusical in nature. Verbal behavior also indicated a division of music instructions $55 \%$, illustration of concepts and musical passages $21 \%$, and evaluation for their performance $24 \%$. Time usage studies of band directors employed a division among verbal instruction, conducting (expressive gestures), and demonstration or modeling. Grant and Drafall (1991) agreed on several limitations of the studies. First, music educators did not agree upon the measures used to measure success. Second, there was 
not a consistent agreement on what is the most important learning outcome as part of the music curriculum. Without this agreement across the spectrum of possible outcomes, it is difficult to measure success. The third and final limitation was the general hesitation to judge successful teaching on student learning. The authors suggest that future research should be qualitative in nature.

To develop the instrument in their study, Kvet and Watkins (1993) studied 219 elementary education majors enrolled in a music education course. The students listed 1,582 successful teaching attributes as being pertinent to the study. All members of the class responded to the study $(100 \%)$. The researchers attempted to (a) develop an instrument that measured perceptions of success related to teaching music, (b) determine what factors elementary music education majors felt contributed to success, (c) determine the relative strength of each factor, and (d) compare these factors with traditional and attribution theory models related to music. The authors defined attribution theory as how individuals perceive causality when concerned with success or failure in achievement type activities. The original sets of causal attribution theory included ability, effort, task difficulty, and luck with further classifications of being internal or external to the person. A dimension of causality included stable or unstable, all incorporated into a $2 \times 2$ matrix.

Three judges categorized these attributes into the following categories: effort, luck, musical ability, teaching ability, affect for music, affect for teaching, classroom management, personality, and miscellaneous. Inter-rater reliability was .91 . The survey used a 5-point Likert-type scale using 90 attributional statements.

Researchers had all of the elementary education majors $(n=306)$ enrolled in a music education course rate the degree to which factors contributed to the success of 
teaching and learning music. Principal factor analysis yielded four factors accounting for $53.1 \%$ of the total variance. The first factor (understanding and organizing for individual differences in children) and the third factor (proactive personality characteristics) proved to be similar to extant literature on teacher effectiveness. The second factor (musical ability and positive feelings for music) and the fourth factor (external factors affecting music teaching) were both analogous to traditional attribution models.

Teachout (1997) developed a 40-item list of skills and behaviors indicating effective music teaching. He gathered items from the existing literature and from a questionnaire sent to music education students enrolled at three different universities. Music education students and experienced music teachers received the questionnaire with 98 preservice and 78 experienced teachers returning the form. All of the students in the three populations responded to the survey for a return rate of $100 \%$. A random sample of preservice teachers $(n=35)$ and experienced teachers $(n=35)$ enrolled at three universities served as the population for data analysis. Five experts in music education verified the results to complete the 40 -item list given to an equal distribution between preservice teachers and experienced teachers. He posed three questions as part of the study: (a) "Which of the top ten ranked teaching behaviors belong to both groups?"; (b) "Which behaviors are rated differently between the two lists?"; and (c) "Which items assumed an equal ranking between groups?"

Seven out of the top ten skills and behaviors appeared in common from both lists. These seven most common items included: (a) be mature and have self-control, (b) be able to motivate students, (c) possess strong leadership skills, (d) involve students in the learning process, (e) display confidence, (f) be organized, and (g) employ a positive 
approach. Experienced teachers ranked "maintain student behavior" first while preservice teachers rated it fourteenth. A two-way analysis of variance calculated whether there were significant differences between the two groups in any of the skill areas (personal skills and behaviors, musical skills and behaviors, and professional teaching skills and behaviors). Both preservice and experienced teachers rated musical skills lower than personal skills and teaching skills. Ten items received different ratings across the two groups (low significance) and nine items were common in ranking (high levels of significance) for both populations.

Teachout (1997) observed that most undergraduate music students had only a performer view of music and little or no teaching experience. Their knowledge and opinions were limited to those experiences viewed from an ensemble member viewpoint. In developing an appropriate music curriculum for music education majors with respect to conducting skills and rehearsal techniques, music education faculty must decide what musical skills and teaching behaviors need development. Preservice teacher input should be given the proper importance, if only as a starting point for the music education program. Prior research provides many examples of effective teaching behaviors, including those studies concerned with characteristics of successful music directors and teachers.

Hamann, Lineburgh, and Paul (1998) determined whether there was a relationship between teaching effectiveness scores and social skills scores for preservice music teachers. The participants were music education and elementary/secondary education students $(n=138)$ studying at three universities in Ohio and Oklahoma enrolled in a music methods course. Seventy-five students were music education students and 63 were 
non-music education majors. All had some form of prior teaching experience and ranged from freshmen to senior level students. All of the students $(100 \%)$ enrolled in these courses responded to the survey. Each student took a self-test to evaluate their social skills and then the researchers videotaped them giving a music lesson.

The Social Skills Inventory (SSI) contained 90 items grouped into six scales including emotional expressivity, emotional sensitivity, emotional control, social expressivity, social sensitivity, and social control. Participants responded to a 5-point Likert-type scale $1=$ Not at all like me, $5=$ Exactly like me. In test and retest situations the SSI verified convergent and discriminant validity. The authors used the Survey of Teaching Effectiveness (STE) instrument to rate musical instruction effectiveness as part of the study. The first area, "lesson presentation and style," and the second, "lesson organization, knowledge, and overall effectiveness," are weighted $40 \%$ and $60 \%$, respectively. The first area contained measures such as vocal inflection, physical gestures, facial expression, eye contact, and posture. The second area included sequencing patterns or rehearsal cycles, presentation knowledge, pacing, teaching style, and organization.

The authors pilot-tested the evaluation and included revisions from 20 education experts. Item evaluations used a Likert-type scale $1=$ poor, $5=$ excellent. They hypothesized that there would not be a significant difference between music education and non-music education scores and employed a multivariate analysis of variance.

Categories on the two tests served as the independent variables and the scores were the dependent variables. To establish relationships between teaching effectiveness and social skills the authors used a regression analysis. To eliminate variables that were not highly 
correlated with each other, a correlation matrix provided the appropriate analysis. Using a MANOVA, no significant difference was found (Wilk's Lambda $=.89$, Rao's Form $2=$ 1.60. $d f=10,127, p=.113)$.

Regression analysis results indicated a significant relationship between teaching effectiveness scores and social skills scores $(r>.64)$. Teachers scoring high in emotional expressivity, emotional sensitivity, and social control highly correlated with overall teaching effectiveness scores $(r>.35)$. The authors contended that this was especially important when colleges and universities worked to develop an appropriate curriculum on behalf of music students who often spend a great deal of time alone in the practice room. The authors used prior research as the reason for framing this study that cited energy and cnthusiasm, verbal and nonverbal skills, and the ability to relate to students as characteristics of effective teachers.

Other research found eye contact, proximity, physical gestures, facial expressions, rehearsal pacing, and voice characteristics as important features of effective teachers. The authors postulated that these types of social or personal skills are more important in determining successful teachers than musical skills such as piano or singing skills.

Duke, Prickett, and Jellison (1998) designed their study to assess pacing in music instruction regarding novice teachers. They defined pacing as the speed of teacher's verbalizations, timing of student assessments, and the rates at which teachers change activities. Pacing is a combination of teacher presentation rate and the frequency of student response. The author noted previous research on the topic indicated that faster pacing leads to raising response rates and increased learning (Chilcoat, 1987; Grobe \& Pettibone, 1975). 
The researchers selected eight 1-to-3 minute excerpts from videotapes of four novice teachers in different settings: a choral rehearsal, a band rehearsal, and two elementary classrooms. The teachers, selected from music teacher education programs enrolled at the University of Texas at Austin or the University of Alabama, demonstrated examples of fast and slow-paced instruction with the teacher and performers in view of the camera.

Three variables indicating proportions of time included the total proportion of each lesson excerpt exhibiting a given behavior, the duration of a given behavior category of behavior, and the rate of occurrences of the behavior over a period of time.

Researchers used a three-way analysis of variance with univariate comparisons across the eight rehearsal excerpts. The faster paced examples all rated higher than the slower examples (mean ratings of 2.2 for fast and 2.9 for slow) indicating that the novice teachers could discriminate between fast and slow examples of instructional pacing, although this was not consistent across the teachers $F(3,126)>4.7, p<.004$.

The researchers concluded that rates of teacher talk events and the resultant student performance events, and the rate of alternation between the two, contributed to their perceptions of pace of instruction. The pace of instruction in music is directly proportional to the number of incidents of student performance opportunities. The researchers suggest that this information can be valuable as music educators train prospective music teachers concerning pacing and seek to quantify their observations.

A qualitative study by M. Schmidt (1998) compared the values and beliefs of four music student teachers as they strived to become good teachers. Throughout their efforts to become good teachers, they interwove the teachings and influence of parents, peers, 
university teachers, cooperating teachers, and the students they taught. Although all four students took the same courses and received the same instruction, the effects of the aforementioned influences and the desire to act as themselves resulted in four different styles of teaching.

Schmidt (1998) used a variety of sources to triangulate the data. Data sources included teaching observations, post rehearsal discussions with the student teacher, seminars led by the university professor, interviews with the cooperating and supervising tcachers, and notes recorded in a journal by the researcher.

The four student teachers indicated that personal qualities contributed significantly to good teaching. Because each of the four came from different educational, economic, and racial backgrounds, each had a slightly different version of good personal qualities. Although all four also viewed respect as an important quality, each again had different versions. One sought respect as a mentor, another as a father figure, a third as an authority figure, and the fourth as trustworthy friend or ally.

The four student teachers all mentioned that building community was an important attribute but some worked personally to create this type of environment while others demanded it from their students in their own personal interactions. Music education courses provided a common learning source of sound instructional practices. Each student teacher, however, took these teaching styles and added their own personal learning strategies into the mix. All four student teachers encouraged their students to learn much as they did as students.

According to the four teachers, interesting, well-paced rehearsals were the best formula for classroom management. Individually they varied as to the implementation of 
these goals. One sought to encourage them through her enthusiasm and caring attitude to lead them to good behavior. Another expected good behavior at all times while the last two found classroom management a more natural task. Both cited strong family influences such as consistency, patience, compassion for individuals, and avoidance of conflict as the primary ingredients.

All four student teachers sought to emulate good teaching practices they witnessed and avoid examples of bad teaching they encountered. M. Schmidt (1998) noted that all of the teachers demonstrated similarities to the instruction they received from their music education sources. Further refinement of their skills resulted from their own personal successes or failures with their students. They described this as an opportunity to incorporate their personality into their successful teaching methods. The data suggested, however, that the amount of supervisory instruction was limited in exposure and follow through. The cooperating teachers provided the most learning through listening, observing, and sharing alternative teaching methods.

Finally, although each student teacher desired a comprehensive community of learning from several sources, typically the cooperating teacher became the biggest influence and the most copied regarding teaching styles and strategies.

Conway (1999) performed a case study to develop teaching cases for students enrolled in music education courses. She used a qualitative study of four experienced music teachers to document daily interactions, decision-making skills, and knowledge of pedagogical content. The author contacted music teachers in New York to recommend four highly regarded music teachers from the state. Two of the teachers were from Long Island, New York and two were from upstate New York all representing typical 
instrumental music education sites. The sample included one elementary, two middle school, and one high school music teachers.

The categories in this study derived from previous research studies included curriculum and related objectives, program administration, recruitment of balanced instrumentation, scheduling music classes, selecting appropriate literature, rehearsal management, motivation, assessment and grading procedures, musicianship, and student rapport. The five research questions were: (a) what type of decisions did the teachers make in their daily interactions; (b) were there decision-making issues that were present for all four teachers; (c) which of these issues does the researcher perceive would foster discussion and debate in an instrumental methods course; (d) what did these instrumental teachers need to know in order to be successful in their work; and (e) how could this information be organized to enhance the curriculum of preservice instrumental methods courses.

The author analyzed the data using case study research analysis procedures as previously defined by Merriman (1988) and Yin (1994). Several issues concerning site teacher willingness, site access, and subjects' previously established relationship with the researcher were not an issue, given the willingness of participants and their teaching experience. Conway (1999) lists one to four narratives in each area as part of the case study that offer insights to good teaching practices exhibited by these experienced music teachers. She suggests that recorded narratives of sound teaching practices in each of these areas are important to the development of music teachers and should be included in undergraduate and graduate curriculums. 
Hamann, Baker, McAllister, and Bauer (2000) studied the effect of classroom delivery skills and lesson content on the assessment of lesson or teacher appeal related to the academic standing of university music students. Music students $(N=511)$ were from three moderate sized universities located in the Midwest or the East. Included in the study were lower division students $(n=231)$ comprised of 94 freshmen and 137 sophomores; upper division students $(n=194)$ comprised of 113 juniors and 81 seniors; and graduate students $(n=86)$ comprised of 51 masters and 35 doctoral students.

Each student viewed videotapes that demonstrated four lessons. The first example demonstrated good delivery skills with good lesson content, the second example displayed good delivery skills with poor lesson content, the third displayed poor delivery skills with good lesson content, and the final example displayed poor delivery skills with poor lesson content.

Delivery skills focused on posture, eye contact, gestures, facial expression, and vocal inflection. Lessons with good content featured an overview of the musical characteristics that were to be taught, examples of performances and musical models of various characteristics that were introduced by the teacher, and a review of all the musical characteristics taught in the lesson. Poor lessons featured times where the teacher strayed from the lesson material including references to performer attire, audience behavior, and what the teacher was planning to make for a meal.

The researcher analyzed the data using a two-way MANCOVA using independent variables (a) students' academic standing and (b) the teaching episode. When asking the question "how interesting was this lesson" a significant difference was found between graduate and upper divisions students interest scores, $(F(2,508)=19.89, p=.0001)$. 
Graduate students found good delivery/poor lesson content more interesting than lower or upper division students. They also found good delivery/good content more appealing to the graduate students.

Related to the question of "how much did you like the way the teacher taught the lesson," graduate students again liked the teacher delivery more than their upper or lower division counterparts $(F(3,1524)=1022.39, p=.0001)$. Scores were also higher for good delivery regardless of lesson content $(F(6,1524)=6.80, p=.0001)$. The authors also found that students of all levels liked good delivery/poor content much more than bad delivery/good content.

Madsen (2003) studied whether the accuracy and delivery of teacher instruction, coupled with student attentiveness, would affect subsequent evaluations of teacher effectiveness. The participants in the study were musicians $(N=168)$ divided equally into four groups: (a) music students $(n=42)$, grades 6-8; (b) music students ( $n=42)$, grades 9-12; (c) undergraduate music majors ( $n=42)$; and (d) experienced classroom music teachers $(n=42)$. (The study did not indicate how the subjects were chosen.)

All four groups rated teacher effectiveness using a 10-point Likert-type scale relating to four categories: (a) Accuracy of Instruction, (b) Delivery, (c) Classroom Management, and (d) Other. The coding of comments resulted in $89.95 \%$ reliability for all written comments. Results indicated a significant difference in levels of teaching effectiveness due to experience level $(F(3,164)=544.48, p<.0001)$ and the main effect of teaching segments $(F(7,1148)=16.46, p<.0001)$. The highest percentages of comments across all four groups were under Accuracy of Delivery: (a) grades 6-8 (39.05\%, (b) grades $9-12(39.72 \%$, (c) undergraduate music students $(38.11 \%)$ and (d) 
experienced music teachers $(33.56 \%)$. As the experience level increased, the percentages of comments regarding delivery increased while percentages of classroom management comments decreased.

Findings suggest that the delivery of teacher instruction affects the opinions of teacher effectiveness much more so than the accuracy of musical context of their teachers' instruction. Undergraduate music majors and experienced music classroom teachers rated accuracy of musical content of teacher instruction, delivery, and classroom management as the most important factors in evaluating teacher effectiveness.

Experienced teachers accounted for more comments regarding accurate instruction than any of the other three groups. Younger students favored enthusiastic teaching over other areas of assessment when determining effective teachers even if the content and accuracy of the lesson were inaccurate. All groups rated delivery as an important facet of effective teaching.

In summary, studies in the area of general music classes delineated many specific assessment areas needed throughout all music teacher evaluative instruments. Basic classroom tools such as communication skills, speech dexterity, teacher attitudes, enthusiasm, discipline, and measurement of student gains are common to all classroom assessment. Additionally, skills related to discovery, student participation, reinforcement tools, feedback, social skill development, classroom management, motivational skills, and leadership skills contributed to the assessment models employed in these studies.

Many areas specifically related to music instruction assessment surfaced that will appear in later sections in the literature review. These areas include amount of music teaching experience, conducting skills, music analysis skills, vocal skills, aural training 
(of the teacher), error detection skills, lesson organization and knowledge, rehearsal pacing, and student enjoyment.

\section{Concert and Marching Band Research}

This second section examines literature related to conductors leading concert or marching bands. As outlined in Chapter 1, administrators often have difficulty assessing conductors leading band rehearsals or performances because of a lack of evaluative training and understanding of many of the principles of effective conducting. The studies provide a number of possible frameworks for understanding the art of conducting and the ramifications of effective assessment procedures.

Ramsey (1979) developed a program designed to train music education students to detect errors in rehearsal and designed a test to measure effectiveness in this area. He proposed using band literature to provide error detection skills, contrary to the traditional training methods employed in music theory courses. He developed a seven-phase program including: (a) determining typical errors; (b) selecting repertoire; (c) assigning crrors to the score; (d) recording the mistakes; (e) validation of the program items; (f) establishing degrees of difficulty; and $(\mathrm{g})$ construct three program sequences. Band literature, selected at the medium difficulty level, provided appropriate instruction for the level of competency the student may expect.

Three judges evaluated the recording of the error-laden selections to determine whether there was more than one error per segment. Those segments containing more than one error faced elimination, leaving 135 items for a pilot study. The test asked the subjects $(N=77)$ to identify the measure where the error occurred, designate which 
instrument it occurred in, and describe the nature of the error. Subjects had completed two years of music theory and ear training.

To develop the final test, every seventh item chosen from the original pool resulted in a new subset of twenty items used in the study. Researchers implemented each of the twenty items using the following protocol: (a) announce the item number, (b) 60 seconds of study time, (c) first hearing of the excerpt, (d) 30 seconds of additional study time, (e) second hearing of the excerpt, (f) 15 seconds of answer time, and (g) 10 seconds to move to the next item. Researchers obtained a reliability coefficient of .71 using the Pearson's $r$ test.

An analysis of variance with repeated measures computed the combined and sample data of pretests to posttests yielding a significant F-ratio of $3.773(p<.01)$ indicating significant gains among all groups. A one-way analysis of covariance indicated that students from the experimental group received significantly higher scores than those in the control group $(F=5.93, p<.005)$.

Garofalo and Whaley (1979) compared two methods of teaching musical concepts and skills through band performance. The two selected high school bands had similar ability, enrollments, rehearsal time, difficulty of literature levels performed, amount of instruction, and socioeconomic factors. Conductors had similar training, experience, and professional development activity.

The ensembles rchearsed a specified selection for a period of five weeks with the experimental group using the Unit Study Composition approach and the other using a traditional band rehearsal method. Materials from the Unit Study Composition model (designed by the author) included: (a) analytical and historical information; (b) a list of 
musical concepts and objectives; (c) a glossary of musical terms used; (d) student activities and assignments; and (e) a method for evaluation of student progress. Researchers tested conceptual knowledge, aural skills, and performance proficiency as part of the study.

Both groups took three tests to measure their skills in achieving the learning objectives - a pretest, posttest, and post posttest to measure retention. Statistical results including means, standard deviations, and paired $t$-tests yielded significant results in favor of the experimental group. Both groups scored at similar levels on the pretests for conceptual knowledge, aural identification, and performance evaluation. Posttest results revealed significantly higher scores for the experimental group. Results from the post posttests for the experimental group indicated they also retained almost all of the information. (Post posttests were not given to the control group because their scores did not change significantly from the pretest to the posttest.)

Price (1983) studied the effects of teaching presentation of musical performance tasks, performer response, and teacher reinforcement/feedback and measured the three variables' affect on performer attentiveness, attitude, and performance level. Subjects $(N$ $=48$ ) were the members of a university symphonic band who were non-music majors. (The author used the members of this ensemble as a convenience sample and made no attempt to utilize random sampling.)

The study consisted of a pretest session where the students sight-read six selections, five treatment sessions using three different variables, and a final posttest performance session. Using a multiple regression analysis the authors selected three treatment variables: (a) Treatment A - verbalizations limited to where to start in the 
music, allowing the band to perform as much as possible, and no facial expressions exhibited by the conductor; (b) Treatment B - verbalizations amounting to $50 \%$ of the treatment duration that include academic task presentations with no reinforcement or facial expressions provided; and (c) Treatment C - directions, verbalizations of academic tasks, facial expression, and reinforcement approvals (80\%) and disapprovals (20\%), the band performs $50 \%$ of the time, and facial expressions reflect the verbal reinforcements. Observers recorded eye contact, student off-task behavior, amount of performance time, number of complete teaching segments, and types of teacher presentation (academic task presentation, directions to starting points in the music, social task presentation, conducting task presentation, and off-task statements).

Interjudge reliability was computed using the Kendall Coefficient of Concordance demonstrating a significance among judges scores (alpha level $=.05$ ). Off-task behavior was highest for the Treatment $\mathrm{A}$ variable and the lowest for the Treatment $\mathrm{C}$ variable. The largest performance gain was seen in the Treatment $C$ variable followed by the Treatment A variable. Student attitude and attentiveness scores were highest in the Treatment $\mathrm{C}$ variable $(F=22.86, p<.0001)$.

Whitener (1983) compared the differences of a comprehensive musicianship approach to a performance-oriented approach when teaching beginning band students in a junior high group. Comprehensive musicianship developed using performance, analysis, and composition, differs from students learning in a performance driven environment. Six band directors and six beginning band classes participated in the study. Researchers collected pretest data from students that had no previous experience playing an instrument. Students $(N=102)$ from 11 to 14 years of age selected from 6 middle school 
band classes in the Anchorage, Alaska area comprised the 57 students in the experimental group and 45 students in the control group. The comprehensive approach featured longrange goals concerning the three areas with biweekly objectives including rhythm, timbre, melody, harmony, dynamics, form, composition, and improvisation. Interjudge reliability for the two judges participating in the study was .77

Knowledge of music, determined using the Music Achievements Test (MAT), and music performance skills, evaluated using the Test of Performance Skills (TPS), provided the appropriate instruments for evaluation. (Since the students were beginners, it was impossible to use the TPS as a pretest.) An analysis of variance (ANOVA) of the pretest scores indicated that the two groups were generally equal. Posttest scores on the MAT indicated a significant difference between the experimental and control groups with the experimental group outperforming the control group on several evaluative measures. On the first part of the test, the experimental group scored higher on interval discrimination and auditory-visual discrimination with both groups scoring equally on pitch discrimination and finding the tonic note. The second and third portions of the test revealed similar scores for finding tonal center of a passage, identification of melodies, and identification of instruments. Results of the TPS test indicated no significant differences between the experimental and control groups.

The author concluded that musical elements and concepts could be part of an instructional strategy used in conjunction with performance skills. This would not negatively affect the performance ability of the students. (This is an important concept to consider when developing an effective evaluative tool. This study suggests that a 
combination of musical conceptual training coupled with effective performance practices may be the optimal outcome for ensemble instruction.)

Spradling (1985) studied the effect of timeout from performance on university band students' level of attentiveness and attitude regarding frequency and duration. Timeout segments included instruction and lasted 15,30 , or 45 seconds during 3 to 18 randomly selected points during rehearsals. The study focused on eight rehearsals lasting two hours each. The subjects were members of the Florida State Concert Band comprised of $65 \%$ music majors and $35 \%$ non-music majors $(N=80)$.

A panel of expcrts selected the music for the study with the following criteria: (a) music should be challenging yet capable of being read with a certain amount of attention to musical details; (b) it should represent different styles and composers; (c) pieces should be of sufficient duration to permit natural interjection of information during timeout segments; (d) pieces should avoid extended solo or small section segments that would cause the rest of the ensemble to sit; and (e) none of the selections should have been performed during the last two years. During each rehearsal, two different conductors led the ensemble in one new selection apiece, for a total of 16 selections over 8 rehearsals.

Two trained observers recorded the number of student off-task behaviors during each timeout segment with a third observer watching the timing of each segment. Conductors were given the following instructions prior to each rehearsal: (a) before beginning sight-reading, give the students 15 seconds to review their parts; (b) do not give verbal instructions during the 15 second segment prior to sight-reading; (c) give hand cues only during the performance segments; (d) keep eyes on the score during 
performance segments and avoid making eye contact with the students; (e) limit verbalization during timeouts to musical instruction and do not give approvals or disapprovals; and ( $\mathrm{f}$ ) be aware of light cues from researchers announcing the end or beginning of each timeout segment.

A tabulation of 4,840 occurrences of off-task behavior across the 16 recorded segments resulted in $1,118(23 \%)$ during performance segments and 3,722 (77\%) happening during timeout segments. Off-task behaviors were significantly lower during timeout segments than during performance segments $\left(x^{2}=1,402.36, p<.05\right)$. No significant difference in off-task behavior across different lengths of timeout segments $(15,30$, and 45 seconds). Timeout periods from 1 to 12 segments per selection averaged a mean of $8.51 \%$ off-task behaviors while segments 13 to 18 averaged a mean of $10.95 \%$ of off-task behavior. The study warranted further research on the differences between band and orchestra rehearsal techniques and whether these differences should be included in assessment models.

Witt (1986) compared teacher's use of class time to student attentiveness in secondary music rehearsals. Previous studies in elementary music rehearsals divided the activity in descending amount of time spent on teaching, performing, and getting ready. Private lesson situations had a greater degree of variance between teaching and performing and a comparable amount of time in getting ready. High school and university ensembles devoted increasingly higher amounts of time to performing than their younger counterparts. The amount of time projected on nonperformance activities, individual teaching, and eye contact determined levels of high school ensemble attentiveness. 
College band students exhibited the greatest amount of attentiveness when percentages of performance time increased.

Data, gathered from 48 instrumental music rehearsals with different music teachers $(N=42)$, fell into evenly divided numbers of junior high school and high school ensembles and between a similar number of band and orchestra ensembles. Videotaped observations of student attentiveness during rehearsals became a subject of the study. The music teachers were only aware that the study concerned the use of time management and did not know that student observations were taking place. Observations occurred over a four-month period with every effort to maintain a regular rehearsal environment.

Observation procedures used off-task behavior evaluation techniques while comparing them to different types of activity, as employed in previous research studies. Activities included student performance, teaching moments, and getting ready activities. Reliability increased by using a second trained evaluator to contrast the results. The author used a stepwise discriminant analysis to determine the results.

Orchestra rehearsals proved to have fewer but longer teaching episodes while band rehearsals had more teaching episodes but they were generally shorter in length. Preparation time was significantly greater in orchestra rehearsals largely due to increased amounts of tuning and was most prevalent in junior high rehearsals. Band classes spent more time on music organization activities but orchestra members were consistently more off-task than their band counterparts. Student attentiveness in orchestra rehearsals was typically more off-task than band rehearsals and becomes even more evident when considering the average number of students in orchestra rehearsals $(n=18)$ students as compared to students in band rehearsals $(n=53)$. 
These results may be due to the differences in training of the band and orchestra directors with respect to rehearsal techniques and pacing. The part-writing techniques employed by orchestra and band composers regarding greater and lesser amounts of full ensemble techniques (as compared to traditional orchestral scoring techniques) may have affected these results. (These findings may suggest a different evaluative tool for orchestra conductors than for band conductors, due to the music literature itself. Orchestral literature is generally longer in length and the compositional ideas are more fully developed than their band composer counterparts.)

Goodstein (1987) explored the differences between successful band directors and a randomly sampled group of band directors, studying differences in leadership and environmental variables. Previous research in leadership theory served as the basis for the present study, which postulated that effective leaders are flexible and adjust to changing environments.

The selection of successful band directors, derived through consultation with a national band director organization (National Band Association), yielded a population of 104 successful band directors from across the country. The chosen band directors displayed scores indicating success in all areas of the band program as defined by the National Band Association. One hundred and four randomly selected band directors from three states neighboring Arizona completed the pool for the study. Eighty-nine percent of the successful band directors responded and $63 \%$ of the randomly sampled group responded.

The author sought to discover the relationships between independent variables among populations of successful and random groups of band directors. He considered 
whether there were predictors of membership into these two groups and differences that separated the two populations. Previous researchers concluded that band directors often fail, not because of a lack of musical ability or formal training, but rather because of differences in teacher psychological traits. Leadership behavior studies also framed the study and used four distinct leadership styles comprised of varying levels of task, relationship, and maturity factors.

The independent variables were extensive and included: age, highest degree earned, number of semester hours past the highest degree earned, Likert-type scales describing the socioeconomic environment of the school system, annual fundraising income, average number of out-of-town trips, administrator support (as perceived by the band director), type of disciplinary actions utilized, weekly number of rehearsal hours, existence and strength of the band booster program, average number of hours of nonband related activities required of the director, average number of music contests attended, school population, total number of students in the band program, the size of the marching band, the number of students in the "top" concert band, the average size of the band freshmen class, average number of students participating in solo and ensemble events, demographics of the school location (urban or suburban), number of assistant band directors, average number of musical sectional hours, and the number of years in the present position. The dependent variable was the leadership behavior measured by the assessment instrument.

A stepwise discriminant analysis identified and ranked the variables regarding their ability to distinguish among groups. Results of the study indicated that the following 12 independent variables were statistically significant: age, highest earned degree, 
socioeconomic status of the school district, average amount of fundraising dollars, strength of the band booster organization, school population, marching band size, total number in the program, number of members in the highest level concert band, average yearly number of freshmen band members, yearly number of students participating in solo and ensemble contests, and whether the district location was near an urban area.

Four variables improved a director's chance of belonging to the successful band director classification by comparison of group means: size of the marching band ( $21 \%)$, average number of band freshmen (5\%), the socioeconomic nature of the school district $(3 \%)$, and the size of the top concert band $(2 \%)$. The squared canonical correlation score indicated that these four factors increased the likelihood of belonging to the successful band director population by more than $30 \%$. Thirty-four of the randomly selected band directors met the criteria for successful band directors. Leadership variables posed no significant differences between successful and randomly selected directors.

Results suggest that due to the complex nature of assessing band programs, varying criteria must be employed to assess the effectiveness of band directors, given the size and scope of their programs. (This suggests that the focus of a band program may warrant different types of evaluative tools given the number of possible ancillary type band activities that may accompany the traditional band setting.)

Dickey (1991) studied the effectiveness of verbal and modeling instruction in middle school band rehearsals. The subjects $(N=128)$ were band students from three middle schools in southeastern Michigan. He hypothesized that modeling was a more effective technique than verbal instruction. The author defined "verbal instruction" as directions, explanations, imagery, metaphors, and analogy. Modeling instruction featured 
alternations between the teacher modeling musical ideas on their instruments with students imitating these styles and concepts on their instruments. The comparison of the two styles of teaching was to determine whether one approach yielded better results with regards to melodic ear-to-hand skills, kinesthetic response skills, and general musical discrimination skills.

The author taught one class using a verbal instruction style and taught another band using a modeling style. Another band director (the replicator) taught one band from his school using a verbal instructional style and taught the other band from his school using a modeling style of instruction. The replicator received training for a period of one month before the test. Using the Pearson correlation matrix, the interjudge reliability was .99.

Dickey (1991) used four test instruments in the study. The first three measured pretest-to-posttest gains in varying areas of musical achievement and a fourth instrument analyzed differences in gains based on individual musical aptitudes. (No reliability or validity statistics were noted in the study.) The first test evaluated a student's ability to listen to and imitate various examples of musical meters and tempos. The second test measured a student's ability to reproduce musical phrases and patterns after listening to a prerecorded example. The third test asked students to discriminate musical nuances of tonality, melody, phrasing, tone quality, expressive nuance, intonation, balance, and the number of parts in an ensemble.

Dickey (1991) used one-way analysis of variance tests across the variables to reveal that students in the two modeling-based instructional classes achieved significantly higher scores than did their verbal instruction counterparts $(\mathrm{F}=11.41, p<.01)$ for the 
modeling group, $(F=3.94, p=.05)$ for the verbal instruction group. This was true in tests relating to car-to-hand skills and kinesthetic response skills. There was not a significant difference in the test of general musical discrimination skills.

Bergee (1995) investigated the hypothesis that concert band performance evaluations divided into three levels of judgment increasing in order of importance. The study featured the ratings of a recorded performance of Rhapsodic Episode by Charles Carter by graduate and undergraduate students $(N=245)$ currently participating in concert bands at three major universities.

The students used the 48-item Band Performance Rating Scale (BPRS), developed by Sagen (1983) and the researcher used an analysis of variance to determine interjudge reliability. The student raters did not have musical scores to look at during the process and heard the recording as often as necessary. Three interrelated primary factors were tone quality/intonation, musicianship/expressiveness, and rhythm/articulation. To determine interjudge reliability, a panel of graduate music education students $(n=7)$ evaluated five recordings of high school bands. Different groupings of rating variables and different performance orders yielded a high interjudge reliability. Interjudge reliability for tone quality/intonation was .96 , musicianship/expressiveness was .95 , and rhythm/articulation was .85 . Although the number of subjects in the study was 245 and the rating variables ranged from $40-80$ variables, the standard error was low (.064), as Bergee (1995) observed.

The first factor, tone quality/intonation, accounted for $27 \%$ of the variance. The second factor, musicianship/expressiveness, accounted for $8 \%$, and the third factor, rhythm/articulation, accounted for $6 \%$ of the total variance. Correlations between the 
student rater rankings and the panel of adjudicators rankings ranged from .84 to .91 with .88 as the total score correlation $(p<.05$ for all). Tone quality/intonation was clearly the highest ranked factor followed by musicianship/expressiveness, and then rhythm/articulation. The author noted that musicianship/expressiveness rose significantly when analyzing solo performance. The results of the study suggest that these three areas need attention in assessments instruments to effectively rate music teachers.

Goolsby (1996) examined the amount of time spent in rehearsals across 14 variables, comparing time use by experienced, novice, and student music teachers. Band directors $(N=30)$, randomly chosen within a 75 mile radius of the Atlanta metropolitan area, taught at the secondary level and were divided into three equal groups. The experienced conductors $(n=10)$ represented established conductors in the field with eight or more years of teaching, possessing a comprehensive program (concert, jazz, and marching bands), consistent high schools at music festivals, and experience as a cooperating teacher. Novice conductors $(n=10)$ were in the first or second year of teaching, and student teachers came from large university programs within a 75-mile radius. Researchers attempted to select diverse schools across the region.

To control the experiment, student teachers conducted the same ensembles as the experienced conductors did and received considerable freedom in music selection and rehearsal structure. Researchers videotaped all conductors twice within 3 to 9 days before a school or festival concert. Variables included: total duration of rehearsal, preparation time, initial teacher talk, total warm-up time, first break, time spent on first selection, second break, time spent on second selection, third break, time spent on a third selection, fourth break, time spent on a fourth selection, final teacher talk, and dismissal. 
Timings, recorded in seconds and then converted to percentages, equaled the total rehearsal time. Analysis of variance (ANOVA) indicated that any variations in rehearsal length did not violate assumptions for the test. The correlation between the two researchers computing the results was $r=.90$, a clearly acceptable rate. Mean percentages of rehearsal time indicated that experienced teachers spent the most time in musical instruction and performance $(80.6 \%)$, followed by student teachers $(76.9 \%)$, and novice teachers $(67.3 \%)$. Experienced teachers scored the highest on performance $(51.2 \%)$, lowest on nonteaching activities, slightly more time on warm-up activities, and less time between rehearsing sections.

Results indicated that student teachers talk more than their experienced conductor counterparts did and they did not allow their bands to perform. This behavior of talking during rehearsal resulted in greater off-task behavior exhibited by the performers while the experienced teachers moved from one musical section to the next with less nonteaching time in between segments. An ANCOVA indicated differences in preparation times $(F(2,26)=18.5, p<.01)$ with experienced teachers using $2.9 \%$ of the time in this area compared to $7.8 \%$ for student teachers, and $9.3 \%$ by novice teachers. Experienced teachers also allowed their ensembles to perform for longer periods between teaching segments. This finding is consistent with other studies and should be part of new assessment models. (This factor should be included in evaluative instruments. Otherwise, the lessening of verbal instruction may be confusing to the administrator and may have a negative effect on their overall rating.)

Goolsby (1997) investigated the use of verbal instruction during 60 rehearsals led by three levels of conductors: expert, novice, and student teachers. He hypothesized that 
expert teachers, as compared to novice and student teachers, spent more rehearsal time performing, spent less time verbalizing instruction, and stopped for shorter periods of time between performance segments. Study variables included 15 performance variables, 10 rehearsal variables, and 3 complete sequential teaching pattern variables. A second portion of the study determined the degree of change observed through guided instruction as part of a music education course.

Goolsby (1997) selected band directors $(N=30)$ divided equally among expert, novice, and student teachers. Selected expert teachers had a minimum of 8 years teaching experience, led a comprehensive band program, received consistent superior ratings at music festivals, and served frequently as a cooperating teacher for student teachers. These teachers were selected because of their participation in a study by the author the previous year. All teachers came from a 75-mile radius with all of the student teachers enrolled at one of four universities in the Atlanta metropolitan area. Music supervisors and local university music educators viewed all novice teachers selected as exceptional teachers and conductors. Student teachers used in the study came from programs in nearby regional universities. The sample included a cross section of socioeconomic status of students, cultural diversity, and locations close to a large city.

The study was limited to descriptive statistics including measures of central tendency and discriminant analysis. Mean frequencies across the three types of variables served as the basis for comparison. Goolsby (1997) noted that expert teachers devoted a higher percentage of rehearsal time to musical instruction and performance $80.6 \%$, whereas as novice teachers devoted $67.3 \%$ and student teachers devoted $76.9 \%$ to musical instruction and performance. 
Expert teachers spent more time on sound production, intonation (tuning) information and training, and guided the listening skills of the performers. Novice conductors spent more time tuning individual notes while student tcachers spent the majority of their time fixing wrong notes. Expert teachers stopped more often to correct problems and employed short musical exercises to teach musical concepts or phrases. Novice teachers stopped less than the student teachers and spent most of their time working on rhythm and tuning. Although they employed the highest percentage of positive reinforcement, most of their comments were unspecific in nature. Student teachers stopped frequently without apparent reason and often offered little or no feedback. Student teachers and novice teachers used fewer percentages of complete sequential segments and gave general types of positive feedback in contrast to the expert teachers. Similar to previously cited examples of research, all three groups of teachers spent a majority of their time on rhythm and tempo more than any other performance variable.

The second portion demonstrated significant growth in the percentage of complete sequential patterns as students received more instruction and training. These results, tempered by the lack of a control group for comparison, suggest further research and study of the use of focused questions as a means of teaching musical concepts in rehearsal. (This interactive style of teaching musical concepts is an important tool in teaching with respect to musical instruction.)

Blocher, Greenwood, and Shellahamer (1997) noted that band students spend a great amount of time preparing for an average of more than 42 public performances each year. Prior research and casual observations indicate that band directors spend most of 
their time preparing for these performances. Band directors focus their efforts on increasing their student's performance skills and not on developing cognitive musical skills. Many researchers proposed a balanced approach to performance preparation and knowledge development. For purposes of this study, the author investigated the amount of time junior high and high school directors spent on different teaching techniques during rehearsals, specifically regarding the teaching of musical concepts.

Two experienced music educators (chosen as a covariance sample) cvaluated participants $(N=21)$ representing a full range of abilities, as recommended by a panel of five music educators for purposes of the study. Participants were junior high and high school band directors from the state of Florida. Of the 12 junior high directors selected for the study, three of the directors did not record the required number of rehearsals and were not included in the study. The videotapes of the remaining nine directors were of differing lengths and required segmentation into randomly ordered 20 -minute sections. All nine high school directors successfully produced usable videotapes and in a similar fashion, divided the recordings into randomly selected segments.

After reviewing the 18 videotapes, the authors selected rehearsal behaviors utilizing a "teaching cycle" approach borrowed from existing research. The resulting behavioral categories were included: nonmusical (preparation activities, disciplinary actions, and announcements not related to the music); nonverbal instruction (conducting gestures and body language); verbal instruction (instructions related to the music); noninteractive listening (teacher is listening but providing no feedback or stimulus to the students); nonverbal feedback (body language or conducting gestures that let the student know how they are doing); verbal feedback (director gives information about the nature 
of the student's performance); and conceptual teaching (director reinforces, questions, or answers questions in a manner that leads to greater understanding and appreciation of musical concepts).

The two evaluators performed a practice test using several of the discarded videotapes not accepted as part of the study and the actual data recording of the junior high school participants. A second test also practiced on the discarded videotapes and then recorded information from the nine high school directors, yielding a relatively high interobserver reliability $(r=.80)$ between the two sessions. Interpretation of the results indicated that directors used nonverbal communication more of the time than verbal communication, with high school directors scoring four times higher in this category. Directors used verbal communication virtually the same amount of time in rehearsals. Non-interactive listening consumed $22 \%$ of the time, with middle school directors spending three times more time in this area than their high school counterparts.

Nonverbal and verbal feedback on average accounted for only 1 minute and 36 seconds out of a 19-minute, 20-second rehearsal. Nonmusical activities consumed approximately $8 \%$ of both junior high and high school rehearsals. Conceptual teaching behaviors only occurred on average for 32 seconds out of a 19-minute, 20-second rehearsal across both populations. Results from the study suggest that successful programs find a variety of methods to teach musical concepts but limit the exposure to these techniques to short durations during rehearsals.

King (1998) performed a 10-month qualitative study of an internationally acclaimed music teacher. The author sought to study the personal and professional qualities of a successful band director, (David Dunnet). Through participant observation, 
ethnographic interview, and artifact collection the author sought to create a rich-thick description of the personal and professional qualities of a respected music educator. He gathered the data and then organized the results into emerging themes associated with an effective music teacher.

The author first researched the personal background of Dunnet. As a youngster, Dunnet heard many touring military bands and was influenced by these performances and the band medium. Although his parents were not musical, they were supportive of his early efforts on the trumpet and membership in school bands and attended summer music camps. He successfully completed his undergraduate and graduate studies in Musical Arts at the University of Washington. At age 23, he began a highly successful teaching career receiving many accolades and nominations to music education organizations.

Four major themes emerged from hundreds of sub-themes in the qualitative study. The first theme recognized the subject's high level of verbal and non-verbal language. He possessed a high level of musical and general knowledge and employed a creative manner of presenting this knowledge to his students. His communication skills (command of the language and the information) enabled him to convey this information and link it to pre-existing knowledge in meaningful ways, setting him apart from other teachers.

The second theme related to creating an organizational framework to enable his artistry in teaching to reach exemplary levels of teaching. The routines that he utilized provided a level of reassurance and confidence in his students. He possessed great attention to detail and demanded consistency in every phase of his program. His 
punctuality, commitment, and level of integrity allowed him to help his students reach their greatest potential.

The essential nature of humor in exemplary teaching is an important attribute in expert teachers, found in subtle and intellectual ways. Humor added a variety to the normal routine and kept his students anticipating a change in delivery as a normal part of his instruction. He often used humor to reinforce musical concepts, rehearsal discipline, and social conduct. He used humor as an effective means of communication on a daily basis.

The final theme revolved around maintaining a quality environment to teach and to learn. The organization of the physical setting connects with other aspects of teaching and represents a comfortable climate for the students to learn. He insisted on a collegial environment among students and stressed interpersonal skills. His sense of commitment, consistency, and personal moral values exemplified his belief that people are far more important than things in life. King (1998) noted that the overall success of Dunnert and his program over 28 years related directly to his ability to weave these four themes throughout this teaching.

Goolsby (1999) studied experienced and novice teachers to determine characteristics that were common to effective band directors. This particular study was the third in a series of inquiries by the author pertaining to elements of successful band director instruction. The author used the same participants from his two previous studies. This study shifted the focus of the investigation to determine if there were differences between experienced and novice conductors in their use of rehearsal time and verbal instruction. 
Participants were band directors $(N=20)$ who all prepared the same Grade III+ (medium difficulty) composition randomly chosen but evenly divided between middle school and high school directors. Eight of the expert teachers selected participated in a previous study by the author and with three of the middle school teachers also participating in an earlier study. All directors came from the Atlanta metropolitan area.

The first study controlled for time and found that experienced conductors spent significantly more time employing nonverbal modeling/demonstration techniques than their novice counterparts did. Novice conductors used $40 \%$ more time using verbal behaviors during rehearsal and relied on verbal discipline far more than the experienced conductors. The emphasis of the second study was to measure 25 variables to establish categories of verbal teaching and the frequency of complete sequential teaching patterns. Interpretation of the results found that experienced conductors stopped more often than novice conductors but for shorter amounts of time. Novice conductors only completed $12 \%$ of their sequential patterns while experienced conductors completed $22 \%$.

Experienced conductors also directed their comments concerning tone quality, intonation, expression, articulations, and guided listening more often than the novice conductors did.

Each band director started from the initial sight-reading through to the concert performance. An initial problem of the study was to choose a band piece that was not only manageable by middle school and high school bands but also was of good quality and less than five minutes in length (to prevent performer fatigue from becoming a factor). The selected composition needed at least three contrasting styles within the piece with a contrasting assortment of articulation styles, rhythms, expressive segments, and a 
variety of compositional techniques. The final selection met all of these criteria and was representative of quality of band repertoire on the Grade III level.

The participants for the third study were novice conductors (between 2 to 5 years of teaching in a recognized quality program) equally divided between junior high and high school programs $(N=10)$. All of the high school directors conducted their second band as part of the study. Videotapes contained samples of rehearsals and the culminating concert performance. Five university band directors with significant adjudication skills received audiocassette copies of the final performances. The scoring system employed a rating scale of I to IV with no ratings below a score of III (I being the highest rating possible and IV being the lowest).

Tables of means and standard deviations for the time variables and the organization of time percentages were used to contrast the experienced conductors with the novice conductors. A multivariate analysis of variance computed the differences for school level or interaction after first using Levene's test for homogeneity of variance. A post-hoc analysis of variance tested for significant differences between the variable scores. As Goolsby (1999) predicted, novice conductors used more rehearsal time to prepare the selected piece than did the experienced conductors and there was a similar amount of time devoted to nonmusical activities. (The study did not reveal the actual findings related to rehearsal time preparation.)

Results of the study were very similar to those of the previous two studies completed by the author. Novice conductors used $35 \%$ of the rehearsal time in performance, $44 \%$ of the time in verbal instruction, $2.4 \%$ of the time modeling, and $6 \%$ of their teaching segments were complete. This compared favorably with previous studies 
with experienced teachers spending $51 \%$ of their time in performance, $32 \%$ in verbal instruction, $5 \%$ modeling, and $15 \%$ of their teaching segments were complete.

Novice conductors corrected problems more often by rote while the experienced conductors encouraged the students to find solutions through various techniques. Both groups addressed issues of rhythm or tempo more than any other variable, followed by problems concerning articulations, notes, and dynamics. Novice conductors also started and stopped without any apparent reason at a more significant rate than the experienced conductors.

One final comparison noted the difference of novice conductors using a technique of teaching the composition in order from the beginning to end. In contrast, the experienced conductor used more creative methods of learning the piece. They would often introduce the difficult passages and transitions first before working on the easier tutti (full ensemble) sections as part of their rehearsal process. The study suggests that innovation in teaching style and delivery should be an integral part of any assessment model when measuring conductor effectiveness.

Doerksen (1999) studied the differences in aural-diagnostic and prescriptive skills used by preservice and expert instrumental music teachers. Prior research indicated that certain teaching characteristics were germane to specific disciplines. Regarding conducting musical ensembles, the proper diagnosis and remediation of problems that arise in rehearsal are two qualities inherent in effective music teaching. Teachers with a higher accumulation of teaching experience (as compared to novice teachers) have an obvious advantage. Teaching experience, however, does not always correlate with higher 
prescriptive skills. (The identification of these diagnostic and remediation skills in music teachers by administrators is an important aspect of the evaluation process.)

The author used preservice teachers and expert teachers for the study $(N=60)$. The study enlisted preservice teachers $(n=23)$ at the junior and senior level enrolled in music education. Selection of expert teachers $(n=37)$ came from those directors receiving the highest ratings in band performance at state festivals over a five-year period. Band performances divided into four categories for use in the study: difficult music and excellent performance, difficult music and average performance, moderate music and excellent performance, and moderate music and average performance. A collection of state and national festival recordings provided a suitable amalgamation of band performances for the first stage of a three-step process.

Second, five different repertoire-rating guides provided the difficulty ratings for the selected music. The final stage of the process involved a panel of three highly qualified state adjudicators who rated the recordings using state approved adjudicator forms. The adjudication forms rated items on a 1 to 5 scale and included the following independent variables to classify the type of performance: tone quality, intonation, blend/balance, rhythm/precision, articulation, technical facility, musical interpretation, phrasing, and dynamics. Study participants received a copy of the score and five copies of the evaluation instrument (one copy was a trial copy) and completed the forms while listening to the recording.

Nine individual two-way analysis of variance (ANOVA) procedures assessed each of the independent variables, including tone quality, intonation, blend/balance, rhythm/precision, articulation, technical facility, musical interpretation, phrasing, and 
dynamics. Each ANOVA included a between-factor analysis for both the preservice and expert teachers and the four levels of performance. The only large difference in significance for between-group comparisons across both groups was Intonation. Tone quality $(F(3,147)=3.09, p<.05)$, intonation $(F(3,146)=4.60, p<.005)$, articulation $(F(3,147)=2.74, p<.05)$, and dynamics $(F(3,146)=3.40, p<.05)$ demonstrated significant interactions. The participants ranked the evaluation elements from 1 to 9 with "1" being the strongest performed elements and "9" being the weakest. Each element, placed into one of the nine matrices, recorded and grouped the qualitative data for both the diagnostic comments and the prescriptive comments.

Findings from the study indicated that tone quality, intonation, articulation, and dynamics were most significant for achieving musical excellence with preservice teachers, who ranked intonation lower $(34.8 \%)$ than did the expert teachers $(25.0 \%)$. Higher percentages of expert teachers rated blend/balance and musical interpretation as being the weakest performed elements $(21.7 \%$ preservice and $25.0 \%$ expert $)$.

Doerksen (1999) noted that when considering prescriptive groupings, preservice teachers believed that nonverbal communication was more important while expert teachers placed greater importance on instruments/accessories. This may be an indication that expert teachers regularly use verbal explanations to correct musical problems. The author suggested that future research concerning the study of this type of training within music education curricular models might illuminate this point further.

Rogers (1985) surveyed high school band programs $(N=421)$ to determine the type and number of marching band contest participation and attempted to explain their popularity. The author posed two hypotheses: the first hypothesis suggested different 
geographic regions of the country have varying amounts of contest activity. The second hypothesis was that there were statistical differences between band directors and principals' perceptions of the educational value of marching band contests. Each band director and principal received a survey with $77 \%$ of the band directors and $85 \%$ of the principals returning the forms. Both the band director and the principal both returned the form in 284 schools or $67 \%$ of the total. Six questions asked the band director and principal the value of: (a) a general educational experience, (b) students' personal benefits, (c) motivating students and recruiting, (d) improving financial support of the band, (e) improving administrative support, and (f) improving public relations for the school.

There were significant differences $(p<.05)$ in number of contests across geographic regions with the West scoring highest in contest attendance $(M=2.75)$ and the Midwest the fewest $(M=1.00)$. Principals rated the value of the marching band contests slightly higher than band directors did in all categories except in improving financial support and improving administrative support. Use of the Pearson pair-wise comparison of band directors and principals, although statistically significant, demonstrated low levels of agreement between the two.

A stepwise multiple-regression found that the number of awards won at contests and size of the band budget were significant predictors $(p<.05)$ of band director value scores. Based on the results of the study, marching band directors' tend to value nonmusical aspects of the activity more than the musical performance benefits. Regarding the popularity of marching band contests, Rogers (1985) reasoned that the 
high number of returns and the high value scores indicated a positive sentiment for this type of activity.

In summary, within concert and marching band research articles, several reoccurring themes related to bands emerged. Conducting skills such as eye contact, gestures, expression, reaction to errors, and non-verbal skills were prevalent in many of the studies. Rehearsal preparation and implementation attributes such as rehearsal structure, on-task and off-task rehearsal segments, musical error detection, teaching style characteristics, student involvement in the learning process, use of audio visual aids in teaching, and classroom control and discipline also appeared with regularity throughout the studies. Motivational and leadership aspects such as rehearsal pacing techniques, student responses to non-verbal techniques, and student achievement as related to conductor skills were also predominant.

(Because of the diverse nature of the ensemble settings studied, including concert band, marching band, and subsets of these settings, it is apparent that different evaluative criteria must be included to obtain an accurate assessment of teacher skills and outcomes.)

\section{Choral and String Ensemble Research}

As mentioned in the previous section, repertoire may effect on the criteria used when evaluating conductors. Band, choral, and orchestral repertoire offers additional variances that should be noted and ultimately included in an assessment instrument. Band programs often have more different types of ensembles or subsets of the primary ensemble than do orchestras or choirs. Orchestras and choirs, however, also have 
different expectations and subsets of their primary ensembles, which should be considered.

Yarbrough (1975) investigated the result of magnitude of conductor behavior on two areas concerning mixed choruses: performance attentiveness and attitude of students. The purpose of the study was to compare the rehearsal effects on four different ensembles, when working with their regular conductor, a conductor with high magnitude characteristics, and one with low magnitude characteristics. The ensembles consisted of one university and three high school choirs.

The author defined magnitude as what conductors did physically to make rehearsals more interesting and exciting for the performers. Students $(N=207)$ participating in the study were members of mixed choruses randomly chosen from the Tallahassee, Florida area. Recordings of rehearsals occurred during regular rehearsal times and the musical selection was accessible to the participating choirs and used prescribed segments for purposes of the study. Each of the three types of conductors (regular conductor, high magnitude conductor, and low magnitude conductor) received instructions and feedback designed to keep their approval/disapproval at even levels.

After exposure to the three levels of magnitude, each chorus sang the prescribed excerpts for a panel of judges for a performance rating with each of the three conductors. Performance rating indicators were: intonation, blend, balance, tempo, dynamics, tone quality, rhythm, phrasing, ensemble, diction, style, and overall artistic effect. Interjudge reliability was high $(r=.97, p<.05)$ signifying little discrepancy between ratings.

The authors also recorded behavioral observation of student attentiveness (ontask, off-task behavior) and student self-reports of attitude. Teacher behavior variables 
were: eye contact, closeness, volume and modulation of voice, gestures, facial expressions, and rehearsal pace. Rehearsal observation variables included: teacher instruction, teacher singing, other teacher responses, nonperformance segments, and performance segments. Researchers watched videotaped rehearsals three times and divided the number of variables recorded evenly among the viewings.

A two-way analysis of variance among the three groups showed little difference in posttest scores although the lowest scores received were from the low magnitude conductor groups. Most of the musical gains occurred in all treatments during the initial learning segment. The greatest amount of off-task student behavior occurred during the regular conductor and low magnitude conductor groups. The greater amount of eye contact, body movement indicating approval, and higher percentages of reinforcement by high magnitude conductor behavior provides a possible explanation for this effect. Eye contact mean frequency percentages were 60.75 for high magnitude conductors, 25.75 for baseline conductors, and 3.50 for low magnitude conductors. Approach mean frequency percentages were 17.00 for high magnitude conductors, 5.75 for baseline conductors, and 0.00 for low magnitude conductors. Contingent reinforcement mean frequency percentages were 51.56 for high magnitude conductors, 23.04 for baseline conductors, and 24.00 for low magnitude conductors.

Cooksey (1977) constructed a test-rating scale designed to measure high school choral performances using a facet-factorial method. The author first collected evaluative criteria to describe high school choral performance from 618 high school chorus adjudication sheets, 52 critiques of high school choral performances by choral teachers, and 12 essays provided by experts on high school choral performance. More than 500 
evaluative statements, checked for redundancy, reduced the final number to 147 statements concerning evaluation. The author used a facet-factorial analysis to determine evaluative factors germane to high school chorus evaluation. Five-point Likert-type scales measured ratings of one point for strongly disagree to five points for strongly agree.

Seven evaluative factors surfaced from the analysis: diction, precision, dynamics, tone control, tempo, balance/blend, and interpretation/musical effect. There were 39 subquestions related to the seven general categories. A Hoyt analysis of variance procedure established high reliability coefficients for the three control groups of teachers were above .98 with the reliability coefficient for the student judges was .97 . Interjudge reliability was above .95 for the three judges, and above .92 for the students.

Larson (1977) investigated undergraduate music major detection abilities regarding melodic error detection, melodic dictation, and melodic sight singing. The subjects $(N=90)$ were junior and senior level students enrolled as music majors at the State University College at Fredonia, New York in 1974 randomly selected from a pool of 174 students. Three classifications of melodies from published sight-singing texts used in the study were diatonic (using notes of a major scale), chromatic containing accidentals and notes not in a regular major scale) or atonal (no tonal center) in nature. The researchers altered the melodies for a final group of 12 melodies randomly selected from an original pool of 60 melodies. Two tests of interjudge reliability for three judges provided scores of .89 and .79 . The 90 subjects were divided into three cells for the three areas of investigation. 
Student achievement (dependent variables) was highest when the influence of the three melodic styles proceeded in the following order of tasks (independent variables): error detection, sight singing, and dictation. An analysis of variance revealed significant differences and interactions between tasks and styles $(p<.0001)$. The melodic styles did not significantly affect the scores of the three tasks. A high level of significance, however, occurred between error detection and dictation consistently across all twelve variables. The author contended that ear training exercises in music curriculums should (a) provide opportunities for error detection skills development, (b) view dictation as an important means of developing aural-visual discrimination abilities, and (c) continue to value sight-singing as a valuable music competency.

Cox (1989) studied the varying kinds of rehearsal structures employed in choral rehearsals found in choral music education literature. Previous research was not conclusive as to one method being superior to the others. Three different models of rehearsal pacing offered no common thread or theme for effective rehearsal structure. The participants in the study were Ohio high school mixed chorus directors who performed at least two state-level choral association contests over a three-year period $(N$ $=5$ ). This implied that these directors received a superior rating at a district-level competition and suggested that the ensemble was of higher than average quality. Directors, students, and administrators received one of three questionnaires designed to assess organizational rehearsal structure and student attitudes. Each participant completed the directors' questionnaire and selected students $(n=12)$ completed the student questionnaire (with a student leader administering the test). 
The author utilized two administrator observations of student attitudes toward the chorus and the teaching style employed. The first was the student perception of the teaching style used by the conductor. The second measured the student's perception and attitude towards the choral ensemble. The teaching styles divided into three categories including very little change in the pace or design of the rehearsal, a moderate change in rehearsal structure and pace, and the third designation, more aggressive changes in the change of rehearsal pace. A pilot study involved 5 choral directors, 60 students, and 10 administrators. The purpose of the pilot study was to determine: clarity of the study instructions, the response rates of the three populations, the suitability of data analysis, and the validity of the measurement instruments. A Pcarson product-moment correlation yielded a high correlation between paired data including student and administrator questionnaires and rehearsal organizational structures. Results of the pilot study confirmed that all of the stated objectives were satisfactory with a high correlation between administrator and student responses $(r=.80, p=.05)$.

A response rate of 72 of the 85 selected participants with an additional 12 schools eliminated (incomplete returns or new directors assuming positions since the choir performed at contest) yielded a final response rate of $71 \%$. One of the three rehearsal structures was statistically significant over the other two as result of a chi-square test. An analysis of variance demonstrated no significant differences between student preferences for rehearsal structures, $(F(92,706)=1.245)$. However, a Newman-Keuls test demonstrated that directors employing a rehearsal structure related to the first or third design enjoyed significantly higher student attitudes towards chorus although the mean responses were not measurably different (.14). 
Results also included an indication that the second style of rehearsal structure (utilizing slower-paced activities, methodical study tools) conveyed a greater sense of patience, $(F(2,706)=4.419)$. The first style structures (higher-paced, high-energy rehearsals) yielded higher scores suggesting that they were more enthusiastic and stimulating. Administrator results provided no preference to one teaching style over another. One additional finding suggested that all directors encourage a form of closure in rehearsals when moving from one musical selection to another and as a consummating act of each rehearsal.

Yarbrough and Price (1989) examined existing research on effective teaching and the extent to which teachers used the research results and applied them in their music teaching. The research observed rehearsals of experienced and novice instrumental and choral teachers and students $(N=79)$. The research examined experienced instrumental teachers $(n=15)$, experienced choral teachers $(n=15)$, freshmen music education majors $(n=30)$, and sophomore music education majors $(n=19)$. Teacher presentation independent variables were academic musical task preparation, social task presentation, giving directions, questioning, and interruptions in rehearsal. The three student responses were: performance by entire section or ensemble, verbal response, or nonverbal response. Teacher responses (dependent variables), coded by approvals and disapprovals, examined correct or incorrect sequencing measuring time segments spent in each area.

All areas except freshmen spent a greater percentage of time $(70.25 \%)$ in incorrect sequential cycles. Presentation of tasks and students responses ranked higher than reinforcement in all groups. Student responses for all groups were mostly performance orientated ( $47.91 \%$ band and $49.23 \%$ chorus) with relatively few verbal and 
nonverbal responses $(0.52 \%$ band and $1.18 \%$ chorus $)$. The total time spent giving directions and performing was well over $50 \%$ with very little time spent reinforcing behavior. Experienced teachers, as compared to freshmen and sophomores, had higher rates of disapprovals. Musical information training appeared in less than $20 \%$ of all groups' rehearsal totals except for sophomores. The authors suggested that more time in teacher training should be spent on methods of presenting musical information, of allowing student response time, and of providing appropriate reinforcement.

Hamann, Mills, Bell, Daugherty, and Koozer (1990) studied classroom environments as evaluated by high school instrumentalists, choral students, and teachers $(N=1,843)$ to determine if any significant difference existed among selected variables. These independent variables were: musical achievement (music contest scores), the status of the teacher or the students, male or female, or type of performing group (instrumental or choral). The researchers used the Classroom Environment Scale, Form R (CESR) to evaluate classroom environments (dependent variables). The CESR contained 90 true or false questions of 10 randomly distributed questions for each of the 9 different scales: (a) involvement, (b) affiliation, (c) teacher support, (d) task orientation, (e) competition, (f) order and organization, (g) rule clarity, (h) teacher control and (i) innovation.

An ANOVA analysis used contest rating as the dependent variable and the independent variables were the nine CESR scale scores. Significant mean differences were found for CESR variables of involvement, affiliation, teacher support, task orientation, and order and organization. A second ANOVA, with the dependent variable being subject status (music education majors as compared to non music education majors), yielded significant differences for involvement, affiliation, task orientation, 
order and organization, rule clarity, and teacher control. The third ANOVA tested for male or female significant differences in the area of teacher support. The fourth ANOVA tested for group influence and found significance for teacher support, task orientation, order and organization, rule clarity and innovation. Choral subjects had significantly higher responses for teacher support, rule clarity, and innovation. Instrumental subjects had higher mean scores for task orientation and order and organization. Females had higher mean scores for support and affiliation while males scored higher on the competition scale.

Bergee (1992) created a scale to assess music student teacher effectiveness in rehearsal. A total of 615 secondary school music teachers, university music education professors, university music teachers, and graduate music education students received copies of the criteria with the accompanying Likert-type scales. From this pool of 615 music teachers, 251 respondents returned the forms $(41 \%)$. Because a sample size of more than 250 yields reasonably stable correlation matrices, no further mailings were necessary.

Prior research regarding music teaching effectiveness employed scale construction strategies utilizing factor analysis methodology. These studies provided the theoretical framework for the research. The intent of the study was to develop a scale assessing rehearsals performed by music student teachers in a secondary school setting. The three areas of research advanced by the study were to: (a) develop evaluation measures that illuminate various aspects of the student teacher's rehearsal effectiveness; (b) delineate elements germane to proficient rehearsal techniques; and (c) ascertain interjudge reliability and the criterion-related validity of the proposed scale resulting 
from the study. To verify reliability for the criteria-based items from the evaluation instrument (developed from the study as compared to the generic student teacher evaluation form), the author compared final ratings from a panel of expert adjudicators with the final student teacher evaluations.

Previous scale factors obtained from the Music Educators National Conference (a professional music association), several music education textbooks, extant research on the topic, and several experienced cooperating music teachers and evaluators of music student teachers provided the initial evaluation criteria. After eliminating repeated evaluation areas, 54 items of distinguishing traits regarding effective music student teachers rehearsal techniques surfaced. A panel of five experienced music educators offered no additional modifications to the established criteria. These criteria were randomly ordered and matched with a 5-point Likert-type scale: SA (strongly agree), A (agree), N (neutral), D (disagree), and SD (strongly disagree).

Bergee (1992) analyzed the data using squared multiple correlations to determine the factor subscales (dependent variables). A panel of five experienced music educators used the resulting scale, Student Teachers' Rehearsal Effectiveness Rating Scale (STRERS - the independent variables), to assess interjudge reliability. The thirty-item STRERS evaluation instrument rated eight student teachers on videotape. Conducting, the context-specific factor, correlated significantly with the other two areas, TeacherStudent Rapport and Instructional Skills. Using interjudge reliability, the author found that conducting technique $(r=.91)$ was higher than teacher-student rapport $(r=.86)$, and instructional skills $(r=.77)$. 
Bergee (1992) noted that college and university music education curriculums typically segregated conducting technique courses from instructional skills courses. Implications of the study suggested that since these areas were so obviously connected, their presentation should occur simultaneously in music education courses within the curriculum. Although the internal consistency for the subscale and the total scores were significant for the STRERS test $(r=.91)$, several factors may have contributed to levels of insignificance between STRERS and the generic evaluation form. The small sample of videotaped student teachers and the lack of content-specific items (conducting) on the generic evaluation form are two examples. Other areas included on the generic form may be difficult to assess accurately on a one-time observation such as "demonstrating positive interpersonal relationships with other educational staff" and "assumes responsibilities outside of the classroom related to the school". Further research suggests that studies should focus on different populations of music conductors such as choral conductors and instrumental conductors (band and orchestra).

Gumm (1993) studied secondary choral teacher perceptions of their individual teaching style regarding consistency and effectiveness. Teaching style, defined as consistent patterns of teaching behaviors, guided the direction and purpose of the study. The four research objectives were to: (a) determine measurable dimensions of choral music teaching style, (b) identify the teaching style of groups of secondary choral music directors, (c) determine the validity of the dimensions and groups, and (d) develop a reliable and valid self-report instrument designed to assess teaching style. Dimensions of teaching style were defined as based on related forms of teaching behaviors. The author 
identified teaching styles as the result of compilations of groups of teachers sharing a common model of dimensions.

The researchers randomly selected samples from 2,000 subjects for the standardization and 700 for validation purposes. The samples were drawn from high schools across the nation, limited to choral directors to increase reliability with a return rate of $26.25 \%$. This did raise some doubt as to the representative population of clusters of teacher behaviors. Reliability was limited due to teachers that taught in more than one area such as band and orchestra; and elementary, middle school, and high school. The researchers employed teacher ratings, a process where teachers reported the rate with their utilized specific teaching behaviors.

The author developed 10 dimensions of choral music teaching style through common factor analysis of 134 teaching behaviors developed through the Music Teaching Styles Test. He validated eight of the ten dimensions through confirmatory factor analysis using split-half and Cronbach's alpha reliability to measure the sampling adequacy and labeled the dimensions: student independence, teacher authority, positive learning environment, aesthetic music performance, nonverbal motivation, time efficiency, group dynamics, and music concept learning. (The study did not report discreet data values.)

A $k$-means cluster analysis of choral directors teaching dimensions, used to detect non-overlapping groups, produced eleven choral teaching styles: student-centered comprehensive musicianship oriented, teacher-controlled comprehensive musicianship oriented, student/subject matter interaction oriented, task oriented, music performance oriented, cooperative learning oriented, concept presentation oriented, content oriented, 
low teacher involvement oriented, discovery oriented, and non-focused low-interaction oriented. To accomplish this, a mean profile generated from each cluster detected teaching styles common to each cluster. The author contends, however, that the primary purpose of the study was not conclusive. The author proposes that the development of a comprehensive model will take further study and comparison.

Brendell (1996) studied the relationship between rehearsal time and student attentiveness to the effective use of the beginning or warm-up phase of high school choral rehearsals. The author divided the warm-up segments into six areas: getting ready, physical warm-up, vocal warm-up, sight-reading, literature instruction, and other nonmusical activities unrelated to music making. Subjects were public high school choral conductors $(N=33)$ representing the entire population of public high school choral conductor members of the Florida Vocal Association from the northwest and north sections of central Florida. The observers recorded (audio only) each conductor during the first 30 minutes of rehearsal with an advanced choral ensemble. Observers recorded the number of seconds spent in each area/variable of concern.

Observer agreement computations considered the total number of agreements divided by the number of disagreements. Interobserver reliability ranged from .93 for offtask behaviors, .88 for activity coding, and .85 for timing of activities. The formula for observer agreement was determined by dividing the number of total number of agreements by agreements plus disagreements. Conductors averaged 14 minutes and 19 seconds of warm-up activities with a standard deviation of 517.44 seconds (more than 8.5 minutes). Compared against the total time spent in rehearsal, conductors spent the largest segment of time in sight-reading activities $(22.23 \%)$ followed by vocal warm-up $(9.63 \%)$, 
getting ready (6.75\%), physical warm-up (3.37\%), literature instruction (1.84\%), and other activities $(1.46 \%)$.

One-third of the conductors started the rehearsal precisely when the bell rang while others began several minutes into the allotted rehearsal time. More than one-half of the conductors began working on the literature segment of rehearsal during the first 15 minutes of class. Students were consistently more on-task during that required active participation rather than passive segments where they received information from the conductor. Off-task behavior reached the highest levels during getting ready portions of the rehearsal. Off-task behavior also reached higher levels during physical and vocal portions of warm-up segments. The lowest levels of off-task behavior occurred during sight-reading parts of the rehearsal.

Skadsem (1997) suggested that effective communication was one of the most important facets to consider when examining conductor effectiveness. The author reasoned that one of the goals of virtually all performing ensembles was performing at appropriate dynamic levels and compared verbal instruction with nonverbal or gestural instruction. The study included singers $(N=144)$ who sang along with a videotape recording while listening to a choir through a set of headphones. The singers were divided into three equal groups with varying degrees of musical experience: conductors $(n=48)$, college singers $(n=48)$, and high school singers $(n=48)$. Conductors, defined as having at least one year of conducting training, contrasted with the college singers and high school singers, who did not have any previous training in conducting.

The high school and college singers received training on the selection from their regular choral director while the conductors prepared the selection independently. The 
four variables affecting dynamic levels were (a) verbal instructions about the dynamic levels that the performer should use, (b) written instructions about the dynamic levels, (c) changes in physical conducting gestures, and (d) dynamic level changes in the choir (as heard over the headset). A panel of three judges used a Continuous Response Digital Interface (CRDI) to evaluate individual singers' responses to the four variables.

Researchers used a three-way ANOVA across the three groups. Results of the study demonstrated that verbal instructions from the conductor (independent variables) produced higher levels of singers (dependent variable) dynamic level response (alpha = $.05)$. Singers responded with greater dynamic level contrast after receiving verbal information from conductors regarding softer passages than louder sections. A post-hoc Tukey HSD multiple comparison test indicated that although all three groups reacted significantly to verbal instruction, the conductor group responded to a higher level (gestural soft $=46.06)$ related to conducting gestures than the college (gestural soft $=$ 29.06) or high school singers did (gestural soft $=34.44$ ). As the excerpts progressed, the author noted an increase in cye contact between the singer and the conductor. The author suggested that conductors should receive training to lead performers gradually away form markings in the music or verbal instructions and eventually rely more on conducting gestures as a more efficient method of communication.

Yarbrough and Madsen (1998) designed their study to detect the occurrence/nonoccurrence of effective teaching characteristics. These attributes were an amalgamation of effective teaching aspects collected from previous studies. The participants $(N=89)$ were music majors chosen from a large southern university. Groupings included graduate students $(n=47)$ or undergraduate students $(n=42)$, and 
choral $(n=26)$ or instrumental programs $(n=63)$. A trained choral faculty member led the choral ensemble comprised of freshmen and sophomore music majors and all levels of non-music majors. Videotapes of the rehearsals recorded the conductor during semester-ending concert preparations. Seven excerpts from throughout the semester covered two different musical selections. One selection was fast and lively and the other was slow and expressive. Participants examined the seven excerpts using a scale from 1 to 10 with " 1 " denoted as poor, low, slow, or dull depending on the evaluation variable, and "10" indicating superb, high, fast, or sparkling. Two independent experts also rated the results obtained by watching the videos.

Using an analysis of variance comparing the undergraduate and graduate groups yielded no significant differences between these two groups. Comparing excerpt ratings, there was a significant difference $(F(7,432)=16.96 ; p=.0001)$. Four sets of data emerged from the study including independent variables: (a) numerical ratings of the 10 teaching behavior; (b) observation information regarding physical movement, eye contact, etc.; (c) measurements of time spent in different rehearsal components; and the dependent variable (d) participant comments written on the evaluation form. Utilizing an analysis of variance, no significant differences between undergraduate and graduate music students or vocal and instrumental groups emerged.

Higher rated excerpts of student performance contained (a) more instances of eye contact, (b) more rehearsal pacing changes, (c) shorter segments of teacher and student activities, and (d) less off-task student behavior. A comparison $\underline{t}$-test determined that the slower tempo selection had a significantly higher mean rating $(M=89.14)$ than the fasterpaced selection $(M=69.79)$. A Spearman correlation coefficient determined high 
relationships between the evaluation areas and several correlations between ratings and the observation data including: (a) time use was highly related to musicianship, accuracy of presentation, performance quality, enthusiasm, intensity, and overall effectiveness; (b) musicianship was highly related to time use, accuracy of presentation, overall effectiveness; (c) accuracy of presentation was highly related to musicianship and overall effectiveness; (d) performance quality was highly related to time use, enthusiasm, intensity, personality, and overall effectiveness; (e) enthusiasm was highly related to time use, performance quality, intensity, pacing, personality, and overall effectiveness; (f) intensity was highly related to time use, performance quality, enthusiasm; pacing, personality, and overall effectiveness; (g) pacing was highly related to enthusiasm and intensity; and (h) personality was highly related to performance quality, enthusiasm, intensity, and overall effectiveness.

Overall effectiveness related highly to all categories except attentiveness and pacing. There were no positive, high and significant correlations between student attentiveness and any other category. Throughout the study, the highest rated rehearsal excerpts received positive comments regarding (a) student attentiveness, (b) enthusiasm, (c) pacing, and (d) general teaching effectiveness. The lower rated rehearsal excerpts contained negative comments regarding student attentiveness, pacing, and general teaching effectiveness.

Davis (1998) evaluated performance, observed time expenditures in rehearsal, and classified teaching behaviors during instructional methods. Researchers recorded eightythree rehearsals and four performances of two different high school choruses on videotape $(N=87)$. Both ensembles had received superior ratings at music festivals for 
periods of 14 to 17 years, demonstrating high levels of musical accomplishment. Independent variables included teacher academic and social instruction. Dependent variables related to student nonperformance response; rated performance response with and without verbal teacher facilitation; and teacher feedback. Researchers recorded variables using a Continuous Response Digital Interface (CRDI). Ratings were a 1 to 5 scale with 1 = superior, 5 = poor. Ratings were computed in percentages for comparison across variables. Results indicated a correspondence between the amount of improvement leading up to the final performance for both beginning and advanced choruses. The reliability for teacher instruction criteria was $r=.92, r=.98$ for student practice criteria, and $r=.67$ for teacher feedback criteria.

Although Davis (1998) warned that results might not be indicative to a general population due to the sample size, she found that teachers in the control group affected improvement at the same rate with both beginning and advanced ensembles. She also found that conductors employed more nonverbal communication and less verbal communication as their ensembles improved. Less instructional sequences were present as the ensembles improved and positive comments outnumbered negative comments generally throughout the process. The results of this study are consistent with findings of earlier research studies cited in the article. All ensembles needed more instructional assistance at the outset of learning each selection, but as the students became more familiar with the repertoire, they began to respond to nonverbal conducting techniques.

Rutgers (1998) determined rehearsal behaviors and evaluated performance achievement with respect to rehearsal preparation. Prior research grouped teaching behaviors (independent variable) into the following categories: (a) verbal instruction 
preceding student performance (questioning, lecturing, modeling, etc.); (b) verbal instruction during student performance (singing, teaching); (c) verbal feedback (positive and negative); and (d) nonverbal behavior (conducting gestures, facial expressions, etc.). Student behaviors (dependent variables) fell into three categories: (a) student performance; (b) student response; and (c) on or off-task behavior. Few of the prior studies related rehearsal attributes to effective performance qualities.

Having demonstrated musical excellence through the state festival system, two high school choral directors participated in the study. One director received superior ratings for 17 years while the other received superior ratings for 14 years. The researcher videotaped 83 rehearsals leading up to four culminating performances from four high school choral ensembles directed by the two participants. Each teacher conducted one beginning ensemble and one advanced ensemble. An experienced high school choir adjudicator used a CRDI dial to provide numerical ratings for criteria defined by the state choral festival guidelines and previous music rehearsal research. Scoring (dependent variable) fell into the following categories: (a) superior, 1.00 to 1.50 ; (b) excellent, 1.51 to $2.50 ;$ (c) good, 2.51 to 3.50 ; (d) fair, 3.51 to 4.50 ; and (e) poor, 4.51 to 5.00 . Performance rating means yielded results that demonstrated increases in performance ratings for both conductors at similar stages in beginning and advanced ensemble rehearsals. The profile for both conductors established that verbal instruction decreased as performance ratings increased. Both conductors exhibited increased nonverbal instruction (conducting) and less modeling or verbalizing as the ensemble ratings improved. (Absent proper training for administrators, recognizing this change of 
instruction over the course of time may indeed be a challenging aspect of music teacher evaluation.)

Similarly, fewer teaching sequences occurred as performance ratings improved and both conductors exhibited a high ratio of positive to negative instances of feedback. One difference between the conductors was the use of verbalization during rehearsals. One conductor used verbalization to assist students in learning the music while the other conductor used verbalization to invoke critical thinking of higher order musical concepts.

Yarbrough and Henley (1999) suggested as their premise that few studies included student achievement (or ratings) as the dependent variable in determining teacher effectiveness. Their study sought to examine effective choral techniques by determining whether shifting the focus from observing teachers to observing students had an effect on the assessment of choral rehearsal teaching.

Subjects $(N=175)$ were university music education majors from schools of music in four large state universities including graduate students $(n=57)$, undergraduate $(n=$ $119)$, vocal $(n=89)$, instrumental $(n=81)$, or both vocal and instrumental $(n=3)$, males $(n=64)$, and females $(n=111)$. Subjects were assigned randomly to one of two experimental groups: one group $(n=89)$ evaluated videotapes of segments of choral rehearsals where the camera focused on the conductor. The other group $(n=87)$ evaluated segments where the student performers were the focus of the camera. The videotapes of rehearsals included segments from across one full semester featuring a university choral conductor and a university choral ensemble preparing for a semester ending performance. Members of the ensemble were a combination of freshmen or sophomore music majors and non-music majors working on two contrasting selections. 
One camera focused solely on the conductor (the independent variable); the other rotated every 15 seconds from one group of students within the ensemble (the dependent variable) to another group.

The subjects analyzed the rehearsal effectiveness using the following categories: student off-task behavior; rehearsal time - teacher talk/students response; approval/disapproval ratio; nonverbal teacher behavior - body movement and expressive conducting; eye contact; facial expression; musical concepts taught; pacing characteristics - activity changes, teacher activities, and student activities; mean activity time; mean teacher time; mean student time; and length of excerpt. Students assigned numerical ratings on a scale of 1 (poor, low, slow, or dull depending on the evaluation characteristic) to 10 (superb, high, fast, or sparkling). Three separate ANOVAs were calculated for comparisons by gender, major (instrumental or vocal), and level (graduate or undergraduate). A subsequent ANOVA examined the characteristics of observation focus (conductor versus student).

Results of the study indicated higher ratings from the teacher focus observations $(M=6.79)$ than from the student focus group $(M=5.83)$. The highest rated excerpts (on a $0-100 \%$ scale) contained: (a) the lowest amounts of student off-task behavior $(6.53 \%)$, (b) a high ratio of approvals $(71 \%)$, (c) moderate eye contact $(27.30 \%)$, (d) many activity changes (27\%), (e) a high percentage of student response time $(66 \%)$, and (f) rapid pacing (14.49\%). A final ANOVA compared the ratings of the 10 areas by observation focus and resulted in higher ratings in all 10 areas for the conductor observation focus than for the student observation focus. 
Yarbrough and Henley (1999) suggested that there was often an apparent lack of communication between conductor and performer. They proposed that musical training should focus on this apparent deficiency. They also observed that although the three variables - student attentiveness, positive reinforcement, and pacing - were deemed the most important, music education training curriculums often neglect these areas in their instruction.

Stuart (1974) examined the degree that training using videotapes, slides, text materials, and class discussion regarding error detection assisted undergraduate music majors in identifying errors in string techniques. Errors of recognition included the following categories: position, rhythm, music interpretation, bowing, and intonation. Subjects chosen were juniors and seniors with at least one completed course in conducting before their student teaching experience $(N=28)$. The treatment group used 20-25 minutes of each 50-minute class in error detection training with the control group spending the entire time conducting the string orchestra. Pretests and posttests for both groups measured the students' ability to recognize the targeted errors. Both tests included an analysis of a string score, multiple-choice questions about bowing tcchniques, and an analysis of a videotaped session with a string quartet.

Researchers used pretest (covariate) and posttest scores (dependent variable) in an analysis of covariance (ANCOVA). Results from the ANCOVA indicated a significant difference between the two groups (Group 1: $M=44.91$, Group 2: $M=28.67$ ) on the pretest. Additional $t$-tests demonstrated that the error detection training group (experimental) did achieve significantly higher scores that the control group. An interrater reliability test achieved by using a post hoc procedure (Pearson Product- 
Moment Correlation) indicated a correlation of .70 between the two raters, significant at the .05 level. A $\underline{t}$-test to judge statistical differences in conducting skills between the two groups found no significant differences.

In summary, throughout the choral and string ensemble research examined, several common themes of conductor evaluation emerged. Relating to education or preparation: conductor behavior; conductor experience with musical error detection; teaching style characteristics; rehearsal structure design; rehearsal pacing techniques; student involvement in the learning process; use of audio visual aids in teaching; and classroom control and discipline. Physical movement played a significant role in conducting technique; as did basic communication skills from the podium; conducting gestures and eye contact, student responses to non-verbal techniques, and student achievement as related to conductor skills.

\section{Applied Music Research}

Because conductors often provide individual instruction to students in their ensembles, it is important to consider teaching skills related to applied instruction. Applied instruction is defined as a one-on-one learning session that provides individual attention to technical skills and musical considerations. This setting allows the conductor to solve individual musical issues outside of rehearsal time, thus eliminating long periods of time spent with only one member of the ensemble while the other members sit and wait.

Duke and Prickett (1987) studied the observations of non-music education majors $(N=143)$ enrolled in a music course regarding one-on-one private lessons using an 
ANOVA study design. The goal of the study was whether observers could actually witness the teaching processes occurring in a one-on-one lesson or if they were affected by the vantage point of their observation. Participants observed one of three 11 minute videotaped observations of a violin lesson. The versions of the lesson included threc different viewpoints: (a) teacher only, (b) student only, or (c) both student and teacher. Previous research findings indicated that the personal goals and experiences of the observer may affect how and what they notice during observations. Some observers may notice instances of positive or negative feedback more readily while others may focus on delivery and mastery of material. The lesson included an 11-year-old female student and a 30-year-old female teacher.

The lesson topics included intonation and bowing. The recordings utilized techniques regarding observation intervals and elements germane to applied instruction borrowed from previous research. The camera direction of the video included segments of student performance, teacher performance, student and teacher performance, and recorded teacher and student verbalization. Participants viewed only one of the three videotaped versions: the student and the teacher $(n=30)$, only the teacher $(n=54)$, or only the student $(n=59)$. In addition to using an evaluation form developed by Madsen and Madsen (1983), participants recorded the number of teacher approvals and disapprovals given during the lesson.

The form included the following points of evaluation: lesson organization, clarity of teacher's presentation, quality of teacher's musicianship, teacher creativity, teacher's attitude toward student, reinforcement effectiveness, quality of instruction, student 
participation, student's general attitude, and overall effectiveness of lesson. The form also provided two lines for recording the number of approvals and disapprovals.

Using an ANOVA study design that found no significant differences $(p<.05)$ surfaced during a preliminary analysis, a stepwise discriminant analysis compared the participant responses from the 10-point scale across the three different viewpoints. The teacher-focused viewpoint yielded a significantly lower mean score $(M=7.63(1.67))$ that the teacher-student viewpoint $(M=8.19(1.78))$. In the same way, student attitudes were lower in the student-focused observations $(M=7.59(1.73))$ than in the teacher-student viewpoints $(M=7.85(1.52))$. Interpretation of the data suggests that the vantage point of the observer influenced components of perceived teacher effectiveness and student interactions.

Duke and Prickett (1987) noted that the viewpoint caused a greater number of recorded instances of disapproval from the teacher when the viewpoint focused on the teacher as compared to the student or teacher-student vantage point, although the actual number did not vary across viewpoints. This finding is consistent with previous research by Duke (1983).

Schmidt (1992) studied the reliability of ratings given by untrained observers in an applied music instruction setting using an Abeles's validation study. Three perspectives framed the study: (a) test-retest reliability; (b) interrater reliability across the teacher sample; and (c) the interrater reliability of the samples of evaluators in applied music instruction. The researchers used the Applied Teaching Rating Scale (ATRS) featuring 36 five-point Likert-type scales. 
The data collection process, divided into three phases, first examined music instructors $(N=39)$ performing a videotaped 40-minute applied lesson. The study examined the interrater reliability for samples of three different raters who each evaluated the applied music lessons. Each of the instructors had three or more years of teaching at the university level in keyboard, strings, vocal performance, or winds. Three independent music educators viewed 25-minute segments from the lessons. Each evaluator used the Likert-type scale to assess the teacher's verbal behaviors. The reliability of the evaluator's ratings was tested using Cronbach's alpha procedure.

In the second phase, the retest reliability of the ratings given by untrained observers was the focus. Forty undergraduate and graduate students heard the identical 25-minute excerpt on two separate occasions. Spearman Rank Order Correlations tested the stability of the two sets of ratings for each of the 36 evaluation items. The third and final phase tested the interrater reliability for evaluators who heard the same lesson.

The interjudge reliability of the individual lessons by the 39 teachers displayed a wide range across the 36 items. The range was .00 to .81 with a medium of .57 . The highest ratings were for teacher rapport $(\alpha=.94)$, with clarity of musical explanation, and the use of praise and criticism also scoring high. The lowest coefficient rating recorded $(\alpha$ $=.00)$ was for the perception of teacher feedback as control. Other low interjudge reliability occurred for teacher's tendency to be repetitive $(\alpha=.33)$, suitability of music section rated to student ability $(\alpha=.35)$, the teacher's perception of student ability $(\alpha=$ .39), knowledge of vocal or instrumental technique $(\alpha=.40)$, and speaking ability $(\alpha=$ .40 ). 
The test-retest reliability of untrained observer's evaluations of an applied music lesson yielded two sets of ratings, one week apart, using the Spearman Rank Order correlation coefficients. Even though the correlation of the majority of the items ( 29 of 36) was statistically significant at the .05 level, each evaluation item varied regarding stability. High coefficients were obtained for (a) teacher shows a genuine interest in the student as a person, (b) demonstrates patience and understanding, (c) level of music seems appropriate to the student's ability level, (d) verbal explanations are clear and concise, (e) demonstrates the ability to break down a task or concept into its component parts, and (f) teacher seems to have an accurate perception of the student's ability. Low coefficients were obtained for (a) teacher's absent-mindedness, (b) teacher's analytical skills, (c) difficulty in communication, and (d) hesitant speaking style.

The third research question focusing on interrater reliability coefficients ranged from .36 to .83 for the 50 evaluators of one of the two teachers. High interrater reliability was found for (a) analytical approach to teaching, (b) teacher brings out the best in the student, (c) teacher is too overbearing, (d) genuine interest in the student, (e) demonstrates patience and understanding, (f) gives explicit directions, $(\mathrm{g}$ ) suitability of music to student's ability level, (h) clarity of verbal instruction, (i) ability to diagnose technical problems, (j) provision of specific technical information, $(\mathrm{k})$ knowledge of repertoire, (l) use of praise and criticism, (m) instills a sense of responsibility, (n) repetitive speaking style, (o) accurate perception of student ability, and (p) emphasis of feedback on specific information.

Low interrater reliability was found for two items: extent to which the teacher dealt with important musical problems, and whether the teacher used an appropriate 
balance of praise and criticism. Schmidt (1992) concluded that untrained observers could evaluate some applied teaching behaviors while other behaviors needed additional study.

McPherson (1994) studied factors and abilities that influence sight-reading skills in musicians. The study posed four research questions: (a) determining abilities between sight-reading and performing music repertoire, (b) locating the most common types of mistakes during sight-reading, (c) ascertaining whether musicians of different levels of ability make different types of mistakes during sight-reading, and (d) finding strategies that distinguish students with differing ability to sight-read.

Researchers used the Watkins-Farnum Performance Scale (WFPS) with randomly sampled high school clarinet and trumpet students $(N=101)$ out of a pool of 689 taking the Australian Music Examinations Board (AMEB) performance tests. (Over 100,000 Australian students take the AMEB each year in order to move from grades $1-4$ to grades 5-8.) The sample included girls $(n=52)$, boys $(n=49)$, clarinetists $(n=54)$, and trumpeters $(n=47)$. The WFPS examination includes the following evaluation factors: pitch, rhythm, slurring/articulation, tempo, expression, pause/fermata, and repeats.

A pilot study using 25 students tested for interjudge reliability yielded a score of .99 for the researcher and .98 for the two independent judges. The highest percentage of errors across all grade levels was rhythm error, $59 \%$ to $64 \%$, compared to the next highest category, pitch, at $14 \%$ to $18 \%$ of the total errors. Researchers noted that results from the study indicated a low level of significance for sight-reading skills as related to ability to perform music repertoire in early stages of musical development (grades 7-9).

Older students (grades 10-12) did show a dramatically stronger significance for sight-reading skills. Younger students who scored higher on sight-reading tests were not 
necessarily the best performers. Older students who excelled at sight-reading, however, were typically the better performers. During interviews of students, the researchers noted that the poorer sight-readers often did not note the key signature or meter before beginning, while their older counterparts spent part of their pretest time looking at the key signature and identifying any difficult rhythms or note passages.

Davidson, Moore, Sloboda, and Howe (1998) examined characteristics of teachers in the development of music ability in students as compared to their level of achievement. The authors cited several factors that affected studies of this nature including: age of the students (and how they felt about their teacher), positive or negative relationships at home with their parents, gender of the student, and the change in teachers as the young musician progresses. The study addressed those students who have achieved high levels of musical performance skills and comparing them to children who stopped taking music lessons. The study divided into four areas of concern: (a) how children assess individual personal and professional traits of teachers, (b) the effect of the learner's gender on their perception of the teacher's characteristics, (c) the frequency and subsequent reason for changing teachers, and (d) the proportion of lessons taught in a group setting versus a one-on-one setting.

The subjects were young students from England $(N=257)$ between 8 and 18 years old who had previously received training on a musical instrument. The researchers divided the population into five groupings representing a diverse population of students cvenly divided between male and female students. Group 1 consisted of highly successful and serious musicians $(n=119)$ enrolled in a highly competitive music school. Group 2 was a group of students $(n=30)$ who were talented musically but had not received 
admittance into one of the competitive music schools. The third group of young musicians ( $n=23$ ) was musically talented but their parents had not followed up admission procedures to one of the competitive music schools. Group four $(n=27)$ included students who learned instruments at a noncompetitive school and did not consider music as a potential career. The fifth group $(n=58)$ consisted of students who had begun learning an instrument at the same school as students from group four but had stopped taking music classes at least one year prior to the study.

Each child and one of his or her parents were interviewed by the researchers and asked to rate the characteristics of the child's first and last music teachers using scales degrees, to give the dates when they changed teachers, to give reasons why they changed teachers, and to denote whether the lessons were on an individual or group basis. The researchers had a $95 \%$ interrater agreement obtained in the study. There was no difference in gender effects in the first group teachers as compared to the last or fifth group of teachers, seen as being generally more "pushy" by the boys in the study. Results from groups one through four indicated that students viewed their teachers positively regarding friendliness of teachers, how relaxed they were, how chatty they were in lessons, and how encouraging they were. Group 5 gave the least positive scores in all areas.

Findings indicated that successful young musicians generally regarded their teachers as being friendly, relaxed, chatty, and providing encouragement for their careers. The only significant difference between boys and girls was that boys found their last teachers to be "pushicr" than did the girls. Successful music students changed teachers 
more often and had a mixture of individual and group lessons as compared to students who did not fare as well.

In summary of applied music research, although many of the rehearsal aspects studied in the concert band, choral, and string article reviews are present in this section, several distinctions occur. Physical gestures, eye contact, proximity to the students, and other conducting techniques were not present in these studies when evaluating teaching effectiveness. Pedagogical aspects of applied teaching, however, were studied including assessment of student performance; recognition and correction of musical errors; motivational skills; ability to teach sight-reading skills to students; knowledge of subject matter and relationships to study materials; and the effects of positive and negative feedback. Although some of these criteria are present in a broader sense in some assessment instruments, attributes and criteria specifically related to music instruction are decidedly absent.

\section{Elementary Music Instruction Research}

Elementary music instruction provides another challenge in determining assessment instruments for conductors, considering that the level of musicianship of elementary students is in the early stages of development. The corresponding type of instruction must generally be basic in nature and therefore is more easily identifiable. Elementary rehearsals have more pauses for verbal instruction and students focus on basic music abilities rather than the bigger musical picture.

Froehlich (1977) investigated the result of observational variables that contribute to effective teaching of singing in an elementary general music class using an ANOVA 
design. The author developed an instrument designed to illustrate activities and patterns related to teaching singing and their relationship to selected measurement variables. A class of 14 students served as the basis for the study. Four variables framed the observations: (a) area of instruction, (b) teacher activity, (c) student activity, and (d) materials or media.

Time-coded observations indicated whether variables were carried out by (a) an individual student, (b) part of the group of students, or (c) the entire group. Variables related to the teacher's teaching and musical background included number of years taught, principal instrument or voice, external musical activity participation, most difficult problems while teaching singing, and size of the group. Eight different lessons, taught by eight different teachers and observed by two evaluators, framed the study. Variables with correlation coefficients below $r=.50$ were eliminated, leaving 19 variables included in the results.

Diction, phrasing, pitch, blending, and overall musicality framed the intercorrelation matrix of criterion data for each class. Relationships between the criterion and observational variables yielded the following significant common variances: (a) special work on phrasing accounted moderately for phrasing (37\%) and voice blending (21\%); (b) instrumental accompaniment accounted at a high level for all of the criterion variables; (c) conducting by use of hand signals/beat indication accounted for the highest percentage of common variance with the variable quality of diction; and (d) student performance accounted for $45 \%$ of the variable quality of diction, phrasing $(67 \%)$, pitch accuracy $(34 \%)$, blending of voices $(46 \%)$, and musicality of performance $(48 \%)$. 
The author found high common variances between criterion variables and the teaching background variables: number of years teacher taught the group, number of students receiving private instruction, and teacher's participation in external musical activities such as workshops, clinics, and other forms of musical growth and development. The author found the highest amount of common variance between the number of years teaching and the number of students taking private lessons. The higher performance quality indicators included special phrasing work, teacher conducting and not playing the piano, and having students play instruments during performance.

Wagner and Strul (1979) compared the amount of time spent on various music classroom activities, the number and type of reinforcements, and the students' attitude about participation in music class. The researchers conducted two observations of teachers with varying amounts of experience $(N=27)$ using a one-way analysis of variance. The teachers were divided into the following experimental groups: experienced teachers $(n=9)$, student teachers $(n=9)$, and undergraduate music students $(n=9)$. They observed the subjects teaching two different elementary music classes and recorded the number and type of reinforcements, kinds and amounts of different activities, duration of each activity, and information concerning class size and grade level. Nine different schools were included in the study with fifteen-minute teaching segments for each session. An interobserver rating of .91 indicated a high level of agreement between the two observers.

Observations divided the categories for assessment into three areas: teaching activities, music activities, and nonteaching activities. Teacher activities included instruction, discussion, written assignments, and directions; music activities included 
singing, playing instruments, rhythm activities, and movement activities; and nonteaching activities consisting of preparation activities, teacher talk, interruption, and instances of lost control of the class. Approvals and disapprovals included areas associated with academic behavior, social behavior, academic mistakes, and social mistakes.

Results of the study indicated that experienced teachers spent significantly less time giving directions than student teachers or undergraduate music majors (NeumanKeuls multiple comparison rating of $7.5 \%$ ). Positive reinforcements averaged $50 \%$ across all three groups. No other significant differences among variables surfaced among the three groups. The authors noted that generally, students were happy to attend music class and to spend time outside of school in music related activities.

Taebel and Coker (1980) studied selected competency measures, measures of student achievement, and attribute variables of effective teaching using multiple regression analysis. They determined: (a) which teaching competencies corresponded with pupil achievement; (b) whether classroom observation was measurable; (c) if effective teachers could be differentiated from less effective teachers based on their teaching competencies; and (d) if any relationships existed between student achievement and attitude with socio-economic status, grade level, class time, and external music lessons. Elementary music teachers $(N=29)$ from the Atlanta area with 1 to 15 years of teaching experience served as the sample with students from grades 3 to $7(n=735)$. Three observers made 174 class visits and recorded 696 observation records.

The study of the 26 teaching competencies demonstrated the coefficients for reliability: (a) teacher discussion and response to students (.60), (b) time on task (.57), (c) use of student ideas in teaching (.52), and (d) students initiating verbal exchange (.51) 
had the highest reliability scores. Teacher evaluating individual differences, giving clear directions, use of variety of activities, use of low-level cognitive questions, and teachers working with large groups were determined to be unreliable.

Multiple regression analysis indicated that four competencies which related most significantly with student achievement gains were: (a) teacher relates objectives to student interests and needs (.32), (b) students initiate verbal exchange (.29), (c) teacher uses student ideas in instruction (.26), and (d) students give correct answers to teacher questions (.26). Effective teachers exhibited the ability to check for cognitive status, allowing students to suggest ideas for class, and motivating students to be responsive and enthusiastic. Finally, outside music lessons and class time amounts showed almost no correlation with student achievement.

Sang (1985) focused on the teacher-student interaction in the classroom and sought support for a theoretical model for instructional effectiveness evaluating beginning music teachers. Seven subjects participated in a series of seven tests to measure modeling, discrimination, and diagnostic/prescriptive skill ability levels. Two secondary purposes of the study included: (a) determining which skill, by itself or in combination with others, causes the greatest amount of variance in music teacher's instructional effectiveness; and (b) determining the statistical applicability of path analysis regarding research on music teacher rehearsal effectiveness.

He proposed an Interactive Instructional Effectiveness Cycle utilizing three categories of music teaching skills: (a) the teacher demonstrates essential music performance elements; (b) the teacher identifies student performance problems; and (c) the teacher assesses and corrects student musical problems. These three categories 
comprised the independent variables in the study with the degree of effectiveness in each area serving as the dependent variable.

A panel of three evaluators evaluated each of the seven subjects teaching a fourthgrade recorder class. The three evaluators received training before viewing the videotape of the lesson to increase the reliability of the observation procedure. Each evaluation produced a single effectiveness rating for the respective participant. Before completing the path analyses, the author employed a regression on all pairs of variables. The resultant coefficients did not match the slope of the scatter diagrams due to the small sample sizes. It became necessary to change the raw scores into ranks to determine a Spearman RankOrder Correlation Coefficient. The resulting coefficient $(\alpha=.01)$ suggested that there was not a significant difference among group means regarding the independent variables.

Modeling and discrimination skills rated higher with respect to instructional effectiveness, while instructional effectiveness rating for diagnostic/prescriptive skills rating much lower. A direct path from discrimination skills to effectiveness yielded a negative coefficient. A replication study confirmed these same results.

Sang (1985) concluded that musical modeling needed to become an integral part of music teacher training. Although not at the expense of diagnostic/prescriptive training, modeling and discrimination skills need to be present earlier in the music education curriculum. (This also needs to be a part of the evaluation process training for administrators so they can fully appreciate the significance of this type of musical instruction.)

Hendel (1995) studied three questions: (a) examine aspects of effective elementary music teaching; (b) using qualitative study methods, compare teacher-defined 
teaching values with characteristics of good teaching defined through quantitative methods; and (c) investigate whether qualitative and quantitative methods of study might complement each other. Nine experienced specialists from three different regions of the country were observed, videotaped, and interviewed using qualitative and quantitative methods for analysis.

All nine teachers had a minimum of five years teaching experience and received an excellent teacher status from local music supervisors and music education faculty members. Each teacher identified specific students $(n=8)$ from fourth grade classes, equally divided between boys and girls, to create the overall sample $(N=72)$.

Researchers transcribed, coded, and analyzed qualitative data collected from audiotapes, videotapes, and field notes.

Researchers counted and timed nonverbal behaviors including: (a) conditions of magnitude, (b) rate and distribution of instruction time, (c) sequential patterns of instruction, (d) teaching methods, and (e) equipment and materials. To ensure credibility and consistency, researchers made sure of specific lesson plan implementation, collected a broad range of data, provided a series of cross references of data sources before entering data, and entered precise accounts of transcripts. To verify the data further, researchers compared qualitative data to quantitative data.

Qualitative results indicated that all nine teachers possessed similar teaching characteristics with little variation across geographic regions. Researchers also concluded that students recognized positive behaviors and teachers conveyed similar personal values. Students referred to "fun" as the primary descriptor of their teachers and recognized their teaching skills. Four additional characteristics which surfaced: were 
incorporating personal values, demonstrating a love for music, endeavoring to teach the whole child, and having high expectations for both the students and themselves.

Quantitative results indicated: (a) used a high amount of eye contact (91\%), (b) spoke at normal volume (89\%), (c) varied levels of pitch when speaking (86\%), and (d) used instructional gestures $(77 \%)$ and expressive conducting gestures $(23 \%)$. Their approving facial expressions (55\%) outweighed their disapproving facial expression (4\%). From 21 identified categories of teaching methods, the teachers averaged 8.6 methods per class. The top rated methods were: (a) identifying musical elements (96\%), (b) musical drill (94\%), (c) ear training (80\%, (d) sight-reading (65, (e) echo clapping or body percussion $(50 \%)$, (f) vocal modeling (48\%), (g) discussion (48\%), (h) accompanying (46\%), (i) discovery or experimentation, and (j) cross-curriculum integration $(46 \%)$.

Byo (1999) assessed teacher opinions regarding successful teaching of the National Standards of Music Education. These standards, established in 1994 as part of the guiding principles of the National Standards for Arts Education, established guidelines for music educators. These standards were a direct outcome of the Congressional Goals 2000: Educate America Act. The national standards include: singing, playing instruments, improvising, composing, reading/notating, listening/analyzing, evaluating, understanding relationships between music and other disciplines, and understanding music in relation to history and culture. The author noted that these standards provided a daunting challenge for public school programs without the requisite resources to accomplish these initiatives. 
(Prior research indicated that the amount of music teacher aptitude is the prime ingredient for increased student learning thus increasing the need for trained music educators rather than generalists. This is especially true when considering the lack of regular class time devoted to music classes within an elementary school curriculum as compared to junior high.)

The purpose of the study was to test three null hypotheses within the realm of elementary school music classes among an equally divided study group of elementary music teachers and fourth-grade generalists $(N=244)$. A random sample included equal populations of elementary music teachers $(n=122)$ and fourth-grade generalists $(n=$ 122) from schools offering fourth-grade music instruction on a regular basis. No magnet or private schools were part of the study. Participants completed a survey containing seven questions about each of the nine national standards (63 total questions). The first null hypothesis tested was that there was no difference between music teacher and fourthgrade generalist responses.

The second null hypothesis ascertained that there was no difference between responses for the seven questions across the nine content standards. The final null hypothesis tested that there were no interactions between music teachers' and generalists' answers to the seven questions for each of the nine standards. The seven professional and resource areas applied to all nine standards were: teacher's training, interest, ability, sense of responsibility, resources, assistance, and perception of available time. A Likerttype scale anchored by 1 (strongly agree) and 5 (strongly disagree) provided the response choices for the questions. The survey returns reached a response rate of over $70 \%$. 
Data analysis included two-way analysis of variance between variable of the teacher role and the variable relating to the content standard. Results of the study demonstrated that music teacher answers were significantly more positive $(M=13.282)$ toward all of the standards than their generalist counterparts $(M=27.009)$. The author noted that this was not surprising, given the obvious differences in training and experience for music teachers.

Both music teachers and generalists agreed that there was not enough time in the present class structure to implement all of the music standards. Music teachers indicated that they were: (a) prepared to teach singing, reading/notating, and evaluating standards; (b) had reservations about playing instruments and improvising; and (c) experienced difficulty finding the resources for teaching improvising and understanding music in relation to other subjects. Generalists felt that they did not have the proper resources to teach any of the standards and felt somewhat comfortable teaching music in relation to other subjects and understanding music in relation to culture.

Finally, both music teachers and generalists agreed that their lack of time, equipment, and materials signified a need for administrators to re-examine school curriculums, class schedules, and music education programs in order to meet the demands of the national standards movement.

In summarizing the elementary music instruction research, many of the same attributes present in the elementary music research section also appear in the ensemble and applied music sections. Physical movement attributes, motivational tools, pedagogical skills, and musical training all play important roles in the effectiveness of an elementary music teacher. A difference that is noticeable in this section is the need for the 
elementary teacher to have a firm grasp regarding the performance issues related to performance skills on wind, percussion, and string instruments and the need for vocal teaching techniques for young voices. This section illuminates the need for evaluative tools related to the different levels and types of musical instruction.

\section{Conducting Gesture Research}

Perhaps the most confusing skill that administrators should regularly evaluate pertains to conducting gesture and physical movement. Unless administrators have training in identifying effective physical movement communication, clear conducting patterns, conducting gestures that convey musical information, and the use of eye contact, their evaluation will be lacking useful information. Without proper training, there may not be an awareness of the conversation that is occurring between the conductor and the members of the ensemble.

Yarbrough, Wapnick, and Keely (1979) compared two videotape techniques that provided feedback to young conductors. The purpose of the study was to compare effects of the instructor feedback group with a self-observation group. The authors found no research comparing feedback from traditional real time observation techniques with videotaped techniques. Traditional areas of observation studied in textbooks include areas such as appropriate beat patterns, proper stylistic and dynamic communication through physical gestures, eye contact, and the accuracy and appropriateness of cueing gestures. The advent of videotaped feedback provided students and instructors repeated opportunities to review different areas of conducting technique. The three measures employed were: (a) judge's rating of the students' conducting performance, (b) an 
analysis of the students' written self-critiques, and (c) an instructor rating survey designed to measure warmth, academic/intellectual content, and student work/input.

The participants in the study were junior and senior music education majors $(N=$ 47). Senior participants, enrolled in a basic conducting course, were randomly placed in one of two feedback control groups. The first group $(n=14)$ viewed their videotapes with an experienced conducting teacher. The second senior group $(n=14)$ viewed their videotapes individually and detailed comments from their conducting round on an observation form. The juniors, randomly assigned to one of two groups, had no contact with the conducting teacher. The first group of juniors took both the pretest and posttest while the second group only took the posttest to control for previous learning that they may have acquired through rehearsals or observation. The feedback group worked with an instructor who identified conducting problems, modeled a correct manner of conducting, offered suggestions for improvement, and discussed musical implications.

At the end of the course, both groups rated the course effectiveness using an established course rating survey. A panel of three experienced judges rated the ensuing posttests $(n=336)$. A one-way analysis of variance yielded significant differences between the groups. Multiple comparison techniques provided a significant difference between treatment and control groups. Regarding the frequency of statements by the instructor, a Mann Whitney $U$ analysis compared the independent variables and demonstrated a higher number of statements in the feedback group (999) than the observation form group (443). The feedback group and the observation group were not significantly different from each other on any of the variables (instructor warmth, academic/intellectual content, and student work/input). The authors concluded that self- 
observation, (found to be a viable method of learning conducting), would be more effective when used in tandem with videotaped instructor feedback formats.

Yarbrough and Price (1981) examined a teaching/learning model as it related to dependent variables such as performance, attentiveness, and attitude. Previous studies concentrating on teacher/conductor behavior and student/performer response defined teaching characteristics and teaching activities that affected student attentiveness. Teacher reinforcement, positive teacher feedback, consistency in classroom rules, and positive attitudes all had a direct connection to student attentiveness. These studies demonstrated that students were more attentive in music participation classes (ensembles) that in regular academic classrooms.

Yarbrough and Price (1981) sought to establish a strong relationship between offtask behavior caused by the following independent variables: performance time, nonperformance time, frequency of social and academic approval and disapproval indications from the teacher, stops in the rehearsal, complete versus incomplete teaching segments, errors (reinforcement and sequential teaching mistakes), and conductor eye contact. The participants were high school ensemble directors $(N=6)$ and randomly selected students from two choruses (boys and girls combined), three bands, and one orchestra. Videotapes of rehearsals occurred during normal rehearsal times, two weeks before the performance by each ensemble. One camera focused on the conductor and the other observed six students at a time rotating throughout the entire ensemble. Following each videotaped rehearsal, two observers, trained to evaluate the rehearsals, examined the tapes and recorded students displaying off-task behavior and conductor eye contact. 
Yarbrough and Price (1981) used observation procedures based on previous research techniques to operationalize the independent variables. Student behavior variables were (a) on-task active - when students are performing, they must be looking at their music or at the conductor; (b) on-task passive - when not performing students must be quiet and attentive to their music, the conductor, or other performers; (c) on-task other - students must follow the rehearsal directions given by the conductor; and (d) off-task students are not paying attention and are not on-task.

Teacher eye contact was recorded into the four following categories: (a) conducting looking at the group or sections within the group for three or more seconds; (b) looking at an individual for three or more seconds; (c) looking at the their own music (score) for three or more seconds; and (d) the conductor looking at something other than their music, an individual, part of the ensemble, or the entire ensemble. The dependent variables were the student off-task behavior percentages and the sum of the teacher eye contact occurrences directed toward the group or individuals. The researchers recorded the amount of time (in seconds) considering performance and non-performance and the number of times the conductor stopped the rehearsal. Performance, characterized as performing on an instrument or singing, and also characterized as non-performance activities such as teacher instruction, reinforcement, or anything not related to student performance.

A multiple regression analysis determined the off-task predictability related to the independent variables. Information from previous studies guided the independent variables' order of importance. Study results indicated significance between off-task behavior and individual conductors such as: non-performance activity $(p<.05)$, and 
teacher eye contact $(p<.07))$. There were negligible relationships between off-task behaviors and disapprovals, errors, stops, and complete teaching units. Students were consistently more on-task for conductors who employed greater degrees of eye contact in rehearsal and during performance times as compared to non-performance times.

Madsen, Standley, and Cassidy (1989) studied teacher intensity and whether high and low examples of intensity were suitable for instruction for music education majors, using a one-way analysis of variance study design. Prior research identified enthusiasm, magnitude, and affect as three examples of teacher behaviors that fall under the definition of intensity. Levels of intensity for music teachers from previous research divided into several independent variables including eye contact, proximity to students, volume and modulation of the voice, conducting gestures, facial expressions, and rehearsal pacing. Students from these studies responded to and preferred higher levels of intensity.

Three experiments preceded the study. The first experiment contrasted freshmen $(N=42)$ that first conveyed their personal musical ambitions. Then they taught a song to a group of four and five year old preschoolers. The correlation analysis verified that speaking intensity about oneself was not correlated highly to intensity when teaching a music lesson. The second experiment compared the intensity levels of 15 freshmen music education majors, 15 senior music education majors, and 15 senior music therapy majors while teaching a music lesson. The evaluation used a 10-point Likert-type scale to assess levels of intensity.

Mean scores from a one-way analysis of variance revealed significantly different ratings. Following a multiple comparison procedure, freshmen students had significantly 
lower levels of intensity $(M=63.04)$ than their senior music education or music therapy counterparts $(M=66.27)$.

Results of the first two experiments indicated that intensity was a teaching skill that is measurable. The third experiment employed senior music education students $(n=$ 22) in a videotaped rehearsal example of their best teaching. A panel of four music education experts evaluated their performance regarding teaching effectiveness and returned a high level of reliability $r=.86$. Two additional experts evaluated their videotapes for high or low levels of intensity. A Spearman Rank Correlation Coefficient of $r s=.92$ suggested that intensity and teaching effectiveness indeed may be highly related.

The formal study utilized music education majors $(N=94)$ divided into three control groups and one experimental group. The experimental group contained 20 music education majors just about to begin their student teaching assignment. The three control groups, divided into freshmen $(n=23)$, seniors $(n=22)$, and graduate students $(n=29)$, provided data for the study. The experimental group received a 1.5 hour lesson on intensity training and then attempted to imitate these behaviors in a short teaching session. In the subsequent days, student teachers taught increasingly longer segments and altered periods of high to low intensity through similar points in the instruction cycle. A Likert-type scale of 1 to $10(1=$ low intensity and $10=$ high intensity $)$ self-ratings of high intensity ability across the different length teaching segments yielded high levels of accuracy as computed using a Kendall Coefficient of Concordance test.

Comparing scores from the experimental group with the three control groups, again using the Kendall Coefficient of Concordance test, demonstrated a high level of 
significance after comparing the experimental group with the senior and graduate music education students. The freshmen control had significantly lower levels of agreement with the student teacher group (experimental). Analysis of high versus low intensity errors indicated that it was more difficult to assess high intensity when immediately compared to lower levels. The researchers asked students from all four groups to define intensity. The student teacher group had the fewest but most concise number of ideas while the freshmen, seniors, and then graduate students increasingly used more ideas as part of their definition. Tabulations of the items used in the definitions generated a ranked list of intensity variables. The experiments in the study point out that intensity is a valuable teaching tool that is teachable and is easily recognizable by trained and untrained viewers.

Byo (1990) investigated whether undergraduate (novice) conductors could exhibit high and low contrasts of intensity through physical gestures, and whether independent observers could recognize these differences. Nonverbal skills, considered an important element in the art of conducting, served as the basis for the study. The study moved through five phases of development: (a) preparing the students to demonstrate gestures of high and low intensity, (b) developing a pilot tape of students attempting to demonstrate these differences in intensity, (c) the development of a final version of students exhibiting these types of gestures, and (d) independent observations of the videotape by selected subjects. The third phase served as the pilot study, with students rating the gestures using a 10-point, Likert-type scale with 1 indicating instances of the lowest intensity and 10 indicating the highest kind of intensity. 
The final phase was the observation of the videotape by selected subjects $(N=$ $320)$ divided into four groups: graduate music students $(n=80)$, undergraduate music students ( $n=80)$, non-music students $(n=80)$, and high school band chorus members ( $n$ $=80)$.

Of the 25,600 responses, 19,690 correctly identified responses yielded a correct rate of $77 \%$ across all groups. There were twice as many instances of high intensity as low intensity despite the effort to provide equal numbers of both levels of intensity on the videotape. A Newman-Keuls multiple comparison test produced a significant difference $(p<.05)$ for graduate music majors, signifying that they were more accurate than the other groups. Analysis of the relationships between the beginning conductor group and the four independent groups regarding intensity revealed significant agreement using the Kendall Coefficient of Concordance $\left[x^{2}(4,20)=66.88, p<.001\right]$. Byo $(1990)$ contends that training in gestural intensity (conducting gestures that reflect musical intentions) is an effective means of improving nonverbal conducting skills.

Taebel (1990) compared the performance of music teachers with non-music teachers using 10 competencies and several other variables. The author used a one-way analysis of variance for the study. Previous research noted many differences in effective music teaching techniques such as demonstrating musicianship through accurate rehearsal diagnosis, regular eye contact, appropriate facial expressions and physical gestures, and speaking intensity. Non-verbal communication techniques, positive feedback, framing rehearsals with repertoire that is popular with the performers, and varying amounts of direct and indirect methods of teaching (depending on the musical maturity of the students) also varied from regular classroom evaluation competencies. 
The study employed the following 10 competencies (independent variables) developed by a state evaluation program: (a) presents organized instruction, (b) uses materials and equipment, (c) provides for practice and application, (d) monitors student achievement, (e) uses monitoring data, (f) manages classroom time, (g) maintains student behavior, (h) knows subject matter, (i) maintains a positive atmosphere, and (j) communicates clearly and effectively. The observation instrument used as part of the study was the Classroom Observation Record (COR).

Taebel (1990) used several data sources as part of the study. The raw COR data came from a random sample of $10 \%$ of all the teachers in the state $(N=3,191)$ and a sample of 510 music teachers nationwide. The author also used two questionnaires to compare results with the COR data. One questionnaire, given to music teachers, asked them to rate each competency using a four-point scale. The teachers then rated themselves using the 10 classroom competencies using a 10-point scale (a score of 5 is average), and finally, provided comments concerning the evaluation system. Principals from the conductor's schools rated the music teachers using the 10-point scale and suggested improvements for the evaluation instrument.

The first section of the study compared the mean, standard deviation, and standard error for music teacher competencies within the regular classroom population. The second section used one-way analyses of variance to conclude that the differences between grade levels were not significant except for "uses materials and equipment". As expected, music teachers employed more repeated practice, less review, discussion, or presentation. Music teachers scored lowest on "presents organized instruction" $(M=$ $44.5)$ and "provides for practice and application" $(M=44.4)$. 
Music teachers commented that the competencies were not suited to rehearsal situations and offered several additions to the evaluative areas. Some suggested that competencies were not detailed enough with relation to music rehearsal and that student achievement results should be included in the evaluation instrument. One music teacher suggested that music professionals should only be evaluated by music teachers. Almost all music teacher respondents agreed that their principals lacked the competence or persistence to evaluate music teachers properly. This was a significant change in thinking regarding the evaluation of music teachers. The author contended that any conclusion that music teachers are less competent than other teachers is unwarranted due to the differences in classroom techniques when compared to rehearsal techniques.

Fredrickson (1994) studied the effects that pre-conducting behaviors have on musician perception of conductor effectiveness. The design of the study included one control group and three experiential groups. Undergraduate conducting students $(N=20)$ were videotaped and evaluated on pre-conducting behaviors including approaching the podium and preparing the score, setting down the baton, adjusting the stand, and picking up the baton. Conducting behaviors were defined as assuming a ready position, giving a preparatory beat, and conducting one measure. Eight combinations of poor, none, or excellent pre-conducting behaviors combined with poor, none, or excellent conducting behaviors.

Music majors from three comprehensive universities served as evaluators of the videotapes using a 10-point Likert-type scale. A one-way ANOVA indicated significant differences between the 20 conductors $(F(7,1312)=395.01, p<.0001)$. A Scheffe post hoc Multiple Range Test indicated the highest scores were associated with rankings of 
excellent or none conducting regardless of the pre-conducting behaviors: poor/excellent $(M=4.58)$, none/excellent $(M=5.96)$, excellent/excellent $(M=6.81)$, and excellent/none $(M=7.05)$.

Byo and Austin (1994) sought to devise a field test for nonverbal conducting behaviors and to compare the repertoire of nonverbal behaviors of novice conductors conducting middle school or high school bands $(n=6)$ with experienced university band conductors $(n=6)$. The nonverbal categories consisted of right arm/hand gestures (expressive, neutral, and other subcategories); eye contact (to the ensemble, to the score, and other); facial expression (expressive, neutral subcategories); and body movement (expressive and static subcategories). Left hand gestures (expressive, mirrored, and cueing subcategories) and cueing were documented through number of occurrences and duration. The videotaped segments contained 15-minute excerpts of rehearsal activity with the majority of the ensemble playing rather than a run through segment or performance.

Results of a $t$-test indicated a significant difference between the novice and experienced conductors $(t(10)-4.12, p<.01)$. Experienced conductors spent $46.67 \%$ of the rehearsal in performance mode while the novice conductors spent $58.67 \%$. Experienced conductors were more expressive with right arm/hand movement $(M=55.5)$ that the less experienced conductors $(M=33.17)$. Similarly, experienced conductors spent more time with eye contact towards the ensemble $(M=54.5)$ than did novice conductors $(M=49.83)$ and were more expressive $(M=65.17)$ than their less experienced counterparts $(M=31.67)$. Novice conductors, however, displayed less tendency to exhibit mirrored conducting gestures $t(10)=2.25, p<.05$. 
Fredrickson (1994) studied the effect of not having visual and aural stimulus from the conductor and ensemble on the capability of band members to perform music as part of an ensemble. Undergraduate band members from a southeastern university $(N=120)$ played their instruments individually while watching a videotape of a conductor and listening to the sound of the ensemble through headphones. (The study did not indicate how the students were chosen.) The subjects' average number of years experience in band ensembles was 7.62. An ANOVA performed on the different number of years experience in bands $(F=1.796, d f=3,116, p>.05)$ revealed no significant difference between groups. The experimental group lost the sound of the band or the visual image of the conductor or both after the first 16 measures of a 64-measure excerpt. The experimental group had three equally sized groups $(n=30)$, one with no visual contact, one with no aural contact, and one with no aural or visual contact. The control group $(n=$ 30) continued to hear the band and see the conductor. Raters used a Continuous Response Digital Interface (CRDI) instrument that recorded the band members' ability to play along with the tape.

The control group received the highest scores on the test followed by the experimental group scores. Those band members who had just visual or aural stimulation had similar scores (visual only: $M=125.56, S D=42.11$; and aural only: $M=129.99, S D$ $=25.00$ ). The band members who lost aural stimulation often got lost in the music, thus accounting for the larger standard deviation in scores. Those band members in the experimental group that lost both aural and visual stimulation scored the lowest. The second part of the study analyzed the amount of eye contact by band members with the conductor in the control group. The researchers videotaped band members to measure 
frequency and duration of eye contact. Band members looked at the conductor $28 \%$ of the time with eye contact lasting approximately one second each.

Cofer (1998) investigated the effects of conducting gestures on the performance capabilities of junior and middle school band students. The goal of the study was to determine the effect of short-term instruction regarding conducting gestures on the students' ability to recognize these gestures (via a paper and pencil test) and during their performance. He suggested that prior research indicated that band students at this level did not understand these gestures. The literature provided little research on the effect of conducting gestures on student performance levels.

Using a posttest-only control-group design, the author determined: (a) whether students could recognize conducting gestures on two dependent measures, (b) whether there was a relationship between these two measures, and (c) the proportion of students successfully recognizing the conducting gestures. The subjects were seventh-grade band students $(N=60)$ divided into two groups. The treatment group $(n=30)$ received instruction designed to assist them in recognition of conducting gestures as related to music performance. The eighteen conducting gestures selected included indications of dynamics (degrees of loudness and softness and changes in levels), style and length of notes, and changes or stopping of tempo gestures. The control group did not receive any conducting gesture information and employed a warm-up routine that taught elements of musical performance without the use of conducting gestures. Both groups had 15-minute warm-ups over five different days.

Two types of conducting gesture recognition measures were used in the study. The first was through a standard paper and pencil recognition measure and the second 
was through individual performance measures. An independent $t$-test yielded significant differences for the treatment group on both the paper and pencil test and the individual performance test $(t=6.96, d f=58, p<.001)$. An ANOVA also revealed significant differences in the treatment group for the individual musical performance test, $F(1,58)=$ $39.26, p<.0001$.

Results demonstrated that the treatment group recognized conducting gestures better than the control group $(p<.05)$ although both groups experienced difficulty in differentiating between gestures of crescendo or diminuendo (getting louder or softer) with accelerando and ritardando (getting faster or slower). The increase in performance levels indicated that teaching conducting gestures was valuable and should be part of the music curriculum. This instruction should provide student recognition and understanding of these gestures.

Keely (1997) investigated the effect of nonverbal physical conducting gestures on beginning band students $(N=151)$ randomly chosen from eight beginning bands. Performance variables included rhythm, legato and staccato style, phrasing, and dynamics. Using a pretest and posttest comparative study design, the researchers randomly assigned eight diverse band ensembles and their students, all at the beginning level and from culturally and ethnically different backgrounds, into experimental and control groups. Variables concerning rehearsal time, warm-up procedures, and length of conducting gesture instruction were all controlled for greater study reliability. All bands were pretested to assess their abilities on the performance variables. There was no conducting instruction provided during the warm-ups. Conductors led conducting 
exercises later replicated by the students as they stood in front of their chairs in the rehearsal room.

Analysis of covariance results indicated a significant difference $(p<.001)$ between the experimental group and control groups. Findings regarding the interaction between teaching methods and differences in conductors were not significant.

Results of the study suggested that bands exposed to conducting training improved at a greater rate, $(M=22.88$ (pretest) to $M=45.13$ (posttest)), than those in the control group, $(M=32.45$ (pretest) to $M=30.60$ (posttest)), regarding rhythm and phrasing skills. No differences were found with respect to legato and staccato styles, dynamic variation, or overall performance ability. However, researchers discovered greater differences in improvement for ensembles $(M=2.25)$ as compared to individual improvement $(M=2.17)$. Keely (1997) surmised that conducting gestures might have a greater percentage effect on the overall improvement of ensembles as compared to the improvement rates of individuals. Suggestions for further study included increased sample sizes and exposure to conducting gesture training for student conductors.

VanWeelden (2002) examined whether the conductor's body type was relevant in assessing both conductor effectiveness and ensemble performance. The participants $(N=$ 163), were from 6 different universities, all were undergraduate music majors in the second, third, or fourth year of school. The author did not stipulate how the participants were chosen. The groups were comprised of men $(n=69)$, women $(n=94)$, choral majors $(n=68)$ and instrumental majors $(n=95)$. The dependent variables were 12 questions on a 5-point Likert scale related to conductor and performance effectiveness. 
Six graduate student or faculty conductors served as the models during the study. Each participant completed a questionnaire on each of the six conductors.

The mean scores across all variables including body type, gender, and major (choral or instrumental) showed no significant differences (a range of mean scores from 23.56 to 24.75). All participants rated the endomorphic conductors lower their ectomorphic counterparts with the exception of male instrumental conductors. The participants divided by gender and major, and rated posture, eye contact, and facial expressions higher for ectomorphic conductors except for endomorphic instrumental conductors.

There were somewhat strong relationships between performance ratings and conductor facial expression, conductor posture, evaluator confidence in the conductor, and overall conductor effectiveness. The author notes that there were significant differences among conductor ratings: performance $F(5,972)=17.66, p=.001$, eye contact $F(5,972)=70.85, p=.001$, facial expression, posture $F(5,972)=106.12, p=$ .001 , evaluator confidence in conductor $F(5,972)=53.96, p=.001$, and overall conductor effectiveness $F(5,972)=50.08, p=.001$.

Johnson, Fredrickson, Achey, and Gentry (2003) examined the relationships between nonverbal conducting techniques and the assessments of student and professional (experienced) conductors. To accomplish a comparative study of nonverbal techniques, the authors used five basic elements of conducting: right arm movement, left arm movement, eye contact, facial expression, and body movement. Three groups of students $(N=110)$ comprised of undergraduate and graduate music students from two 
large universities viewed 15 student and experienced conductors. (The authors did not reveal how the students were selected for the study.)

The first group $(n=30)$ assessed the positive or negative overall effectiveness of each conductor. The second group $(n=30)$ evaluated right arm movement, left arm movement, eye contact, facial expression, and body movement. The third group $(n=50)$ was randomly divided into five equal groups to evaluate each of the five elements positively or negatively. The device used in the study was a Continuous Response Digital Interface (CRDI). The device continually collected response during the assessment of the 15 conductors.

The results for student conductors indicated a strong correlation among right arm movement $(r=.84)$, left arm movement $(r=.81)$, and body movement $(r=.85)$. The assessment of eye contact and facial expression, however, were not nearly as strong. In contrast, experienced conductors results showed a lower correlation for right arm movement $(r=.41)$. The highest correlation was body movement $(r=.87)$ followed by left arm movement $(r=.72)$, facial expression $(r=.66)$, and eye contact $(r=.60)$.

The authors concluded that the significance in the conducting examples indicated that right arm movement in student conductors was more prevalent in the assessment than of experienced conductors. Left arm movement was a more significant factor for experienced conductors than their less experienced counterparts. Facial expression and body movement were also more significant than those behaviors by student conductors. Eye contact also did not seem as important for the student conductors as it did for the more experienced conductors. 
Kraus, Gonzalez, Hill, and Humphreys (2004) studied the effects of computergenerated musical feedback as compared to results attained through verbal instruction on the development of undergraduate conducting students. Conducting students $(N=52)$ were divided into three groups. The first group $(n=16)$ worked outside of class with the Digital Conducting System (DCS) that plays real-time music etudes in response to fundamental conducting gestures. The DCS system focuses on four gestures/styles (a) preparatory, ictus, and release; (b) legato; (c) tenuto; and (d) staccato. The second group $(n=18)$ worked in class with an instructor who gave verbal feedback only. The third group $(n=18)$ worked outside of class with no instruction and were asked to practice on their own.

Results from four ANCOVA tests pre and posttest results indicated that there were not a significant differences among the three groups related to assessment of legato, tenuto, and staccato styles. Results for the first skill set (preparatory beat, ictus, and release gestures) indicated that the DCS group ranked higher $(M=3.07)$ than the instructor lead group $(M=2.70)$ or the third group that worked outside of class with no instruction $(M=2.47)$. The authors concluded that combining DCS assessment with verbal instruction was likely to improve conducting skills with undergraduate (beginning) conducting students but results warranted further study.

In summary, conducting gesture research focused on many of the physical movement attributes as mentioned in the previous sections. These areas included eye contact, the ratio of conductor eye contact to student response, the ratio of physical gestures to verbal comments, levels of intensity in gestures, clarity of gestures, ability to introduce gestures to students that signified musical expressions or information, and the 
monitoring of student performance through non-verbal reactions. The authors suggested that if conductors expect a fair evaluation based on their physical conducting skills, personnel with a working knowledge of these skills must evaluate them.

\section{Research on Score Study and Evaluation of Students}

The final section of the literature review includes studies associated with evaluative criteria not observable during rehearsals or classroom sessions. Rehearsal preparation must include adequate score study to familiarize the conductor with the music to plan an effective rehearsal. This is not necessarily apparent during a rehearsal observation without the requisite evaluator training. The conductor's evaluation of student progress and resultant grading scale may also be difficult to determine without further investigation outside the rehearsal observation.

Fiese (1991) examined whether there was agreement among college and university band conductors concerning the quality of band scores. The author collected the criteria the researcher used to determine their rankings. The sample consisted of randomly selected college and university band directors listed in a prominent national music publication $(N=100)$. Of the 38 who responded, only 33 provided complete answers to questions in the survey $(33 \%)$. Of the original 100 randomly sampled names, three were from community colleges and the rest worked in 4-year institutions that had music degree granting programs. Full scores of three compositions, each featuring an overture compositional style scored for wind band, were sent to the participating directors with directions and a score ranking form. The title of the work, the composer's name, and the date of the composition were omitted in each score. 
The first score received the highest ranking from 15 of the directors, second highest quality by four directors, and lowest musical quality by 14 of the directors. The second received rankings of 11,15 , and 7 respectively while the third score received rankings of 7, 14, and 12. Using Kendall's Coefficient of Concordance, the measure of agreement among the judges' rankings was near zero $(W=.08, p>.05)$. The ranking generated nine elements of musical criteria: (a) structural unity and coherence of musical elements within a musical form; (b) logical development of musical ideas; (c) use of contrast and variety in rhythm, melody, harmony, texture, timbre, and dynamics; (d) activity and complexity; (e) effective use of instruments; (f) creativity; (g) predictability; (h) evokes interest; and (i) suitability for the band medium. Fiese (1991) concluded that although there was not agreement about the ranking of the three musical scores, there was significant agreement about the criteria used to evaluate the three scores.

Crowe (1996) considered crror-detection as being one of the most important skills for beginning conductors to learn. Music genres possessing more than one timbre were more difficult for error-detection abilities to process than were those composed with similar timbres. Previous studies found that the amount of teaching experience was the primary factor contributing to error-detection abilities. Subjects were undergraduate students $(N=30)$ enrolled in conducting classes at three Midwestern universities.

He investigated the effects of four different types of score study: (a) no score study, (b) study with score alone, (c) study with correct aural example available, and (d) score study at the keyboard. These four variables, compared against the pitch and rhythm error-detection abilities of beginning conducting students, served as the basis for the study. 
Significant differences in score study style were found on test scores $F(3,93)=$ $2.929, p<.05$. Score study with a good aural example was slightly higher than score study alone. There was no difference between score study at the keyboard and other score study styles. Mean score per study style measured in seconds was lowest in the not study sample $(M=4.833, S D=2.078)$ and highest under score study at the keyboard $(M=$ $356.522, S D=630.565$ ). Higher levels of significance, (through use of a post hoc $t$-test) surfaced when the number of parts in the score increased.

McCoy (1991) examined how band and choral directors determined grades for their students and how those systems compared to the systems proposed by principals. The author surveyed band directors and choral directors from 98 randomly selected high schools in Illinois. The author focused on three primary questions: (a) determining how the elements, and their respective proportions, were used to determine the grading system contribute to the final grade, (b) finding what criteria high school principals find appropriate for determining grades, and (c) how principals' suggested grading systems compare with the actual practices of band and choral directors. Results from the study contradicted earlier studies that demonstrated grading systems developed by directors were based on individual instrument achievement as compared to those proposed by the principals.

Descriptions of grading systems from a previous study by the author provided 25 possible criteria for determining grades for band and choral students. Directors indicated which criteria they presently used and weighted each using percentages. Principals, asked to select which criteria they felt should assist in determination of student grades, also considered the weight of their relative importance. Principals returned the survey at a 
$49 \%$ rate and the band directors' return rate was $59 \%$. A series of analyses of variance (ANOVAs) determined the weighting percentages between directors and principals. Results suggested significant differences in basic performance technique $(F=3.25, d f=$ $2, p<.05)$, attendance at concerts $(F=4.31, d f=2, p<.05)$, and behavior $(F=4.26, d f=$ $2, p<.05)$.

Principals placed greater weight on cognitive skills and basic performance and less weight on concert performances than results obtained through directors' criteria. A two-way ANOVA tested to see if mean weights for the various criteria fluctuated due to school size or director experience. Scheffé post hoc tests revealed that directors with five or more years of teaching experience placed greater weight on psychomotor criteria than principals did.

\section{Summary Chapter Two}

In examining the 98 studies that comprised the seven sections in this chapter, four broad groupings emerged: (a) physical conducting/nonverbal skills; (b) personal and preparation skills for teachers; (c) teaching delivery skills; and (d) specific musical skills/learning objectives taught to students. Physical conducting/nonverbal skills relate to movements that enable the conductor to communicate musical concepts efficiently during a rehearsal or performance without stopping to explain these concepts verbally. Personal and preparation skills refer to the knowledge base that conductors should have to be effective in rehearsals and performances.

Teaching delivery skills allow the conductor to convey musical concepts in an efficient and illustrative manner. This helps move the musical concepts from the printed 
page to student performance efficiently. Specific musical skills/learning objectives are the musical skills that all students should have to produce quality musical performances in rehearsal and in performance.

The four categories allow for a comparison between conductor education and training attributes, and between those areas currently identified in assessment instruments adopted by the public schools in the state of Michigan. This comparison allows the researcher to examine the mismatch between conductor training with the attributes measured in assessment instruments used by administrators in Michigan. In Chapter Three, Table 1 provides a numerical summary by topic under four groupings or headings, and further illustrates the research problem identified in Chapter One. The researcher also describes the methodology by which the study data are collected and analyzed. 


\section{CHAPTER III}

\section{METHODS}

The purpose of the study was to assess (a) whether the statewide evaluation of secondary school conductors in the state of Michigan matched the training attributes associated with accomplished conductors; (b) whether there is a relationship between their training and the evaluation instrument; and (c) whether their evaluation positively affects job satisfaction. Three research questions framed this study:

RQ1. To what extent did the conductors' formal training match up with the musical attributes requisite for adequate conducting and musical performance?

RQ2. Did the conductors perceive that their evaluation process addressed these musical attributes?

RQ3. To what extent did the evaluation process contribute to their overall job satisfaction?

Eight sections comprise this chapter. In the first section, the researcher describes the research design used in the study. The second section describes the instrumentation used in the study. The third section describes the study's sample. Participants in the study came from the state of Michigan comprising band and orchestra conductors as recognized by the Michigan School Band and Orchestra Association (MSBOA). The fourth section outlines the data collection procedures. 
The fifth section describes the data analysis. The sixth section describes the reliability and validity of the study. In the seventh section, the researcher outlines the limitations of the study. The eighth section includes the matrix from the literature review.

\section{Research Design}

The researcher used a survey-design to address the three research questions listed above. He wanted to ascertain whether the conductors' formal training matched the attributes outlined in the survey. The researcher chose the state of Michigan because of his knowledge of the region and because of documented interest from MSBOA. As the unifying organizational body for K-12 conductors in Michigan, MSBOA had an interest in the statewide evaluation instruments and the role that they play in assessing and developing conductors. MSBOA Director, Mr. Paul Lichau, co-wrote an introductory letter to lend credibility to the study and to increase the return rate of respondents. For the first research question (RQ1), the researcher examined the extent to which the attributes of successful secondary school conductors, as determined by the literature review, aligned with the training received by the conductors. The researcher compared the means scores and standard deviations for each attribute to determine if there were areas where conductors received the most training or if other trends emerged as related to good teaching attributes. The Appendix contains the survey and related documents (pp. 187200). Survey items 1-9 consist of demographic information. Survey items 10-42 compare formal musical training with the current assessment instrument used to evaluate the participant. 
For the second research question (RQ2), the researcher correlated the formal training received by conductors with the evaluation criteria used by administrators in the current assessment instrument. Survey results identified any participant perceptions of mismatch between conductor skills and the attributes measured.

For RQ3, to measure the extent to which the evaluation process resulted in increased or decreased job satisfaction, the researcher regressed the demographic variables (items 1-9 in the survey) and the five elements of participant satisfaction as dependent variables (items 43-47 in the survey) upon the conductor attributes as independent variables (items 10-42). (Job satisfaction was defined as how content an individual was with his or her job.)

\section{Instrumentation}

Based on his experience as a music educator and professional conductor, the researcher inductively grouped the attributes drawn from the studies reported in Chapter Two into the standard topology displayed in Table 1 (pp. 143-144). For convenience, the survey items were compared in the left hand column with whether their assessment instruments measured these same attributes in the right hand column. The individual attributes comprising each of the categories of the typology were listed in order of frequency. Attributes that had little or no representation $(\leq 3)$ were omitted from the study.

The survey items 10-42 matched up with the four categories comprising the standard typology: (a) physical conducting/nonverbal attributes (survey items 10-14), (b) personal and preparation attributes for teachers (survey items 15-20), (c) teaching 
delivery attributes (survey items 21-27), and (d) specific attributes related to musical skills/learning objectives taught to students (survey items 28-42).

\section{Participants}

The MSBOA offices provided names and addresses of current secondary band and orchestra conductors from all districts in the state of Michigan $(N=1,061)$. All conductors were responsible for conducting a band, an orchestra, or both as part of their teaching responsibilities. The MSBOA annual online registration of conductors created a "clean" data set of participants.

To protect participant anonymity, the researcher ensured that there was no way to divulge the identity of the study participants. The participant anonymity was assured through the researcher's participation in the Institutional Review Board protocols. The researcher received training through Collaborative Institutional Training Initiative headquarter at the University of Miami. To protect anonymity, the participant basic demographic data was kept under lock and key.

\section{Data Collection}

The researcher used the data collection method outlined by Dillman (2007) in using the internet to facilitate an efficient and convenient format for respondents and to increase the return rate. Working with MSBOA, the researcher sent five contacts to the conductors comprising the population, to maximize the return rate. A pre-notice letter, the first contact, let all of the participants know of the upcoming Internet survey and provided a brief description of the importance of the survey. The MSBOA Offices sent 
this pre-notice letter directly to their home addresses via the U.S. Postal Service and included their logo and letterhead identification for authenticity and to illustrate support for the study.

The second letter, also delivered by the U.S. Postal Service but sent by the researcher, included information about the study, about accessing the online survey, and indicated a deadline for completion. Incentives offered to the respondents included access to the study results.

To increase the return rate, a third contact, a follow-up postcard, was sent two weeks after the second letter. The postcard provided the online survey information and reminded the conductors to complete the survey in a timely manner. This contact had a greater sense of urgency, prompting respondents to complete the survey in a timely fashion.

The participants were contacted a fourth time via the US Postal Service with a reminder and a link to the survey sent by the researcher. Respondents completed the online survey per the directions outlined in the letter.

A fifth and final contact in the form of a "thank you" letter was sent to all conductors on the mailing list regardless of whether they had responded previously. This letter provided instructions on to how to complete the survey online and indicated an ending date for the survey.

\section{Data Analysis}

The researcher used different statistical analyses for each research question. 
$R Q 1:$ To what extent did the conductors' formal training match up with the musical attributes requisite for adequate conducting and musical performance?

The researcher computed the means and standard deviations of the conductors formal training with the musical attributes requisite to adequate conducting skill and musical performance. The researcher compared the means scores and standard deviations for all four subsets across the attributes: (a) physical conducting/nonverbal attributes, (b) personal and preparation attributes for teachers, (c) teaching delivery attributes, and (d) specific attributes related to musical skills/learning objectives taught to students. This comparison was used to determine if there were areas where conductors received the most training and where other trends emerged. It also measured the percentage of conductors who received training in the majority of the areas identified in the literature review.

RQ2: Did the conductors perceive that their evaluation process addressed these musical attributes?

To determine whether the conductors perceived that their review process evaluated these musical attributes, the researcher used a Pearson-Product Moment correlation analysis to compare the means of those musical skills received in their studies with the assessment criteria used by administrators. This method measured the strength of the relationship between two variables. Ranging from -1 to $1+$ the instrument measured the association between the variables with $1+$ signifying a perfect positive relationship between the two variables. This correlation measured the participant's perception of whether the conductor's training matched the evaluation instrument criteria employed by school administrators. 
The researcher measured the correlation between the evaluation criteria and the attributes studied as part of their formal training. The researcher examined the whether the conductors' training matched up with the musical attributes necessary for adequate musical performance and whether their musical training matched the evaluative criteria.

RQ3. To what extent did the evaluation process contribute to their overall job satisfaction?

The researcher used a regression analysis to compare overall job satisfaction with the evaluative process and with specific variables that correlated to job satisfaction or dissatisfaction. A regression analysis instrument measured the difference for each factor to determine the statistical association that assessment variables (independent variables) had with job satisfaction (dependent variables). The analysis assessed the statistical significance of the relationships and the degree of confidence of the relationship.

\section{Reliability and Validity}

Several measures contributed to the reliability of the study. The MSBOA assisted in gathering the participant pool thereby increasing the return rate of the data set. A power analysis calculated the minimum number of responses required for a robust result. A high response rate decreased the likelihood of rejecting a true hypothesis.

The researcher used the following statistical test to determine the level of confidence for the response rate. The equation,

$$
1-\Phi\left(t_{\alpha}-\tau \frac{\sqrt{n}}{\sigma_{D}}\right)
$$


determines the power of the test. In our case, $t_{\alpha}=1.64$, because a statistical significance of $5 \%$ was used. In this equation: $\Phi$ is the cumulative distribution function of the normal curve, $t$ subscript alpha is the $t$-value of at significance level alpha, $\tau$ is the estimate from the data, $n$ is the sample size, and sigma of $\mathrm{D}$ is standard error of the values.

The reliability of the instrument was also enhanced by the number of studies examined in the literature review above (98 studies) used to create the frequency matrix, which subsequently formed the basis of the survey. Based on his practical experience in the profession, the researcher used publications in the major music educator and professional conducting journals as the selection criteria for inclusion the literature review.

Two measures contributed to the validity of the study. A pilot survey sent to a small random sample size of conductors determined whether the instrument was comprehended by the respondents. Having determined the four categories, (a) physical conducting/nonverbal attributes, (b) personal and preparation attributes for teachers, (c) teaching delivery attributes, and (d) specific attributes related to musical skills/learning objectives taught to students, the researcher discovered that the attributes identified in the literature review fit exclusively into only one of the four categories described above. This process generated a saturation of the data based on the exclusivity of the four categories.

\section{Limitations of Study}

There were seven limitations of the study. The first limitation was the participant's perception of the data security protecting their anonymity might be a limitation of the study. The second limitation was possible for those conductors who only 
had internet access at the workplace and believed their anonymity might be compromised by administrators viewing their survey responses. A third consideration was whether union/non-union variation of the assessment might be another factor to consider. The variations and frequency of conductor evaluations might have caused shifts in data sets and further research related to the frequency element is recommended. A fourth limitation of the study might be the variance between conducting responsibilities of marching band, concert band, and orchestra conductors. The study might also be affected by differences in certification requirements among different states as a fifth limitation.

A sixth possible limitation of the study, which must be considered, was respondent bias. If a participant had previously experienced a negative assessment process, their responses will be affected by that experience. Conductors might want administrators to have increased knowledge of pertinent assessment attributes associated with good conducting and teaching as part of their regular review process. Conductors with relatively few years of experience or were not as diligent in their craft as their more experienced colleagues, might have preferred an assessment tool that was more general and less specific in nature. These sentiments might have increased respondent bias in both directions on the continuum.

A seventh and final limitation of the study might be that during the calendar year of the survey, state support of schools might have been reduced, adversely affecting the nature of programs. 


\section{Matrix from the Literature Review}

The categories listed in Table 1 below allow for a comparison between conductor education and training attributes and those areas currently identified in assessment instruments adopted by public schools in the state of Michigan. Table 1 provides a numerical summary by topic under four groupings or headings: (a) physical conducting/nonverbal skills; (b) personal and preparation skills for teachers; (c) teaching delivery skills; and (d) specific musical skills/learning objectives taught to students. These four headings provide a framework for this study's survey instrument. Numerical accumulations illuminate the frequency with which these attributes appeared in the literature review and the relative importance of assessment topic areas throughout

\section{Chapter 2.}

There are four subsets of attributes: (a) physical conducting/nonverbal attributes, (b) personal and preparation attributes for teachers, (c) teaching delivery attributes, and (d) specific attributes related to musical skills/learning objectives taught to students. 


\section{Table 1: Musical Training Attributes from the Literature Review}

\begin{tabular}{|c|c|c|c|c|c|c|c|c|}
\hline Attributc or Skill Type & $\begin{array}{l}\text { General } \\
\text { Mlusic } \\
\text { Restarch }\end{array}$ & $\begin{array}{c}\text { Concert \& } \\
\text { Marching } \\
\text { Band } \\
\text { Research }\end{array}$ & $\begin{array}{l}\text { Choral } \\
\text { and } \\
\text { String } \\
\text { Research }\end{array}$ & $\begin{array}{l}\text { Applied } \\
\text { Music } \\
\text { Research }\end{array}$ & $\begin{array}{c}\text { Elementary } \\
\text { Music } \\
\text { Research }\end{array}$ & $\begin{array}{l}\text { Conducting } \\
\text { Gesture and } \\
\text { Score Study } \\
\text { Rescareh }\end{array}$ & $\begin{array}{c}\text { Evaluation, } \\
\text { \& Grading } \\
\text { of Students } \\
\text { Rescarch }\end{array}$ & Total \\
\hline
\end{tabular}

Physical conducting/ nenserbal attributes

Gestures, general nom erbal

Eye contact

Facial expression

Conducting general

Beat pattems left hand

Intensily

Posture

Stylistic gestures. right hand

Preparatory, ictus. \& reteasc gestures

Proximity

Cueing

Personal and preparation att ributes for

$\begin{array}{llllll}2 & 4 & 7 & 3 & 9 & 25 \\ 2 & 2 & 4 & 1 & 9 & 18 \\ 2 & 1 & 3 & 1 & 5 & 12 \\ 2 & 3 & 1 & & 6 \\ 2 & & 1 & 3 & 4 \\ & & 1 & 3 & 4 \\ & & & 2 & 4 \\ & & & 4 & 2 \\ & & & 2 & 2 \\ & & & 1 & 1\end{array}$




\begin{tabular}{|c|c|c|c|c|c|c|c|c|}
\hline Attribute or Skill Type & $\begin{array}{l}\text { General } \\
\text { Musie } \\
\text { Research }\end{array}$ & $\begin{array}{c}\text { Concert \& } \\
\text { Marching } \\
\text { Band } \\
\text { Research }\end{array}$ & $\begin{array}{l}\text { Charal } \\
\text { and } \\
\text { String } \\
\text { Research }\end{array}$ & $\begin{array}{l}\text { Appliced } \\
\text { Music } \\
\text { Restarch }\end{array}$ & $\begin{array}{c}\text { Elementar } \\
\text { y Music } \\
\text { Research }\end{array}$ & $\begin{array}{l}\text { Conductin } \\
\text { g Getsture } \\
\text { and Score } \\
\text { Study } \\
\text { Research } \\
\end{array}$ & $\begin{array}{c}\text { Evaluation } \\
\text { \& Grading } \\
\text { of Students } \\
\text { Research } \\
\end{array}$ & Total \\
\hline \multicolumn{9}{|l|}{ Teaching delivery attributes } \\
\hline Delivery of instruction & 5 & 6 & 9 & 2 & 4 & 3 & & 29 \\
\hline Teaching methods & 8 & 4 & 6 & I & 6 & 3 & & 28 \\
\hline Rehearsal pacing management & 3 & 7 & 8 & & 3 & 4 & & 25 \\
\hline Experience years: teaching \& education & 1 & 6 & 4 & 3 & 3 & 2 & & 19 \\
\hline Reinlorres gond behaviors. respotses & 1 & 4 & 6 & 3 & 2 & 3 & & 19 \\
\hline On task off task ralio & I & 6 & 7 & & 3 & 1 & & 18 \\
\hline Corrective leedback & 2 & 3 & 5 & 3 & 1 & 3 & & 17 \\
\hline Aural delection & 2 & 1 & 2 & 1 & 3 & 2 & 1 & 12 \\
\hline Control and management & 4 & 1 & 4 & & 1 & 2 & & 12 \\
\hline Instructional materials and equip. usage & 1 & 1 & 1 & & 3 & 1 & & 7 \\
\hline Molivational techniques & 2 & 1 & 2 & & 1 & 1 & & 7 \\
\hline Producing student enjoymem & 1 & 1 & 1 & 1 & 3 & & & 7 \\
\hline Discovery teacting & 3 & & 2 & & 1 & & & 6 \\
\hline Social feedback & 2 & 2 & 1 & & 1 & & & 6 \\
\hline Classroom climate & 1 & 1 & 2 & & & 1 & & 5 \\
\hline Student evaluation & 1 & & & & 2 & 1 & & 4 \\
\hline Discipline & 1 & 1 & 1 & & & & & 3 \\
\hline Didactic teaching & 2 & & & & & & & 2 \\
\hline Use of humer & & I & & & & & & 1 \\
\hline \multicolumn{9}{|l|}{$\begin{array}{l}\text { Specifict attributes related to musical } \\
\text { skills/ learning objectives taught to } \\
\text { students }\end{array}$} \\
\hline Attentiveness \& attlitude & & 3 & 4 & 1 & 3 & 1 & & 12 \\
\hline Musical fact concepls skills & & 5 & 4 & i & 1 & & & 11 \\
\hline Rhythm & & 5 & 2 & 1 & 2 & 1 & & 11 \\
\hline Expressive perlormance; interpretation & 2 & 3 & 3 & 1 & 1 & & & 10 \\
\hline Overall performance skills & & 3 & 2 & 3 & 1 & 1 & & 10 \\
\hline Pitch discrimination \& intenation & & 5 & 3 & 1 & 1 & & & 10) \\
\hline Dynamics & & 3 & 3 & & & 2 & & 8 \\
\hline Musical skills & 1 & 3 & & 1 & 2 & & & 7 \\
\hline Aniculation & 1 & 3 & & 1 & & 1 & & 6 \\
\hline Phrasing & & 3 & 1 & & 1 & 1 & & 6 \\
\hline Style & & 2 & 1 & & & 2 & & 5 \\
\hline Tempo & & 1 & 2 & 1 & & 1 & & $s$ \\
\hline Tone quality & & 3 & 2 & & & & & 5 \\
\hline Aural skills & & 2 & 1 & & 1 & & & 4 \\
\hline Butance & & 2 & 2 & & & & & 4 \\
\hline Biend & & 1 & 2 & & 1 & & & 4 \\
\hline Sight singing sight reading & & 1 & 1 & 1 & 1 & & & 4 \\
\hline Diction & & & 2 & & 1 & & & 3 \\
\hline Note accuracy & & 2 & 1 & & & & & 3 \\
\hline Vocal skills & 1 & & 1 & & 1 & & & 3 \\
\hline Composition & & 1 & & & 1 & & & 2 \\
\hline Improvisation & & 1 & & & 1 & & & 2 \\
\hline Melody & & 2 & & & & & & 2 \\
\hline Bowing mechanits & & & 1 & & & & & 1 \\
\hline Ear to hand skills & & 1 & & & & & & 1 \\
\hline Form & & 1 & & & & & & 1 \\
\hline Harmony & & 1 & & & & & & 1 \\
\hline Slurring & & & & 1 & & & & 1 \\
\hline Technical skills & 1 & & & & & & & 1 \\
\hline Timbre & & 1 & & & & & & 1 \\
\hline
\end{tabular}




\section{CHAPTER IV}

\section{RESULTS}

The purpose of the study was to assess (a) whether the statewide evaluation of secondary school conductors in the state of Michigan matched the training attributes associated with accomplished conductors; (b) whether there is a relationship between their training and the evaluation instrument; and (c) whether their evaluation positively affects job satisfaction. This chapter is divided into four sections. The first section demonstrates the power of the survey results. The next three sections outline the study results related to the research questions.

\section{Power of the Survey Results}

Participants in the study came from the state of Michigan comprising band and orchestra conductors as recognized by the Michigan School Band and Orchestra Association (MSBOA). All conductors were responsible for conducting a band, an orchestra, or both as part of their teaching responsibilities. The MSBOA annual online registration of conductors created a "clean" data set of participants. The first item in the survey verified whether the participant was still an active conductor in the state of Michigan. The researcher collected responses $(n=173)$ from the entire mailing list of MSBOA members $(N=1,061)$. A power analysis calculated the minimum number of 
responses required for a robust result. A high response rate decreased the likelihood of rejecting a true hypothesis.

The researcher used the following statistical test to determine the some statistical tests. The equation,

$$
1-\Phi\left(t_{\alpha}-\tau \frac{\sqrt{n}}{\sigma_{D}}\right)
$$

determined the power of the test. In our case, $t_{\alpha x}=1.64$ since a statistical significance of $5 \%$ was used. In this equation: $\Phi$ is the cumulative distribution function of the normal curve, $t$ subscript alpha is the $t$-value of at significance level alpha, $\tau$ is the estimate from the data, $n$ is the sample size, and sigma of D is standard error of the values.

RQ1. To what extent did the conductors' formal training match up with the musical attributes requisite for adequate conducting and musical performance?

The researcher computed the means and standard deviations of the conductors formal training with the musical attributes requisite to adequate conducting skill and musical performance. The attributes were determined by prioritizing the findings in the literature review of those receiving the most examples related to successful musical performance by conductors. The survey results used a scoring scale of strongly agree $=$ 5 , somewhat agree $=4$, neither agree or disagree $=3$, somewhat disagree $=2$, and strongly disagree $=1$. The researcher compared the means scores and standard deviations for all four subsets across the attributes: (a) physical conducting/nonverbal attributes, (b) personal and preparation attributes for teachers, (c) teaching delivery attributes, and (d) specific attributes related to musical skills/learning objectives taught to students. Table 2 contains the mean scores and standard deviations from the areas 
where conductors received the most training. The researcher used a "cut-off" score of 3.5 to determine a significant mean score based on the assumption that rating above 3.5 indicated a rating closer to the "agree" end of the spectrum. Scores under 3.5 indicated scores within the "neither agree or disagree" or "disagree" end of the spectrum. The findings that are underlined in Table 2 indicate significant mean scores above 3.5. 
Table 2: Musical Attributes Related to Successful Musical Performance

\begin{tabular}{|c|c|c|c|c|}
\hline Survey Question & $\begin{array}{r}\text { Formal } \\
\text { Mean } \\
\end{array}$ & Training & Assessment & $\begin{array}{r}\text { Instrument } \\
\text { SD } \\
\end{array}$ \\
\hline \multicolumn{5}{|l|}{ Physical conducting \& nonverbal gestures } \\
\hline Nonverbal gestures & $\underline{4.511}$ & 0.672 & 2.142 & 1.397 \\
\hline Right hand gestures & $\underline{4.674}$ & 0.722 & 1.957 & 1.453 \\
\hline Left hand gestures & $\underline{4.532}$ & 0.798 & 1.993 & 1.417 \\
\hline Facial expressions & $\underline{4.014}$ & 1.102 & 2.248 & 1.358 \\
\hline Eye contact & $\underline{4.688}$ & 0.656 & 2.936 & 1.532 \\
\hline \multicolumn{5}{|l|}{ Personal \& preparation attributes } \\
\hline Music history \& ensemble repertoire & $\underline{3.965}$ & 1.072 & 2.184 & 1.323 \\
\hline Performance skills & $\underline{4.801}$ & 0.510 & 2.199 & 1.600 \\
\hline Sight singing skills \& ear training & $\underline{4.865}$ & 0.496 & 2.234 & 1.646 \\
\hline Modeling musical concepts & $\underline{4.553}$ & 0.701 & 3.148 & 1.434 \\
\hline Score study \& rehearsal preparation & $\underline{4.596}$ & 0.784 & 2.752 & 1.522 \\
\hline Accompanying \& arranging skills & $\underline{3.809}$ & 1.095 & 1.929 & 1.302 \\
\hline \multicolumn{5}{|l|}{ Musical \& teaching delivery attributes } \\
\hline Error detection skills & $\underline{4.142}$ & 0.990 & 2.716 & 1.406 \\
\hline Verbal instruction \& communication skills & $\underline{4.014}$ & 1.035 & $\underline{4.149}$ & 0.999 \\
\hline Leadership skills, helpful personality traits & $\underline{3.887}$ & I. 109 & $\underline{3.901}$ & 1.044 \\
\hline Classroom control \& management & 3.546 & 1.256 & $\underline{4.475}$ & 0.990 \\
\hline Current repertoire of teaching methods & $\underline{4.021}$ & 1.052 & 2.858 & 1.392 \\
\hline Teaching delivery skills & $\underline{3.915}$ & 1.003 & $\underline{4.156}$ & 0.980 \\
\hline Rehearsal pacing skills \& techniques & $\underline{3.716}$ & 1.238 & $\underline{3.745}$ & 1.186 \\
\hline Performance skills & $\underline{4.816}$ & 0.424 & 2.702 & 1.501 \\
\hline \multicolumn{5}{|l|}{ Core musical concepts $\&$ musicianship skills } \\
\hline Expressive interpretation & $\underline{4.617}$ & 0.569 & 2.191 & 1.414 \\
\hline Musical fact/concept skills & $\underline{4.709}$ & 0.515 & 2.844 & 1.485 \\
\hline Rehearsal attentiveness & $\underline{4.404}$ & 0.949 & $\underline{3.801}$ & 1.220 \\
\hline Note accuracy/technical skills & $\underline{4.809}$ & 0.462 & 2.716 & 1.485 \\
\hline Articulation \& slurring & $\underline{4.752}$ & 0.623 & 2.227 & 1.475 \\
\hline Style \& phrasing & $\underline{4.766}$ & 0.530 & 2.269 & 1.468 \\
\hline Rhythm & $\underline{4.851}$ & 0.430 & 2.433 & 1.541 \\
\hline Tone quality & $\underline{4.837}$ & 0.457 & 2.489 & 1.552 \\
\hline Pitch discrimination/intonation & $\underline{4.752}$ & 0.656 & 2.291 & 1.524 \\
\hline Balance \& blend concepts & $\underline{4.716}$ & 0.552 & 2.234 & 1.486 \\
\hline Dynamics & $\underline{4.865}$ & 0.343 & 2.291 & 1.495 \\
\hline Improvisation \& composition & $\underline{3.511}$ & 1.234 & 1.780 & 1.134 \\
\hline Ear to hand/aural training & 4.177 & 1.037 & 2.043 & 1.325 \\
\hline Sight singing/sight reading & $\underline{4.674}$ & 0.649 & 2.298 & 1.534 \\
\hline
\end{tabular}


Under the section, physical conducting and nonverbal gestures, nonverbal gestures $(M=4.511)$, right hand gestures $(M=4.674)$, left hand gestures $(M=4.674)$, and eye contact $(M=4.688)$ all scored high ratings from the respondents. Facial expressions $(M=4.014)$ was not quite as high as the other physical conducting and nonverbal gesture attributes but was still scored relatively high by the respondents.

Under the category of personal and preparation attributes, performance skills ( $M$ $=4.801)$, sight singing and ear training $(M=4.865)$, modeling musical concepts $(M=$ 4.553), and score study and rehearsal preparation $(M=4.596)$ all received high ratings from the respondents. Music history and ensemble repertoire $(M=3.965)$ and accompanying and arranging skills $(M=3.809)$ were slightly lower.

The only attribute within musical and teaching delivery attributes receiving a similar high ranking was performance skills $(M=4.816)$. Some of the attributes in this section were determined to still be relatively important ranging from rehearsal pacing skills and techniques $(M=3.716)$ to current repertoire of teaching methods $(M=4.021)$.

Within the core musical concepts and musicianship skills, most respondents rated these attributes quite high. Note accuracy and technical skills $(M=4.809)$, rhythm $(M=$ 4.851), tone quality $(M=4.837)$, and dynamics $(M=4.865)$ were rated the highest by the respondents. The two areas with slightly lower ratings were improvisation and composition $(M=3.511)$ and ear to hand and aural training $(M=4.177)$. All the other attributes in this section ranged from rehearsal attentiveness $(M=4.404)$ to style and phrasing $(M=4.766)$ demonstrating high mean scores for the top attributes emanating from the literature review. 
All of the musical attributes related to successful musical performance in had relatively high ratings which corresponded to the research outlined in the literature review. The standard deviations for physical conducting and nonverbal gestures, personal and preparation attributes, and core musical concepts and musicianship skills, had generally low scores with the exception of improvisation and composition $(S D=$ 1.234). In the area of musical and teaching delivery attributes, classroom control and management $(S D=1.256)$ and rehearsal pacing skills and techniques $(S D=1.238)$ were slightly higher. The variations within the standard deviations for the attributes may be function of the amount of formal training received by the conductors and may warrant further study.

RQ2. Did the conductors perceive that their evaluation process addressed these musical attributes?

To determine whether the conductors perceived that their review process evaluated these musical attributes, the researcher used Pearson-Product Moment correlation coefficients to analyze the musical skills received in their studies with the assessment criteria used by administrators. This method measured the strength of the relationship between two variables. Ranging from -1 to 1 t the instrument measured the association between the variables with $1+$ signifying a perfect relationship between the two variables. This correlation measured whether the participants that had more training in one area tended to be evaluated more in that area compared to other participants.

The researcher first measured the correlation between the evaluation criteria and the attributes studied as part of their formal training. The researcher then examined the whether the conductors' training matched up with the musical attributes necessary for 
adequate musical performance and whether their musical training matched the evaluative criteria. Table 3 outlines the results from RQ2 and provides the power of the correlation. The underlined figures in Table 3 indicate a stronger correlation. 
Table 3: Musical Training Compared to Assessment Instruments $(N=141)$

\begin{tabular}{|c|c|c|c|c|c|c|c|c|}
\hline & $\begin{array}{c}\text { Formal } \\
\text { Training }\end{array}$ & & $\begin{array}{l}\text { Assessment } \\
\text { Instrument }\end{array}$ & & & & & \\
\hline Survey Question & Mean & SD & Mean & SD & $\begin{array}{c}\text { Correlation } \\
\text { Estimate }\end{array}$ & t-statistic & $\begin{array}{c}p \text { - } \\
\text { value } \\
\text { yalus }\end{array}$ & $\begin{array}{l}\text { Poncr of } \\
\text { Correlation }\end{array}$ \\
\hline \multicolumn{9}{|c|}{ Physical conducting \& nonverbal gestures } \\
\hline Nonverbal gestures & $\underline{4.511}$ & 0.672 & 2.142 & 1.397 & 0.028 & 0.340 & 0.734 & 0.097 \\
\hline Right hand gestures & 4.674 & 0.722 & 1.957 & 1.453 & 0.102 & 1.213 & 0.227 & 0335 \\
\hline Left hand gestures & $\underline{4.532}$ & 0.798 & 1.993 & 1.417 & 0.035 & 0.412 & 0.681 & 0.110 \\
\hline Facial expressions & $\underline{4.014}$ & 1.102 & 2.248 & 1.358 & 0.084 & 0.988 & 0.325 & 0.257 \\
\hline Fye contact & 4.688 & 0.656 & 2.9 .36 & 1.532 & 0.179 & 2.146 & 0.013 & 0.693 \\
\hline \multicolumn{9}{|l|}{ Personal \& preparation attributes } \\
\hline Music history \& ensemble repertoire & $\underline{3.965}$ & 1.072 & 2.184 & 1.323 & 0.146 & 1.736 & 0.1885 & 0.5 .38 \\
\hline Perlormance skills & 4.801 & 0.510 & 2.199 & 1.600 & 0.057 & 0.678 & 0.449 & 0.368 \\
\hline Sight singing skills \& ear traiming & $\underline{4.865}$ & 0.496 & 2.234 & 1.646 & 0.030 & 0.356 & 0.723 & 0.094 \\
\hline Modeling musical concepts & 4.553 & 0.701 & 3.148 & 1.434 & 0.209 & 2.516 & 0.0013 & 0.869 \\
\hline Score study \& rellearsal preparation & $\underline{4.596}$ & 0.784 & 2.752 & 1.522 & 0.167 & 1.995 & 0.048 & 0.639 \\
\hline Accompanying \& arranging skills & 3.809 & 1.095 & 1.929 & 1.302 & 0.191 & 2.292 & a.t.2? & 0.743 \\
\hline \multicolumn{9}{|l|}{ Musical \& teaching delivery attributes } \\
\hline Error detection skills & 4.142 & 0.990 & 2.716 & 1.406 & 0.142 & 1.692 & 0.093 & 0.521 \\
\hline Verbat instr. \& communication skills & $\underline{4.014}$ & 1.035 & $\underline{4.149}$ & 0.499 & 0.191 & 2.297 & 0.023 & 0.745 \\
\hline Leadership skills. personality traits & 3.887 & 1.109 & $\underline{3.901}$ & 1.044 & 0.225 & 2.718 & 0.017 & $0 . x 59$ \\
\hline Classroom control \& managennem & $\underline{3.546}$ & 1.256 & 4.475 & 0.990 & 0.209 & 2.522 & 0.013 & 0.811 \\
\hline Current repertore teaching methods & 4.021 & 1.052 & 2.858 & 1.392 & 0.124 & 1.474 & 63.143 & 0.434 \\
\hline Teaching delwery skills & $\underline{3.915}$ & 1.003 & 4.156 & 0.980 & 0.152 & 1.867 & 10.073 & 0.567 \\
\hline Rehearsal pacing skills \& techniques & 3.716 & 1.238 & 3.745 & 1.186 & 0.106 & 1.257 & 0.211 & 0.351 \\
\hline Perlormance skills & 4.816 & 0.424 & 2.702 & 1.501 & 0.003 & 0.034 & 0.973 & 0.054 \\
\hline \multicolumn{9}{|c|}{ Core musical coneepts \& musicianship skills } \\
\hline Expressive interpretation & 4.617 & 0.569 & 2.191 & 1.414 & 0.012 & 0.140 & 0.888 & 0.067 \\
\hline Musical faticoncept skills & 4.709 & 0.515 & 2.844 & 1.485 & 0.155 & 1.852 & 0.066 & $0.58+$ \\
\hline Rehearsal attentiveness & $\underline{4.404}$ & 0.949 & 3.801 & 1.220 & 0.0012 & 0.023 & 0.981 & 0.053 \\
\hline Note accuracy lechnical skills & $\underline{4.809}$ & 0.462 & 2.716 & 1.485 & -0.069 & -0.820 & 1.587 & 0.206 \\
\hline Articubation \& siurring & 4.752 & 0.623 & 2.227 & 1.475 & -0.063 & -0.740 & 1.593 & 0.184 \\
\hline Style \& phrasing & 4.766 & 0.530 & 2.269 & 1.468 & 0.008 & 0.097 & 0.923 & 0.061 \\
\hline Rhylhm & $\underline{4.851}$ & 0.430 & 2.433 & 1.541 & 0.001 & 0.011 & 0.991 & 0.052 \\
\hline Tone qualily & 4.837 & 0.457 & 2.489 & 1.552 & 0.6153 & 0.625 & 0.553 & 0.155 \\
\hline Pitch discriminat son intonation & +752 & 0.656 & 2.291 & 1.524 & 0.051 & 0.605 & 0.546 & 0.150 \\
\hline Balance \& blend concepts & 4.716 & 0.552 & 2.234 & 1.486 & -10.058 & $-016 \times 3$ & 1.504 & 0.164 \\
\hline Dynamics & $\underline{4.865}$ & 0.343 & 2.291 & 1.495 & -0.146 & -1.740 & 1.916 & 0.5 .39 \\
\hline Improvisation de compesition & $3.5 ! 1$ & 1.234 & 1.780 & 1.134 & 0.132 & 1.567 & 0.119 & 0.471 \\
\hline Ear to hand aural training & 4.177 & 1.037 & 2.043 & 1.325 & 0.072 & 0.856 & (1) 393 & 0.217 \\
\hline Sight singing sight reading & 4.674 & 0.649 & 2.298 & 1.534 & 0.141 & 1.683 & 0.095 & 0.517 \\
\hline
\end{tabular}


Compared to the mean scores of the training received by the conductors, the mean scores as compared to the assessment instruments used were significantly lower. Within the section of physical conducting and nonverbal gestures, mean scores for nonverbal gestures $(M=2.142)$, right hand gestures $(M=1.957)$, left hand gestures $(M=1.993)$, and facial expressions $(M=2.248)$ were much lower as compared to the ratings related to musical training. Eye contact $(M=2.936)$ was the closest to the similar mean score of the musical training $(M=4.688)$.

Personal and preparation attributes as part of the assessment instruments used by administrators were also quite low, ranging from accompanying and arranging skills ( $M$ $=1.929)$ to sight singing and ear training $(M=2.234)$. The results from the assessment instruments questions related to score study $(M=2.752)$ was still significantly different from the musical training in the same attribute $(M=4.596)$. Similarly, modeling musical concepts in the assessment instruments $(M=3.148)$ was also significantly different to the musical training of the same attribute $(M=4.553)$.

Within the section of core musical concept and musicianship skills, the mean scores were quite different comparing the musical training with the assessment instruments. These mean values were generally lower, ranging from improvisation and composition $(M=1.780)$ to tone quality $(M=2.489)$. A few of the attributes including note accuracy and technical skills $(M=2.716)$ and musical facts and concept skills $(M=$ 2.844) were slightly higher. Rehearsal attentiveness was the closest of these three areas comparing the mean score of the musical training $(M=4.404)$ with the same attribute in the assessment instrument $(M=3.801)$. 
The section comparing musical and teaching delivery attributes had the closest mean scores for several areas. The following attributes: verbal instruction and communication skills; leadership skills and helpful personality traits; teaching delivery skills; and rehearsal pacing skills and techniques all had almost identical mean scores. These are the only survey attributes that conductors indicated that the assessment instruments used focused on their musical training.

Table 3 also compares the correlations between the musical training attributes and whether the administrators evaluated those same attributes. Under the heading of physical conducting and nonverbal gestures, only eye contact $(p=0.034)$ correlated positively between the musical training and the assessment instruments used by administrators. This means that conductors that received training in eye contact were more likely to be evaluated on their eye contact. Nonverbal communication, right and left hand gestures, and facial expressions did not have positive correlations. The section on personal and preparation attributes had positive correlations on modeling musical concepts $(p=0.013)$, accompanying and arranging skills $(p=0.048)$, and score study and rehearsal preparation $(p=0.048)$. The rest of the attributes in this section did not positively correlate.

Within the musical and teaching delivery attributes only verbal instruction and communication skills $(p=0.023)$, leadership skills and helpful personality traits $(p=$ $0.007)$, and classroom control and management $(p=0.013)$ had positive correlations. None of the attributes in the core musical and musicianship skills section had positive correlations. 
When looking at the overall correlation of the means, training and evaluation were negatively correlated. This correlation was -.4161 , meaning that conductors overall perceived that their evaluations focused more on the attributes that they received the least training. The $p$-value of this is $.016,(p<0.05)$ so this result is statistically significant.

RQ3. To what extent did the evaluation process contribute to their overall job satisfaction?

To measure the extent to which the evaluation process resulted in increased or decreased job satisfaction, the researcher regressed the demographic variables (items 1-9 in the survey) and a variable that measures the correlation of training and evaluation for an individual (items 10-42) on the five elements of participant satisfaction as dependent variables (items 43-47 in the survey). (Job satisfaction was defined as how content an individual was with his or her job.) Table 4 outlines the results of regression analysis comparing these variables with underlined figures indicating a strong correlation.

The regression results regarding the Evaluation Process as a Good Indicator of Teaching and Conducting Ability demonstrated that if conductors were evaluated on the same attributes on which they were trained it had a strong effect on the opinion of the evaluation process $(t=4.992)$. Also, choral conductors said that their evaluation process was a good indicator of teaching and conducting ability $(t=2.146)$. Conductors with more education were less likely to respond that the process was a good indicator of their ability. All of the other variables in this section including band, orchestra, education, grade level taught, and whether the evaluation process was tied to promotion, tenure, or union factors did not have a strong effect on teaching and conducting ability. 
The second regression showed that a high correlation between training and evaluation increased the agreement of the conductor that the assessment instrument presently used is helpful in identifying areas of needed personal growth and development $(t=3.640)$. The same is true of band directors $(t=3.218)$, choral directors $(t=3.640)$ and middle school/junior high band directors $(t=2.948)$. Conductors with more education were less likely to agree that the assessment instrument identified areas of needed personal growth $(t=-2.118)$. 
Table 4: Evaluation Related to Job Satisfaction $(N=134)$

\begin{tabular}{lrrr} 
Question & $\begin{array}{c}\text { Correlation } \\
\text { Estimate }\end{array}$ & $\begin{array}{c}\text { Standard } \\
\text { Errors }\end{array}$ & t-statistic \\
\hline $\begin{array}{l}\text { The evaluation process presently used is a } \\
\text { good indicator of my teaching and }\end{array}$ & & & \\
conducting ability & & & \\
Correlation of learning and evaluation & 0.808 & 0.162 & $\underline{4.992}$ \\
Bands & 0.035 & 0.204 & 0.171 \\
Orchestra & -0.093 & 0.339 & -0.274 \\
Choral & 1.039 & 0.484 & $\underline{2.146}$ \\
Experience & 0.033 & 0.102 & 0.320 \\
Education & -0.282 & 0.125 & -2.255 \\
Teaches High School & -0.056 & 0.186 & -0.301 \\
Teaches Middle School/Junior High & 0.393 & 0.205 & 1.917 \\
Evaluation Tied to PT or Merit Pay & 0.093 & 0.099 & 0.937 \\
Evaluation Not Ticd to PT or Merit Pay & 0.050 & 0.175 & 0.285 \\
Unions & 0.230 & 0.324 & 0.711
\end{tabular}

The assessment instrument presently used is

helpful in identifying areas of needed

personal growth and development

Correlation of learning and evaluation

Bands

$\begin{array}{rrr}0.625 & 0.172 & \underline{3.640} \\ 0.436 & 0.217 & 2.010 \\ 0.582 & 0.359 & 1.620 \\ 1.652 & 0.513 & \underline{3.218} \\ -0.030 & 0.108 & -0.280 \\ -0.281 & 0.133 & -2.118 \\ 0.240 & 0.197 & 1.220 \\ 0.642 & 0.218 & \underline{2.948} \\ 0.154 & 0.105 & 1.469 \\ -0.244 & 0.185 & -1.315 \\ 0.494 & 0.343 & 1.441\end{array}$

Orchestra

Choral

Experience

Education

Teaches High School

Teaches Middle School/Junior High

Evaluation Tied to PT or Merit Pay

Evaluation Not Tied to PT or Merit Pay

Unions

$\mathrm{R}^{2}=.215$

The person or persons performing my evaluation is/are qualified to make an accurate assessment of my abilities

Correlation of learning and evaluation

Bands

Orchestra

Choral

Experience

Education

Teaches High School

Teaches Middle School/Junior High

Evaluation Tied to PT or Merit Pay

Evaluation Not Tied to PT or Merit Pay

Unions

$\mathrm{R}^{2}=.157$

$\begin{array}{rrr}0.610 & 0.176 & \underline{3.471} \\ 0.392 & 0.222 & 1.763 \\ 0.247 & 0.368 & 0.670 \\ 1.340 & 0.526 & \underline{2.546} \\ -0.187 & 0.111 & -1.686 \\ -0.094 & 0.136 & -0.695 \\ 0.191 & 0.202 & 0.944 \\ 0.312 & 0.223 & 1.397 \\ 0.021 & 0.108 & 0.194 \\ -0.073 & 0.190 & -0.386 \\ 0.057 & 0.352 & 0.163\end{array}$




\begin{tabular}{|c|c|c|c|}
\hline Question & $\begin{array}{c}\text { Correlation } \\
\text { Estimate }\end{array}$ & $\begin{array}{l}\text { Standard } \\
\text { Errors }\end{array}$ & $t$-statistic \\
\hline \multicolumn{4}{|l|}{$\begin{array}{l}\text { The assessment process affects my sense of } \\
\text { job satisfaction }\end{array}$} \\
\hline Correlation of learning and evaluation & -0.081 & 0.178 & -0.453 \\
\hline Bands & 0.438 & 0.226 & 1.941 \\
\hline Orchestra & 0.163 & 0.374 & 0.435 \\
\hline Choral & 0.816 & 0.534 & 1.528 \\
\hline Experience & -0.285 & 0.113 & -2.537 \\
\hline Education & -0.130 & 0.138 & -0.943 \\
\hline Teaches High School & 0.303 & 0.205 & 1.479 \\
\hline Teaches Middle School/Junior High & 0.136 & 0.226 & 0.599 \\
\hline Evaluation Tied to PT or Merit Pay & 0.125 & 0.109 & 1.147 \\
\hline Evaluation Not Tied to PT or Merit Pay & 0.018 & 0.193 & 0.096 \\
\hline $\begin{array}{l}\text { Unions } \\
\mathrm{R}^{2}=.158\end{array}$ & 0.498 & 0.357 & 1.394 \\
\hline \multicolumn{4}{|l|}{$\begin{array}{l}\text { My personal sense of job satisfaction is } \\
\text { high }\end{array}$} \\
\hline Correlation of learning and evaluation & 0.428 & 0.136 & 3.150 \\
\hline Bands & 0.043 & 0.172 & 0.248 \\
\hline Orchestra & 0.055 & 0.284 & 0.195 \\
\hline Choral & -1.208 & 0.406 & -2.973 \\
\hline Experience & 0.177 & 0.086 & $\underline{2.069}$ \\
\hline Education & 0.129 & 0.105 & 1.234 \\
\hline Teaches High School & 0.149 & 0.156 & 0.957 \\
\hline Teaches Middle School/Junior High & 0.229 & 0.172 & 1.330 \\
\hline Evaluation Tied to PT or Merit Pay & 0.159 & 0.083 & 1.915 \\
\hline Evaluation Not Tied to PT or Merit Pay & -0.412 & 0.147 & -2.809 \\
\hline Unions & -0.206 & 0.272 & -0.758 \\
\hline
\end{tabular}

The section comparing Person or Persons Performing my Evaluation is/are Qualified to Make an Accurate Assessment of my Abilities was significantly affected when the training attributes matched the assessment attributes $(t=3.471)$. There was also a positive relationship for choral conductors $(t=2.546)$ but not for any of the other attributes in this section. None of the variables in the Assessment Process Affects my Sense of Job Satisfaction section had a strong effect with the exception of education, which had a negative relationship. 
The final section, My Personal Sense of Job Satisfaction is High, had a strong relationship when conductors were evaluated on the same attributes on which they were trained $(t=3.150)$ and for conductors with more experience $(t=2.069)$. However, choral directors and conductors, whose evaluations were not tied to merit pay, had a negative relationship with job satisfaction. None of the other variables in this section demonstrated a strong correlation. 


\section{CHAPTER V}

\section{SUMMARY, DISCUSSION, AND CONCLUSIONS}

This chapter is divided into four sections. The first section summarizes the importance of the findings of the study and their relevance to the literature on conductor assessment. The second section contains a brief discussion of the findings in the study. The third section contains conclusions made by the researcher. The fourth and final section provides a recommended framework for public school administrators to consider when designing instruments and processes to evaluate conductor effectiveness and to promote professional growth.

\section{Summary}

The study findings are presented in the same order as the three research questions outlined in Chapter I.

RQ1. To what extent did the conductors' formal training match up with the musical attributes requisite for adequate conducting skill and musical performance?

Most conductors perceived that the preparation attributes outlined in the survey were important for adequate conducting skill and musical performance. Survey results supported the literature as to the importance of formal conducting and musical training relative to successful musical performance. Respondents posted generally high indications that the training they had received as part of their formal education was 
indeed important to quality musical performance. Results in the section, personal and preparation attributes for teachers, indicated high means with nonverbal instruction such as right hand instruction $(M=4.674) ;(I=$ strongly disagree, $5=$ strongly agree $)$, left hand instruction $(M=4.532)$, and eye contact $(M=4.688)$. Personal performance skills $(M=4.801)$, sight-singing $(M=4.865)$, modeling musical concepts $(\mathrm{M}=4.553)$, and score study $(M=4.596)$ all had high mean values.

Teaching specific musical concepts also had high linkage to formal training. In the section, specific attributes related to musical skills/learning objectives taught to students, articulation $(M=4.752)$, rhythm $(M=4.851)$, tone quality $(M=4.837)$, and pitch discrimination $(M=4.752)$ were all examples of high mean values. Within the section, personal and preparation attributes for teachers, improvisation skills $(M=$ 3.511), accompanying skills $(M=3.809)$, and within the teaching delivery attributes section, classroom management and control $(M=3.546)$, and leadership skills $(M=$ 3.887) had slightly lower mean values but were still determined to be important by the respondents.

RQ2. Did the conductors perceive that their review process evaluated these same musical attributes?

Conductor responses about their perceived assessment focus by school administrators showed lower correlations than did the responses to formal training. Attributes that were not statically significant $(p>.05)$ and that demonstrated a lack of correlation between conductor training and assessment with the personal and preparation attributes for teachers section included nonverbal gestures $(p=0.734)$, right hand instruction $(p=0.227)$, left hand instruction $(p=0.681)$, and facial expressions $(p=$ 
0.325 ), which all exhibited a large disparity in the results. Similarly, in the personal and preparation attributes for teachers section, performance skills $(p=0.499)$, sight-singing skills $(p=0.723)$, rehearsal pacing skills and techniques $(p=0.211)$, and current repertoire teaching methods $(p=0.143)$ scored low correlations. Not surprisingly with the section teaching delivery attributes, attributes that were statistically significant $(p<$ $.05)$ including measuring the quality of verbal instruction $(p=0.023)$, leadership skills and personality traits $(p=0.007)$, and classroom control and management $(p=0.013)$, all demonstrated higher correlations as evidenced by the conductor responses related to their respective administrators' ability to judge these attributes.

RQ3. To what extent did the review process contribute to their job satisfaction?

When there was higher correlation between the respondents' formal training and the attributes they were evaluated on, they reported a higher correlation with job satisfaction $(r=0.808)$. There was no difference, however, in how the assessment process affected their overall job satisfaction $(r=-.081)$.

\section{Discussion}

Researchers studying conductor evaluation provided evidence that effective tools for evaluation of band and orchestra conductors are prevalent throughout the music education literature. Public school administrators, however, are generally unaware of that literature and often lack adequate assessment instruments to measure conductor effectiveness in rehearsal settings. Given the specialized training that music teachers must complete to achieve certification, it is unfair to expect administrators to evaluate music teachers without having the requisite knowledge of assessment guidelines associated with 
those teachers' daily teaching responsibilities. Evaluation instruments used by public school administrators, typically designed for classroom teaching evaluation, offer little or no relevance specific to music instruction and delivery indigenous to the performance medium.

The researcher was assisted by the state professional organization Michigan State Band and Orchestra Association (MSBOA) that serves conductors and music teachers K12. That assistance in providing a quality pool of respondents $(N=1,061)$ was helpful to the success of the survey. The survey results and conclusions were important to MSBOA as part of their ongoing efforts to provide assistance to conductors. Paul Lichau, Executive Director of MSBOA, supported the study to align the present assessment instruments used in the state with the formal training that conductors receive as evidenced in the findings of the literature review.

Most of the studies cited in the literature review focused on individual districts or schools while this research study focused on all conductors in the State of Michigan. The researcher has been able to develop a recommended framework for an instrument based on the feedback from conductors in the state.

Respondents $(n=173)$ provided a good return $(16.3 \%)$ on the survey. Respondents provided strong fcedback to the musical attributes compared to the findings of the literature review. Additionally, the respondents reacted strongly to evaluation processes with a lack of assessment attributes related to their formal training.

The literature review is replete with examples of conducting skill attributes, musical preparation attributes, and teaching attributes that researchers determined were important aspects of conductor training and assessment. Taebel (1990) compared the 
performance of music teachers with non-music teachers using competencies such as demonstrating musicianship through accurate rehearsal diagnosis, regular eye contact, appropriate facial expressions and physical gestures, speaking intensity, non-verbal communication techniques, positive feedback, framing rehearsals with repertoire that is popular with the performers, and varying amounts of direct and indirect methods of teaching. Yarbrough and Price (1981) studied issues related to aspects of instructional delivery, particularly conductor-student eye contact.

Byo and Austin (1994) sought to devise a field test for nonverbal conducting behaviors including right arm/hand gestures, eye contact, facial expression, and body movement. Johnson, Fredrickson, Achey, and Gentry (2003) studied examples of nonverbal gesture research that compared conductor training with performance outcomes of students using five basic elements of conducting: right arm movement, left arm movement, eye contact, facial expression, and body movement. Duke and Blackman (1991) used four teaching evaluation variables reinforces correct responses, gives corrective feedback, reinforces appropriate behavior, and gives corrective social feedback as a basis of their research.

Several studies compared attributes used in the evaluation of conductors. A research study by Gumm (1993) sought to develop a reliable and valid self-report instrument designed to assess teaching style. Fredrickson (1994) studied the effects that pre-conducting behaviors have on musician perception of conductor effectiveness. Bergee (1992) created a scale to assess music student teacher effectiveness in rehearsal focusing primarily on conducting techniques. Madsen (2003) studied how the accuracy 
and delivery of teacher instruction, coupled with student attentiveness, affected subsequent evaluations of teacher effectiveness.

Sang (1985) focused on the teacher-student interaction in the classroom and sought support for a theoretical model for instructional effectiveness evaluating beginning music teachers focusing on three primary areas of instruction: (a) the teacher demonstrates essential music performance elements; (b) the teacher identifies student performance problems; and (c) the teacher assesses and corrects student musical problems. De Nicola (1990) investigated the historical aspects of instructional language to define an evaluation instrument for preservice elementary and music education majors and included such areas as: subject-matter vocabulary, clarity, fluency, grammar, and articulation. The study provided an appropriate instrument for evaluating teacher effectiveness.

Table 1 highlighted the most frequent conducting and teaching attributes compiled from nearly 100 research studies. These attributes formed the basis for the survey and were divided into four sections. The first section of attributes was related to physical conducting gestures and nonverbal gestures. These attributes included right and left hand gestures, eye contact, facial expressions, body posture, and other nonverbal forms of communication. This section is particularly important for untrained evaluators as they may not be aware of the physical nuances associated with conducting. Accomplished conductors provided great amounts of information through their gestures, facial expressions, and physical reactions to the performers as part of an unspoken musical conversation. This unspoken conversation is comprised of a large repertoire of physical movements that must be first learned by the conductor, demonstrated to the 
performers in rehearsal, and then utilized during performance. Rehearsals offer the opportunity to stop in the midst of a particular passage and verbally explain what is wanted musically by the conductor. Live performance settings do not allow for verbal dialogue, so these unspoken musical conversations are important for achieving high levels of direction and response to the performers' musical efforts.

The second section related to personal and preparation attributes for teachers. These attributes encompassed teaching attributes, planning and preparation skills, score study, accompanying skills, performance skills, and other musical skills. These attributes are related to the development of basic teaching skills, music performance skills, and preparation attributes for teaching music. These attributes are often difficult for administrators to evaluate as many cannot be observed directly. Experienced conductors can determine proficiency in these attributes by the manner in which rehearsals are conducted, instructions given, and how efficiently observed subjects are able to correct and provide musical leadership.

The third section contained elements of musical and teaching delivery attributes. These skills included basic teaching delivery attributes, detection methods, and classroom management skills. The fourth and final section was related to the knowledge and application of core musical concepts and basic musicianship skills.

The lower rankings within the section comparing professional training may be more a result of the degree of broadness across the music training curriculums than a reflection of their importance to quality musical performance. In the section comparing personal and preparation attributes for teachers, these attributes are similar to those commonly observed and evaluated when scoring traditional delivery classroom teachers. 
Additional research may answer the question whether the knowledge of the specific attributes in the administrator's assessment instrument are known to the conductor.

\section{A Recommended Framework for Public School Administrators}

When undergraduate conducting students receive their student teaching assignments, they also receive notification of their cooperating teacher and their supervisory teacher assignments. As a young conductor in a critical developmental stage, the student teacher is assigned a master or cooperating teacher that they will work with over the course of a semester or more. This cooperating teacher is usually a veteran teacher and conductor who has responsibility for several public school ensembles. Over the course of the student teaching assignment, the student teacher has numerous opportunities to conduct and to receive feedback from the cooperating teacher. Lessons plans are often shared, proper preparation is usually discussed, and feedback is offered after each conducting session.

In much the same manner, the supervisory teacher, typically a faculty member from a college or university, offers advice and feedback for all aspects of these conducting assignments. Preparation, delivery, and regular feedback are all normal components of the student teaching assignment. Upon successful completion of predetermined attributes as part of this experience, the student teacher completes their semester with the cooperating teacher and moves on to graduation and certification as a music educator and begins their career as a music conductor.

The contrast between this first regular conducting experience as a student teacher and the responsibilities expected of a young conductor in their first teaching position, 
often just months later, is often stark and quite dramatic. Months earlier, the young conductor learned and grew daily with their accompanying cooperating teacher by their side and those daily observations were complemented with regular visits from their supervisory teacher. Suddenly, in late August or early September, they are thrust into a teaching role without the same feedback, encouragement, and ongoing mentoring. Partnerships between individual school districts and local colleges, regional universities, state music organizations, retired conductors, and master teachers could include both student teaching assignments and, for the first three years, a scheduled number of visits to the new conductor's classroom by local music educators. After this first three year period, the assessment and mentorship connections could then be reduced to yearly evaluations and consultations. Higher education or state entities, which often seek student teaching sites at nominal or nonexistent compensation rates, should be expected to continue their relationships with area school systems by evaluating and mentoring music conductors employed in the those schools.

This three-year intensive timeframe would coincide with the time period needed for achieving tenure in most public schools. All assessments and the corresponding suggestions for further training or development would be done with the school administrator present. This relationship is important not only from the standpoint of delivering an effective assessment, but equally important is the perspective of mentoring and continued growth advice and accompanying opportunities. Armed with knowledge and advice from music faculty, retired teachers, master teachers, or personnel from state music agencies, administrators could not only provide a more accurate yearly assessment of the conductor and support invaluable ideas for further growth and training, but they 
could also move forward knowing that the students in their school are being taught by competent and engaged music conductors and teachers. This type of ongoing relationship with qualified music educators would be a tremendous resource for school systems desiring the very best music instruction for their children. (This same type of relationship could certainly exist in other non-traditional teaching programs in various subject areas taught in the schools.)

Tenured music conductors in the school system would be assigned the duty of maintaining these relationships with these external music assessment individuals in the same way they cultivate musicians and conductors to serve as guest conductors, perform clinics, adjudicate performances, and offer other assistance to the music program. Music programs spend significant amounts of money for this type of assistance for the students; providing a similar network of professionals for appropriate evaluative assistance and qualified mentoring is important to the ultimate success of the music program. The conductor is certainly the main ingredient to the success of any music program, so they should be afforded the same level of support as their students experience in their music programs. The cost of hiring and training new conductors on a too frequent basis, because of burnout or lack of success with their programs, should be weighed against the cost of providing ongoing mentoring and appropriate evaluative processes.

Table 5 offers a recommended framework for music conductor assessment and an evaluation cycle for use in Michigan public schools. The suggested timing of the evaluations includes two evaluations a year for the first three years (pre-tenure) held in the fall and again in the spring. This is an especially important time for young conductors to receive regular feedback and guidance in all four areas of evaluation: physical 
conducting/nonverbal attributes; personal and preparation attributes; teaching delivery attributes; and musical skills/learning objectives. Twice yearly evaluations give the young conductor an opportunity to grow and continue their musical and educational growth following their formal training received in school. After the conductor receives tenure at the end of year three, evaluations are held on a yearly basis unless the public school administrator requests additional evaluations. If there is a concern about the tenured conductor's performance in a given year, the public school administrator has the option to include the master conductor in these additional evaluations.

For the fall evaluation during the first three years, school administrators would be accompanied by university conductors or retired conductors living in the region. This gives the public school conductor the opportunity for expert advice from the master conductor and helps the public school administrator learn how to assist the conductor throughout the school year. As the public school administrator may not have adequate training to identify traits of effective conducting, this partnership with master conductors would be invaluable for assessing the skills and musical attributes of public school conductors, and also may assist administrators with providing ongoing guidance, funds for additional training, and sources of quality mentors.

The timing of the fall evaluation is an important consideration when scheduling the yearly evaluation. Band directors who conduct marching bands in the fall may need two separate evaluations in the fall that include master conductors and educators skilled in the attributes for a successful marching band program and for a concert band program. These master conductors and marching band experts may be one in the same and it is 
important to note that all of the attributes articulated in the study are equally important in the concert hall and on the gridiron. 
Table 5: Conductor Evaluation Schedule

\begin{tabular}{|c|c|c|c|c|c|}
\hline $\begin{array}{l}\text { Frequency of } \\
\text { Evaluation }\end{array}$ & $\begin{array}{c}\text { Physical } \\
\text { Conducting/ } \\
\text { Nonverbal }\end{array}$ & $\begin{array}{c}\text { Personal and } \\
\text { Preparation } \\
\text { Attributes }\end{array}$ & $\begin{array}{l}\text { Teaching } \\
\text { Delivery } \\
\text { Attributes }\end{array}$ & $\begin{array}{c}\text { Musical } \\
\text { Skills/ } \\
\text { Learning } \\
\text { Objectives }\end{array}$ & Evaluators \\
\hline Year 1 - Fall & $\mathbf{X}$ & $\mathbf{X}$ & $\mathbf{X}$ & $\mathbf{X}$ & $\begin{array}{l}\text { Univ/Retired Conductor } \\
\text { School Administrator }\end{array}$ \\
\hline Year 1 - Spring & $\mathbf{X}$ & $\mathbf{x}$ & $\mathbf{x}$ & $\mathbf{X}$ & School Administrator \\
\hline Year 2 - Fall & $\mathbf{X}$ & $\mathbf{X}$ & $\mathbf{x}$ & $\mathbf{X}$ & $\begin{array}{l}\text { Univ/Retired Conductor } \\
\text { School Administrator }\end{array}$ \\
\hline Year 2 - Spring & $\mathrm{X}$ & $\mathbf{X}$ & $\mathbf{X}$ & $\mathbf{x}$ & School Administrator \\
\hline Year 3 - Fall & $\mathbf{x}$ & $\mathbf{x}$ & $\mathbf{X}$ & $\mathbf{x}$ & $\begin{array}{l}\text { Univ/Retired Conductor } \\
\text { School Administrator }\end{array}$ \\
\hline Year 3 - Spring & $\mathbf{X}$ & $\mathbf{X}$ & $\mathbf{X}$ & $\mathbf{X}$ & $\begin{array}{l}\text { Univ/Retired Conductor } \\
\text { School Administrator }\end{array}$ \\
\hline Year 4 - Spring & $\mathbf{x}$ & & $\mathbf{x}$ & $\mathbf{X}$ & School Administrator \\
\hline Year 5 - Spring & $\mathrm{x}$ & $\mathbf{x}$ & & $\mathbf{x}$ & $\begin{array}{l}\text { Univ/Retired Conductor } \\
\text { School Administrator }\end{array}$ \\
\hline Year 6 - Spring & $\mathbf{x}$ & & $\mathbf{x}$ & $\mathbf{X}$ & School Administrator \\
\hline Year 7 - Spring & $\mathbf{X}$ & $\mathbf{X}$ & & $\mathbf{X}$ & $\begin{array}{l}\text { Univ/Retired Conductor } \\
\text { School Administrator }\end{array}$ \\
\hline Year 8 - Spring & $\mathbf{X}$ & & $\mathbf{x}$ & $\mathbf{x}$ & School Administrator \\
\hline Year 9 - Spring & $\mathbf{X}$ & $\mathbf{x}$ & & $\mathbf{x}$ & School Administrator \\
\hline Year 10 - Spring & $\mathbf{x}$ & & $\mathbf{x}$ & $\mathbf{x}$ & $\begin{array}{l}\text { Univ/Retired Conductor } \\
\text { School Administrator }\end{array}$ \\
\hline
\end{tabular}

In the first three years, all four areas of assessment would be included in the evaluations of the conductors: physical conducting/nonverbal attributes; personal and preparation attributes; teaching delivery attributes; and musical skills/learning objectives. The frequency of evaluating these attributes diminishes after receiving tenure but may be included in the yearly evaluation at the request of the public school administrator or the master conductor. Personal and preparation attributes and teaching delivery attributes are given priority in alternate years while physical conducting/nonverbal attributes and musical skills/learning objectives should be evaluated each year.

Table 6 outlines the specific attributes under each of the four areas for use by the evaluators. These four areas were drawn from the research literature. Study results 
supported the validity of that literature source as to the importance of formal conducting and musical training relative to successful musical performance. The scale may be altered to fit in with other evaluative scales used in the public school system. Attributes for evaluative purposes may be added or subtracted per the varying conducting and teaching responsibilities of each conductor as agreed upon by the public school administrator. The area under Suggested Professional Development provides an opportunity for the master conductor, in conjunction with the school administrator, to prescribe meaningful opportunitics to facilitate growth, improve deficiencies, and document efforts by the conductor to continue his or her development. This process provides a documented history of the evaluations and the suggested actions prescribed jointly by the master conductor and the public school administrator. 


\section{Table 6: Music Conductor Evaluation Worksheet}

\author{
Conducting/Teaching Attribute \\ Physical conducting/ \\ Nonverbal attributes \\ Nonverbal gestures \\ Right hand conducting gestures \\ Left hand conducting gestures \\ Facial expressions \\ Eye contact \\ Other
}

Personal and preparation attributes Music history and ensemble repertoire Performance skills

Sight singing skills and ear training

Modeling musical concepts

Score study and rehearsal preparation

Accompanying and arranging skills

Other

Teaching delivery attributes

Error detection skills

Quality of verbal instruction

Leadership skills, personality traits

Classroom control and management

Current repertoire of teaching methods

Rehearsal pacing skills and techniques

Expressive interpretation

Other

Musical skills/learning objectives

Rehearsal attentiveness

Note accuracy/technical skills

Articulation and sluming

Style and phrasing

Rhythm

Tone quality

Pitch discrimination/intonation

Balance and blend concepts

Dynamics

Improvisation and composition

Ear to hand/aural training

Sight singing/sight reading

Other

Conductor Name and School

Public School Administrator Name

Master Conductor, Affiliation
Highly

Successtul

\section{Successful Satisfactory}

Needs

Improvement 
Conclusions by the Researcher

After examining the survey results, the researcher concluded that conductors in the State of Michigan generally perceived that their evaluation process does not adequately measure the quality of their work in rehearsals and is not a good indicator of their abilities. Furthermore, many of the respondents felt that many administrators performing their evaluation were not qualified to adequately assess their work during rehearsals. These administrators often lacked the necessary background or training to adequately assess a conductor's work and then promote future growth and development. Additionally, when conductors were evaluated on things they had learned, they felt the process was helpful and their job satisfaction was higher. The researcher suggests that a good assessment process that contains measurable attributes that were part of the conductor's formal training is a good predictor of job satisfaction. This job satisfaction may lead to greater employee retention, which can lead to improved continuity of program and an overall better experience for the students.

With increasing demands on administrators in the State of Michigan to provide accountability in their buildings and their school districts, administrators are faced with the need for even more scrutiny of the effectiveness of teachers and for selection of appropriate measurement instruments. This demand is problematic when considering the myriad of subjects taught in the public schools. It would be impossible for administrators to have the requisite knowledge, across the spectrum of disciplines, to assess effectively their teachers in an appropriate manner. This is especially true for conductors, who by nature of the type of subject matter taught, do not teach in a normal classroom lecture format. Art teachers, foods and nutrition instructors, physical education teachers, 
coaches, school media specialists, and music conductors are examples of non-traditional course delivery disciplines which need a specialized assessment instrument to effectively measure these teachers in a variety of settings.

When providing viable assessment methods, evaluators must first determine whether the conductor is performing their duties appropriately from the podium and teaching effectively. Then they must also recommend appropriate training, education, or mentorship to facilitate ongoing growth and development. Without the proper background or training, it is difficult for the administrator to prescribe appropriate remedies or courses of action, given their general lack of understanding of the discipline, their limited knowledge of suitable professional organizations to recommend, and incomplete information on degree programs or other forms of training that would be helpful. As in many of the other non-traditional teaching disciplines, having a sense of how conductors might or should continue their growth and become experienced conductors is critically important to the evaluation process.

The literature review provided innumerable examples of the many courses and teaching methods that colleges and universities use to train conductors as part of their formal undergraduate or graduate education. Conducting workshops, professional music organizations, and other forms of continuing education offerings provide conductors opportunities to continue their growth and improve their skills post-graduation.

In all non-traditional delivery disciplines, school systems must find new and innovative ways to refocus their evaluative processes to align the annual assessment and subsequent growth opportunities with the idiosyncrasies of these varied areas of 
discipline. The final section of this chapter outlines a recommended framework for administrators to use to effectively assess music conductors.

\section{Final Recommendations}

Having qualified assessment and mentoring for conductors and music teachers at the elementary, middle school, and high school levels would increase continuity for the music programs in those schools through improved retention of teachers and provide a quality musical experience for children throughout their public school education. Policy makers are charged with providing the highest quality instruction for our students. Therefore, we owe our conductors and music teachers the opportunity for a quality assessment process and ongoing opportunities for growth and mentoring. The State of Michigan has a vast supply of qualified music faculty across the state, whether faculty at colleges and universities, retired master conductors and teachers, or other conducting professionals, who could make this process a reality in the near future. 


\section{REFERENCES}

Bergee, M. J. (1992). A scale assessing music student teacher's rehearsal effectiveness. Journal of Research in Music Education, 40, 5-13.

Bergee, M. J. (1995). Primary and higher-order factors in a scale assessing concert band performances. Bulletin of the Council for Research in Music Education, 126, 114.

Blocher, L., Greenwood, R., \& Shellahamer, B. (1997). Teaching behaviors of middle school and high school band directors in the rehearsal setting. Journal of Research in Music Education, 45, 457-469.

Brendell, J. K. (1996). Time use, rehearsal activity, and student off-task behavior during initial minutes of high school choral rehearsals. Journal of Research in Music Education, 44, 6-14.

Brophy, J., \& Evertson, C. (1976). Learning from teaching: A developmental perspective. Boston: Allyn and Bacon.

Brophy, J., \& Good, T. L. (1986). Teaching behavior and student achievement. Wittrock, M. C. (Ed.). Handbook of Research on Teaching. New York: Macmillan Publishers.

Byo, J. L. (1999). Classroom teachers' and music specialists' perceived ability to implement the national standards for music education. Journal of Music Education, 47, 111-123.

Byo, J. L. (1990). Recognition of intensity contrasts in the gestures of beginning conductors. Journal of Research in Music Education, 38, 157-163.

Byo, J. L., \& Austin, K. R. (1994). Comparison of expert and novice conductors: an approach to the analysis of nonverbal behaviors. Journal of Band Research, 30(1), 11-34.

Cattell, R. B. (1978). The scientific use of factor analysis in behavioral and life sciences. New York: Plenum Press.

Chilcoat, G. W. (1987). Teacher talk: Keep it clear. Academic Therapy, 22, 263-271. 
Clark, C., Gage, N., Marx, R., Peterson, P., Stayrook, N., \& Winne, P. (1979). A factorial experiment on teacher structuring, soliciting, and reacting. Journal of Educational Psychology, 71, 534-552.

Cofer, R. S. (1998). Effects of conducting-gesture instruction on seventh-grade band students' performance response to conducting emblems. Journal of Research in Music Education, 46, 360-373.

Coleman, J., Campbell, E., Hobson, C., McPartland, J., Mood, A., Weinfield, F., \& York, R. (1966). Equality of educational opportunity. Washington, DC: U.S. Office of Health, Education, and Welfare.

Conway, C. M. (1999). The development of teaching cases for instrumental music methods courses. Journal of Research in Music Education, 47, 343-356.

Cooksey, J. M. (1977). A facet-factorial approach to rating high school choral music performance. Journal of Research in Music Education, 25, 100-113.

Cox, J. (1989). Rehearsal organizational structures used by successful high school choral directors. Journal of Research in Music Education, 37, 201-218.

Crowe, D. R. (1996). Effects of score study style on beginning conductors' errordetection abilities. Journal of Research in Music Education, 44, 160-171.

Davis, A. P. (1998). Performance achievement and analysis of teaching during choral rehearsals. Journal of Research in Music Education, 46, 496-509.

Davidson, J. W., Moore, D. G., Sloboda, J A., \& Howe, M. J. (1998). Characteristics of music teachers and the progress of young instrumentalists. Journal of Research in Music Education, 46, 141-160.

De Nicola, D. N. (1990). Historical perspectives on instructional language as applied to an assessment of preservice teachers. Journal of Research in Music Education, $38,49-60$.

Dickey, M. R. (1991). A comparison of verbal instruction and nonverbal teacher-student modeling in instrumental ensembles. Journal of Research in Music Education, 39, 132-142.

Dillman, D. A. (2007). Mail and internet surveys: The tailored design method (2nd ed.). New York: John Wiley and Sons.

Doerksen, P. F. (1999). Aural-diagnostic and prescriptive skills of preservice and expert instrumental music teachers. Journal of Research in Music Education, 47, 78-88. 
Duke, R. A., (1983). The effects of laboratory and field-based teacher training on observation and teacher responses. Music Educators National Conference Southern Division Research Presentation, Louisville, Kentucky.

Duke, R. A., \& Blackman, M. D. (1991). The relationship between observers' recorded teacher behavior and evaluation of music instruction. Journal of Research in Music Education, 39, 290-297.

Duke, R. A., \& Prickett, C. A. (1987). The effect of differentiating focused observation on the evaluation of instruction. Journal of Research in Music Education, 35, 27 37.

Duke, R. A., Prickett, C. A., \& Jellison (1998). Empirical description of the pace of music instruction. Journal of Research in Music Education, 46, 265-280.

Edwards, C. M. Jr. (1986). An "effective teaching" approach to teacher evaluation and staff development. ERS Spectrum, 4, 3-8.

Fiese, R. K. (1991). The relationship among conductors' rankings of three unfamiliar wind band scores. Journal of Research in Music Education, 39, 239-247.

Flanders, N. (1970). Analyzing teacher behavior. Reading, MA: Addison-Wesley.

Fredrickson, W. E. (1994). The effect of pre-conducting and conducting behaviors on the evaluation of conductor competence. Journal of Band Research, 33(2), 1-12.

Fredrickson, W. E. (1994). Band musicians' performance and cye contact as influenced by loss of a visual and/or aural stimulus. Journal of Research in Music Education, 42, 306-317.

Froehlich, H. (1977). The relationship of selected observational variables to the teaching of singing. Journal of Research in Music Education, 25, 115-130.

Garofalo, R. J., \& Whaley, G. (1979). Comparison of the unit study and traditional approaches for teaching music through school band performance. Journal of Research in Music Education, 27, 137-142.

Good, T., \& Grouws, D. (1977). Teaching effects: A process-product study in fourth grade mathematics classrooms. Journal of Teacher Education, 28, 49-54.

Goodstein, R. E. (1987). An investigation into leadership behaviors as descriptive characteristics of high school band directors in the United States. Journal of Research in Music Education, 35, 13-25. 
Goolsby, T. W. (1999). A comparison of expert and novice music teachers preparing identical band compositions: An operational replication. Journal of Research in Music Education, 47, 174-187.

Goolsby, T. W. (1997). Verbal instruction in instrumental rehearsals: A comparison of three career levels and preservice teachers. Journal of Research in Music Education, 45, 21-40.

Goolsby T. W. (1996). Time use in rehearsals: A comparison of experienced, novice, and student teachers. Journal of Research in Music Education, 44, 286-303.

Grant, J. W., \& Drafall, L. E. (1991). Teacher effectiveness research: A review and comparison. Bulletin of the Council for Research in Music Education, 108, 31-48.

Grobe, R. P., \& Pettibone, T. J. (1975). Effect of instructional pace on student attentiveness. Journal of Educational Research, 69, 131-134.

Gumm, A. J. (1993). The development of a model and assessment instrument of choral music teaching styles. Journal of Research in Music Education, 41, 181-199.

Hamann, D. L., Baker, D. S., McAllister, P. A., \& Bauer, W. I. (2000). Factors affecting university music students' perception of lesson quality and teaching effectiveness. Journal of Research in Music Education, 48(2), 102-113.

Hamann, D., Lineburgh, N., \& Paul, S. (1998). Teaching effectiveness and social skill development. Journal of Research in Music Education, 46, 87-101.

Hamann, D. L., Mills, C., Bell, J., Daugherty, E, \& Koozer, R. (1990). Classroom environment as related to contest ratings among high school performing ensembles. Journal of Research in Music Education, 38, 215-224.

Hendel, C. H. (1995). Behavioral characteristics and instructional patterns of selected music teachers. Journal of Research in Music Education, 43, 182-203.

Johnson, C. M., Fredrickson, W. E., Achey, C. A., and Gentry, G. R. (2003). The effect of nonverbal elements of conducting on the overall evaluation of student and professional conductors. Journal of Band Research, 38(2), 64-77.

Keely, S. N. (1997). Effects of conducting instruction on the musical performance of beginning band students. Journal of Research in Music Education, 45, 295-305.

King, G. (1998). Exemplary music educator: A case study. Bulletin of the Council for Research in Music Education, 137, 57-72. 
Kraus, B. N., Gonzalez, G. M., Hill, G. W., and Hunphreys, G. T. (2004). The effect of computer-generated feedback on the development of conducting students. Journal of Band Research, 39(2), 35-44.

Kvet, E. J., \& Watkins, R. C. (1993). Success attributes in teaching music as perceived by elementary education majors. Journal of Research in Music Education, 41, 70-80.

Larson, R. C. (1977). Relationships between melodic error detection, melodic dictation, and melodic sight singing. Journal of Research in Music Education, 25, 264-271.

Madsen, C. K. (2003). The effect of accuracy of instruction, teacher delivery, and student attentiveness on musicians' evaluation of teacher effectiveness. Journal of Research in Music Education, 51, 38-50.

Madsen, C. H., \& Madsen, C. K. (1983). Teaching/discipline: A positive approach to educational development. Raleigh, N.C.: Contemporary Publishing Co.

Madsen, C. K., Standley, J. M., \& Cassidy, J. W. (1989). Demonstration and recognition of high and low contrasts in teacher intensity. Journal of Research in Music Education, 37, 84-92.

Marchand, D. J. (1975). A study of two approaches to developing expressive performance. Journal of Research in Music Education, 23, 14-22.

Marsh, J., \& Wilder, E. (1954). Identifying the effective instructor: A review of the quantitative studies 1900-1952. Air Force Research Bulletin, A-FPTRC-T-54-44, $1-151$.

McCoy, C. W. (1991). Grading students in performing groups: A comparison of principals' recommendations with directors' practices. Journal of Research in Music Education, 39, 181-190.

McPherson, G. E. (1994). Factors and abilities influencing sight-reading skill in music. Journal of Research in Music Education, 42, 217-231.

Medley, D. (1979). The effectiveness of teachers. Petersen, P. \& Walberg, H. (Eds.). Research on Teaching: Concepts, findings, and implications. Berkeley, CA: McCutchan.

Merriman, S. B. (1988). Case study research in education. San Francisco: Jossey-Bass.

Nuthall, G., \& Church, J. (1973). Experimental studies of teaching behaviour. Chanan, G. (Ed.). Towards a science of teaching. London: National Foundation for Educational Research. 
Popham, W. (1971). Performance tests of teaching proficiency: Rationale, development, and validation. American Educational Research Journal, 8, 105-117.

Porter, A. C., \& Brophy, J. (1988). Synthesis of research on good teaching: Insights from the work of the Institute for Research on Teaching. Educational Leadership, 45, 74-85.

Price, H. E. (1983). The effect of conductor academic task presentation, conductor reinforcement, and ensemble practice on performers' musical achievement, attentiveness, and attitude. Journal of Research in Music Education, 31, 245-257.

Ramsey, D. S. (1979). Programmed instruction using band literature to teach pitch and rhythm error detection to music education students. Journal of Research in Music Education, 27, 149-162.

Rogers, G. L. (1985). Attitudes of high school band directors and principals toward marching band contests. Journal of Research in Music Education, 33, 259-267.

Rosenshine, B. (1971). Teaching behaviors and student achievement. London: National Foundation for Educational Research.

Rosenshine, B., \& Furst, N. (1973). The use of direct observation to study teaching. Travers, R. M. (Ed.). Second Handbook on Research on Teaching. Chicago: Rand McNally.

Rutgers, A. P. (1998). Performance achievement and analysis of teaching during choral rehearsals. Journal of Research in Music Education, 46, 496-509.

Sagen, D. P. (1983). The development and validation of a university band performance rating scale. Journal of Band Research, 18, 1-11.

Sang, R. C. (1985). Path analysis of an instructional effectiveness model for instrumental music teaching. Bulletin of the Council for Research in Music Education, 85, 195 206.

Schmidt, C. P. (1992). Reliability of untrained observers' evaluations of applied music instruction. Bulletin of the Council for Research in Music Education, 112, 17-28.

Schmidt, M. (1998). Defining “good" music teaching: Four student teachers' beliefs and practices. Bulletin of the Council for Research in Music Education, 138, 19-46.

Skadsem, J. A. (1997). Effect of Conductor verbalization, dynamic markings, conductor gesture, and choir dynamic level on singers' dynamic responses. Journal of Research in Music Education, 45, 509-520. 
Soar, R. S. (1968). Optimum teacher-pupil interaction for pupil growth. Educational Leadership, 26, 275-280.

Spradling, R. L. (1985). The effect of timeout from performance on attentiveness of university band students. Journal of Research in Music Education, 33, 123-137.

Stallings, J., \& Kaskowitz, D. (1974). Follow through classroom evaluation 1972-1973 (SRI Project URU7370). Stanford, CA: Stanford Research Institute.

Standley, J. M., \& Madsen, C. K. (1991). An observation procedure to differentiate teaching experience and expertise in music education. Journal of Research in Music Education, 39, 5-11.

Stuart, M. (1974). The use of videotape recordings to increase teacher trainees' error detection skills. Journal of Research in Music Education, 22, 14-19.

Taebel, D. K. (1980). Public school music teachers' perceptions of the effect of certain competencies on pupil learning. Journal of Research in Music Education, 28, 185-197.

Taebel, D. K. (1990). An assessment of the classroom performance of music teachers. Journal of Research in Music Education, 38, 5-23.

Taebel. D. K., \& Coker, J. G. (1980). Teaching effectiveness in elementary classroom music: Relationships among competency measures, pupil product measures, and certain attribute variables. Journal of Research in Music Education, 28, 250-264.

Teachout, D. J. (1997). Preservice and experienced teacher's opinions of skills and behaviors important to successful music teaching, Journal of Research in Music Education, 45, 41-50.

VanWeelden, K. (2002). Relationships between perceptions of conducting effectiveness and ensemble performance. Journal of Research in Music Education, 50, 165176.

Wagner, M. J., \& Strul, E. P. (1979). Comparisons of beginning versus experienced elementary music educators in the use of teaching time. Journal of Research in Music Education, 27, 113-125.

White, K., Wyne, M. D., Stuck, G. B., \& Coop, R. H. (1987). Assessing teacher performance using an observation instrument based on research findings. $N A S S D$ Bulletin, 71, 89-95.

Whitener, W. T. (1983). Comparison of two approaches to teaching beginning band. Journal of Research in Music Education, 31, 5-13. 
Witt, A. C. (1986). Use of class time and student attentiveness in secondary instrumental music rehearsals. Journal of Research in Music Education, 34, 34-42.

Wolfe, D. E., \& Jellison, J. A. (1990). Music and elementary education student's evaluation of music-teaching scripts. The Journal of Research in Music Education, 38, 311-321.

Yarbrough, C. (1975). Effect of magnitude of conductor behavior on students in selected mixed choruses. Journal of Research in Music Education, 23, 134-146.

Yarbrough, C., \& Henley, P. (1999). The effect of observation focus on evaluations of choral rehearsal excerpts. Journal of Research in Music Education, 47, 308-318.

Yarbrough, C., \& Madsen, K. (1998). The evaluation of teaching in choral rehearsals. Journal of Research in Music Education, 46, 469-481.

Yarbrough, C., \& Price. B. (1981). Prediction of performer attentiveness based on rehearsal activity and teacher behavior. Journal of Research in Music Education, 29, 209-217.

Yarbrough, C., \& Price, H. E. (1989). Sequential patterns of instruction in music. Journal of Research in Music Education, 37, 179-187.

Yarbrough, C., Wapnick, J., \& Keely, R. (1979). Effect of videotape feedback techniques on performance, verbalization, and attitude of beginning conductors. Journal of Research in Music Education, 27, 103-112.

Yin, R. K. (1994). Case study research design and methods. Newbury Park, CA: Sage. 


\section{APPENDIX}

1. MSBOA pre-notice letter to participants

2. Letter from Eric Becher to participants

3. Reminder postcard sent to participants by Eric Becher

4. Second reminder postcard to participants

5. Thank you letter and reminder

6. Participant survey 
November 2010

Dear MSBOA member:

You are invited to participate in survey designed to compare the formal conductor training you received in college with the performance review indicators used by your school administrators. This study will compare the correlation between conductor training and school performance reviews. The primary investigator for the study is Dr. John Keedy and the co-investigator is Eric Becher. Eric was a former music faculty member at the University of Michigan and he is working to complete his Ph.D. in Higher Education Administration.

Results from this research study will be shared with MSBOA and will be made available to all members. All individual responses will be kept completely confidential. Your completed survey will be stored anonymously only for the duration of the study. The survey will take approximately 15 to 20 minutes to complete. You can access the survey by entering the following web address hitp:/ www surveymonkey.com/s/conductorsurveyebecher.

If you have any questions about the research study, please contact Eric Becher at (973) $290-4455$.

Sincerely,

Paul W. Lichau

Exccutive Director

Michigan School Band Orchestra Association 
November 2010

Dear MSBOA Member.

This is just a reminder to take part in a voluntary survey designed to compare the formal conductor training you received in college with the performance review indicators used by your school administrators. This study will compare the correlation between conductor training and school performance reviews.

The survey will take approximately 15 to 20 minutes to complete. You can access the survey by entering the following web address

http//www. surveymonkey.com/s/conductorsurveyebecher.

If you have any questions about the research study, please contact Eric Becher, the coinvestigator at (973) 290-4455.

Thank you!

Eric Becher 
December 2010

\section{Dear MSBOA Member.}

This is just a reminder to take part in a voluntary survey designed to compare the formal conductor training you received in college with the performance review indicators used by your school administrators. This study will compare the correlation between conductor training and school performance reviews.

The survey will take approximately 15 to 20 minutes to complete. You can access the survey by entering the following web address

hitp//www surveymonkey com/s/conductorsurveyebecher.

If you have any questions about the research study, please contact Eric Becher, the coinvestigator at (973) 290-4455.

Thank you!

Eric Becher 
January 2011

Dear MSBOA Member.

This is just a reminder to take part in a voluntary survey designed to compare the formal conductor training you received in college with the performance review indicators used by your school administrators. This study will compare the correlation between conductor training and school performance reviews. The study will be closing in the next two weeks and I would appreciate your response.

The survey will take approximately 15 to 20 minutes to complete. You can access the survey by entering the following web address

http:/www. survevmonkey.com/s/conductorsurveyebecher.

If you have any questions about the research study, please contact Eric Becher, the coinvestigator at (973) 290-4455.

Thank you!

Eric Becher 
January 2011

Dear MSBOA Member.

Thank you for taking part in a voluntary survey designed to compare the formal conductor training you received in college with the performance review indicators used by your school administrators. This study results will compare the correlation between conductor training and school performance reviews. The study is now closing; there are only a few days for you to complete your response.

The survey will take approximately 15 to 20 minutes to complete. You can access the survey by entering the following web address

http:/www surveymonkey.com/s/conductorsurveyebecher.

If you have any questions about the research study, please contact Eric Becher, the coinvestigator at (973) 290-4455.

Thank you for your participation!

Eric Becher 


\section{Participant Survey}

The questionnaire format is an online format and should take about 15 to 20 minutes to complete. Please complete the survey as soon as possible for proper and timely inclusion in the study.

All survey answers will remain confidential and will not be disclosed. No personal information will be shared, only the aggregate statistical information will be shared in published findings, in any future presentations by this researcher, and in any literature distributed by the Michigan School Band and Orchestra Association (MSBOA).

This survey is to be filled out by the respondent to the best of their ability given the present evaluation process used by their school district. Questions related to education and training are specific to the level of instruction and training received as of the date of this survey.

Thank you for your participation in this important research study. Please direct any question or comments to the study's primary investigator, Eric Becher, at eabecher@gmail.com.

\section{Conductor Demographic Data}

This section provides background information regarding your experience and training. It also provides basic questions concerning your workplace evaluation.

1. Are you currently a secondary school teacher in a Michigan school and a member of MSBOA?

a) I am a secondary school teacher in Michigan

b) If no, thank you for your participation in this survey

2. What ensembles do you conduct as part of your teaching responsibilities?
a) Band
b) Orchestra
c) Choral
c) More than one

3. How many years have you been conducting bands and/or orchestras in the public schools?
a) $0-2$ years
b) 3-7 years
c) $8-12$ years
d) 13 or more years

4. What is your highest degree attained?

a) Bachelor 
b) Master

c) Masters plus 30

d) $\mathrm{PhD}$ or $\mathrm{DMA}$

5. What school level do you conduct your primary ensemble? (Considered your primary teaching responsibility)

a) Middle School or Junior High

b) High School

c) More than one

6. How often are you evaluated?

a) More than twice a year

b) Twice a year

c) Once a year

d) Every several years

e) Never

7. Who does your evaluation?

a) Principal

b) Assistant Principal

c) Music Coordinator for the District

d) Department Chair

e) External evaluator

f) No one does my evaluation

8. Is your evaluation tied to promotion or tenure $(\mathrm{P} / \mathrm{T})$ or merit pay decisions?

a) Yes, this is part of the $\mathrm{P} / \mathrm{T}$ or merit pay process

b) No, this has no bearing on $\mathrm{P} / \mathrm{T}$ issues or merit pay

9. Are you part of a union or other collective bargaining group?

a) Yes

b) No

Formal Training vs. Current Assessment Instrument Used

Statements in this section relate to your education and the formal conductor training that you received both prior to being hired and since that time. Each statement compares your training with whether the evaluation instrument uses these same attributes. The statements ask you to rate the degree to which you agree with whether you received this type of training and whether the assessment currently used in your evaluation measures this attribute.

10. My conducting courses focused on nonverbal gestures.

Formal training

1) Strongly agree
Assessment instrument measured this attribute

1) Strongly agree 
2) Somewhat agree

3) Neither agree or disagree

4) Somewhat disagree

5) Strongly disagree
2) Somewhat agree

3) Neither agree or disagree

4) Somewhat disagree

5) Strongly disagree

11. I received right hand conducting development training.

Formal training

1) Strongly agree

2) Somewhat agree

3) Neither agree or disagree

4) Somewhat disagree

5) Strongly disagree
Assessment instrument measured this attribute

1) Strongly agree

2) Somewhat agree

3) Neither agree or disagree

4) Somewhat disagree

5) Strongly disagree

12. Left hand gesture development was an area of focus in my training.

Formal training

1) Strongly agree

2) Somewhat agree

3) Neither agree or disagree

4) Somewhat disagree

5) Strongly disagree
Assessment instrument measured this attribute

1) Strongly agree

2) Somewhat agree

3) Ncither agree or disagree

4) Somewhat disagree

5) Strongly disagree

13. My instructors worked with me on developing facial expressions in my conducting classes.

Formal training

1) Strongly agree

2) Somewhat agree

3) Neither agree or disagree

4) Somewhat disagree

5) Strongly disagree
Assessment instrument measured this attribute
1) Strongly agree
2) Somewhat agree
3) Ncither agree or disagree
4) Somewhat disagree
5) Strongly disagree

14. I was taught to use eye contact as an effective means of musical communication. Formal training
1) Strongly agree
2) Somewhat agree
1) Strongly agree
3) Neither agree or disagree
2) Somewhat agree
4) Somewhat disagree
3) Neither agree or disagree
5) Strongly disagree
4) Somewhat disagree
5) Strongly disagree

Assessment instrument measured this attribute

15. My instructors focused on music history and ensemble repertoire related to my primary conducting ensemble.

Formal training
1) Strongly agree
2) Somewhat agree
3) Neither agree or disagree
4) Somewhat disagree
5) Strongly disagree

Assessment instrument measured this attribute

1) Strongly agree

2) Somewhat agree

3) Neither agree or disagree

4) Somewhat disagree

5) Strongly disagree 
16. Performance skills on my primary instrument or voice were an important part of my musical training.

Formal training

1) Strongly agree

Assessment instrument measured this attribute

2) Somewhat agree

1) Strongly agree

3) Neither agree or disagree

2) Somewhat agree

4) Somewhat disagree

3) Neither agree or disagree

5) Strongly disagree

4) Somewhat disagree

5) Strongly disagree

17. I received training in sight singing skills and ear training development.

Formal training

1) Strongly agree

Assessment instrument measured this attribute

2) Somewhat agree

1) Strongly agree

3) Neither agree or disagree

2) Somewhat agree

4) Somewhat disagree

3) Neither agree or disagree

5) Strongly disagree

4) Somewhat disagree

5) Strongly disagree

18. My instructors stressed modeling musical concepts in rehearsals.

Formal training

1) Strongly agree

2) Somewhat agree

3) Neither agree or disagree

4) Somewhat disagree

5) Strongly disagree
Assessment instrument measured this attribute

1) Strongly agree

2) Somewhat agree

3) Neither agree or disagree

4) Somewhat disagree

5) Strongly disagree

19. Score study and rehearsal preparation was an area of focus in my coursework.

Formal training

1) Strongly agree

2) Somewhat agree

3) Neither agree or disagree

4) Somewhat disagree

5) Strongly disagree
Assessment instrument measured this attribute

1) Strongly agree

2) Somewhat agree

3) Neither agree or disagree

4) Somewhat disagree

5) Strongly disagree

20. Accompanying and arranging skills were part of my training.

Formal training

1) Strongly agree

2) Somewhat agree

3) Neither agree or disagree

4) Somewhat disagree

5) Strongly disagree
Assessment instrument measured this attribute

1) Strongly agree

2) Somewhat agree

3) Neither agree or disagree

4) Somewhat disagree

5) Strongly disagree

21. My instructors helped me develop good error detection skills.

Formal training

1) Strongly agree

2) Somewhat agree

3) Neither agree or disagree
Assessment instrument measured this attribute

1) Strongly agree

2) Somewhat agree

3) Neither agree or disagree 

4) Somewhat disagree
4) Somewhat disagree
5) Strongly disagree
5) Strongly disagree

22. Verbal instruction, the quality of my verbal instruction, and basic communication skills were taught as part of the curriculum.

Formal training

1) Strongly agree

2) Somewhat agree

3) Neither agree or disagree

4) Somewhat disagree

5) Strongly disagree
Assessment instrument measured this attribute

1) Strongly agree

2) Somewhat agree

3) Neither agree or disagree

4) Somewhat disagree

5) Strongly disagree

23. My instructors provided me with insights related to leadership skills and helpful personality traits as part of my training to become an effective conductor.

Formal training

1) Strongly agree

2) Somewhat agree

3) Neither agree or disagree

4) Somewhat disagree

5) Strongly disagree
Assessment instrument measured this attribute

1) Strongly agree

2) Somewhat agree

3) Neither agree or disagree

4) Somewhat disagree

5) Strongly disagree

24. Classroom control and management was covered in my training.

Formal training

1) Strongly agree

2) Somewhat agree

3) Neither agree or disagree

4) Somewhat disagree

5) Strongly disagree
Assessment instrument measured this attribute

1) Strongly agree

2) Somewhat agree

3) Neither agree or disagree

4) Somewhat disagree

5) Strongly disagree

25. I was provided with a current repertoire of teaching methods that prepared me for my current conducting responsibilities.

Formal training

1) Strongly agree

2) Somewhat agree

3) Neither agree or disagree

4) Somewhat disagree

5) Strongly disagree
Assessment instrument measured this attribute

1) Strongly agree

2) Somewhat agree

3) Neither agree or disagree

4) Somewhat disagree

5) Strongly disagree

26. My training included an emphasis on teaching delivery skills.

Formal training

1) Strongly agree

2) Somewhat agree

3) Neither agree or disagree

4) Somewhat disagree

5) Strongly disagree
Assessment instrument measured this attribute

1) Strongly agree

2) Somewhat agree

3) Neither agree or disagree

4) Somewhat disagree

5) Strongly disagree 
27. My conducting classes provided me with rehearsal pacing skills and techniques.

Formal training

1) Strongly agree

2) Somewhat agree

3) Neither agree or disagree

4) Somewhat disagree

5) Strongly disagree
Assessment instrument measured this attribute

1) Strongly agree

2) Somewhat agree

3) Neither agree or disagree

4) Somewhat disagree

5) Strongly disagree

\section{Teaching Musical Concepts and Skills}

Indicate the degree to which you received training in the following skill sets and concepts. Also, rate the following musical skill sets or concepts and areas versus the emphasis placed on these areas in the assessment instrument currently used.

28. Performance skills

Formal training

1) Strongly agree

2) Somewhat agree

3) Neither agree or disagree

4) Somewhat disagree

5) Strongly disagree

29. Expressive interpretation Formal training

1) Strongly agree

2) Somewhat agree

3) Neither agree or disagree

4) Somewhat disagree

5) Strongly disagree

30. Musical fact/concept skills Formal training

1) Strongly agree

2) Somewhat agree

3) Neither agree or disagree

4) Somewhat disagree

5) Strongly disagree

31. Rehearsal attentiveness

Formal training

1) Strongly agree

2) Somewhat agree

3) Neither agree or disagree

4) Somewhat disagree

5) Strongly disagree
Assessment instrument measured this attribute

1) Strongly agree

2) Somewhat agree

3) Neither agree or disagree

4) Somewhat disagree

5) Strongly disagree

Assessment instrument measured this attribute

1) Strongly agree

2) Somewhat agree

3) Neither agree or disagree

4) Somewhat disagree

5) Strongly disagree

Assessment instrument measured this attribute

1) Strongly agree

2) Somewhat agree

3) Neither agree or disagree

4) Somewhat disagree

5) Strongly disagree

Assessment instrument measured this attribute

1) Strongly agree

2) Somewhat agree

3) Neither agree or disagree

4) Somewhat disagree

5) Strongly disagree 
32. Note accuracy/technical skills

Formal training

1) Strongly agree

2) Somewhat agree

3) Neither agree or disagree

4) Somewhat disagree

5) Strongly disagree

33. Articulation and slurring Formal training

1) Strongly agree

2) Somewhat agree

3) Neither agree or disagree

4) Somewhat disagree

5) Strongly disagree

34. Style and phrasing

Formal training

1) Strongly agree

2) Somewhat agree

3) Neither agree or disagree

4) Somewhat disagree

5) Strongly disagree

35. Rhythm

Formal training

1) Strongly agree

2) Somewhat agree

3) Neither agree or disagree

4) Somewhat disagree

5) Strongly disagree

36. Tone quality

Formal training

1) Strongly agree

2) Somewhat agree

3) Neither agree or disagree

4) Somewhat disagree

5) Strongly disagree

37. Pitch discrimination/intonation

Formal training

1) Strongly agree

2) Somewhat agree

3) Neither agree or disagree

4) Somewhat disagree
Assessment instrument measured this attribute

1) Strongly agree

2) Somewhat agree

3) Neither agree or disagree

4) Somewhat disagree

5) Strongly disagree

Assessment instrument measured this attribute

1) Strongly agree

2) Somewhat agree

3) Neither agree or disagree

4) Somewhat disagree

5) Strongly disagree

Assessment instrument measured this attribute

1) Strongly agree

2) Somewhat agree

3) Neither agree or disagree

4) Somewhat disagree

5) Strongly disagree

Assessment instrument measured this attribute

1) Strongly agree

2) Somewhat agree

3) Neither agree or disagree

4) Somewhat disagree

5) Strongly disagree

Assessment instrument measured this attribute

1) Strongly agree

2) Somewhat agree

3) Neither agree or disagree

4) Somewhat disagree

5) Strongly disagree

Assessment instrument measured this attribute

1) Strongly agree

2) Somewhat agree

3) Neither agree or disagree

4) Somewhat disagree 
5) Strongly disagree

38. Balance and blend concepts

Formal training

1) Strongly agree

2) Somewhat agree

3) Neither agree or disagree

4) Somewhat disagree

5) Strongly disagree

\section{Dynamics}

Formal training

1) Strongly agree

2) Somewhat agree

3) Neither agree or disagree

4) Somewhat disagree

5) Strongly disagree

40. Improvisation and composition

Formal training

1) Strongly agree

2) Somewhat agree

3) Neither agree or disagree

4) Somewhat disagree

5) Strongly disagree

41. Ear to hand/aural training

Formal training

1) Strongly agree

2) Somewhat agree

3) Neither agree or disagree

4) Somewhat disagree

5) Strongly disagree

42. Sight singing/sight reading

Formal training

1) Strongly agree

2) Somewhat agree

3) Neither agree or disagree

4) Somewhat disagree

5) Strongly disagree
5) Strongly disagree

Assessment instrument measured this attribute

1) Strongly agree

2) Somewhat agree

3) Neither agree or disagree

4) Somewhat disagree

5) Strongly disagree

Assessment instrument measured this attribute

1) Strongly agree

2) Somewhat agree

3) Neither agree or disagree

4) Somewhat disagree

5) Strongly disagrce

Assessment instrument measured this attribute

1) Strongly agree

2) Somewhat agree

3) Neither agree or disagree

4) Somewhat disagree

5) Strongly disagree

Assessment instrument measured this attribute

1) Strongly agree

2) Somewhat agree

3) Neither agree or disagree

4) Somewhat disagree

5) Strongly disagree

Assessment instrument measured this attribute

1) Strongly agree

2) Somewhat agree

3) Neither agree or disagree

4) Somewhat disagree

5) Strongly disagree 


\section{Assessment and Job Satisfaction}

The following statements relate to your opinion of the assessment instrument used by your administrator.

43. In a general sense, the evaluation process presently used is a good indicator of my teaching and conducting ability.

1) Strongly agree

2) Somewhat agree

3) Neither agree or disagree

4) Somewhat disagree

5) Strongly disagree

44. The assessment instrument presently used is helpful in identifying areas of needed personal growth and development.
1) Strongly agree
2) Somewhat agree
3) Neither agree or disagree
4) Somewhat disagree
5) Strongly disagree

45. The person or persons performing my evaluation is/are qualified to make an accurate assessment of my abilities.
1) Strongly agree
2) Somewhat agree
3) Neither agree or disagree
4) Somewhat disagree
5) Strongly disagree

46. The assessment process affects my sense of job satisfaction.
1) Strongly agree
2) Somewhat agree
3) Neither agree or disagree
4) Somewhat disagree
5) Strongly disagree

47. My personal sense of job satisfaction is high.

1) Strongly agree

2) Somewhat agree

3) Neither agree or disagree

4) Somewhat disagree

5) Strongly disagree

Thank you for your participation in this survey! 


\title{
CURRICULUM VITAE
}

\author{
Eric A. Becher \\ 2 Wood Duck Pond Road \\ Bedminster, NJ 07921 \\ (734) 904-5324 \\ eabecher@gmail.com
}

\section{Professional Experience}

\author{
Society for College \& University \\ Planning: \\ SCUP Planning Institute \\ Certification \\ Graduate, Thrivent Associates - \\ Lutheran College \& University \\ Leadership Program \\ Senior Management Teams \\ Strategic Planning \\ Budget and Policy Development
}

\author{
University Faculty Member (20+ years) \\ Institutional Advancement \\ Capital Campaign/Fundraising \\ Alumni Association \\ Marketing and Communications \\ Enrollment Management \\ Performing Arts Series \\ Community Development \\ Public Speaker/Presenter
}

\section{Institutional Advancement}

The College of St. Elizabeth, Morristown, New Jersey

2008 to 2011

Founded in 1899, The College of St. Elizabeth is a 2,200-student private, undergraduate, residential liberal arts institution sponsored by the Sisters of Charity. Founded initially as a Women's College, in 1995 the College expanded into masters and doctoral programs for both men and women. The College offers more than 32 academic majors and features many preprofessional institutes leading to graduate study and continuing studies for adult students.

Vice President for Institutional Advancement

Created an advancement model approach to fundraising for the college directly tied into the strategic planning process. Provided oversight for the offices of development, annual fund, community relations, communications, special events, implementation processes for the strategic plan, and coordination with the office of alumni relations. Restructured advancement office functions to correct past issues related to marketing, and communications, branding, gift accounting practices, underdeveloped fundraising practices, and IA staff job assignments. Responsible for organizing an institution-wide effort to advance the mission of the college by increasing the external exposure to the College through a presenting series.

- Member of the President's Cabinet, the senior management team for the college. 
- Created a comprehensive plan to meet annual fund goals of $\$ 2,000,000$ of repeatable funds.

- Developed annual fund and stewardship efforts, setting target goals and major gift donor identification processes resulting in two consecutive years of increased giving totals, numbers of gifts, and new donors.

- Began preparations for the launch a $\$ 35$ million Campaign for Chemistry as a springboard for other science-related capital campaign initiatives.

- Worked on implementation facets for the Strategic Plan process:

- Worked directly with the President and Academic Vice President to create an integrated strategic planning and implementation process

- Began implementation efforts on behalf of the college using a department level approach

- Created measurement metrics and benchmarks for strategic plan related to Advancement Team work

- Worked with other College administrators to prioritize new program initiatives per the strategic plan

- Identified major gift prospects and alignment with emerging strategic initiatives

- Assisted with Board of Trustee functions including:

- Meeting and topic preparation

- Report generation, outlines of body of work, etc.

- Trustee Retreat leadership

- Restructured the work of the Development and Marketing Committee of the Board of Trustees and provided information concerning the role of advancement throughout all IA job functions.

- Worked with the Communications Team to revamp the comprehensive marketing/media placement plan for the college.

- Revamped the format and increased the College magazine to twice a year format.

- Created the "Emerging Stories" Committee, dramatically increasing the exposure of the campus through press releases, articles, etc. to the external world.

- Chaired the Web Committee, which provides oversight for the development, training, and maintenance of the new college website. 
- Created and implemented a social media strategy for the College including leadership for the Social Media Committee.

- Policy development for Institutional Advancement procedures including performance metrics and an evaluation system for IA staff. Worked to improve a wide variety of IA staff issues related to job performance, accountability, level of finish, work attendance, job responsibilities, etc.

- Created a CSE Presents Advisory Committee to facilitate a presenting series format for the College that ensures quality, revenue, assessment, and enhanced exposure for the College.

- Created and chaired a new strategic scheduling process for the College.

- Led a database transition effort with the Office of Technology.

- Restructured the role and presentation format for the Administrative Council.

- Regular speaker and representative for the College of Saint Elizabeth in the Madison County community including the Morris County Chamber of Commerce, Madison Area Cultural Alliance, Rotary, Tri-County Scholarship Program, ctc.

Albion College, Albion, Michigan

2007 to 2008

Founded in 1835, Albion College is a 1,950-student private, undergraduate, residential liberal arts institution related to the Methodist Church. Albion offers 27 academic majors and features many pre-professional institutes leading to graduate study.

Vice President for Institutional Advancement

Completely overhauled the advancement office functions to correct past issues related to gift accounting practices, alumni giving percentages, underdeveloped fundraising practices, and IA staff ethics. Created an advancement model approach to fundraising for the college directly tied into the strategic planning process. Provided oversight for the offices of development, annual fund, alumni relations, community relations, communications, special events, and strategic planning. Responsible for organizing an institution-wide effort to advance the mission of the college including the leadership for the planning, implementation, and metrics of the strategic plan.

- Member of the President's Administrative Council, the senior management team for the college.

- Led the Albion College 2015 Strategic Plan process:

- Worked directly with the President to create an integrated strategic planning and implementation process

- Organized nationwide focus groups of various internal and external college constituencies to gather information, assisted with creating the vision and mission statements, and provided a method of prioritization and implementation

- Facilitated implementation efforts on behalf of the college using a department level approach 
- Created measurement metrics and benchmarks for strategic plan initiatives by departments

- Promoted a creative thinking and problem-solving environment for new programs, enhanced revenue, and by developing efficiencies in existing programs

- Prioritized new program initiatives

- Facilitated the requisite analysis framework for new or revised programs

- Created a project analysis process and structure enabling the college to provide thorough research for new or revised initiatives and programs on campus

- Worked with faculty to create a strategic plan and implementation plan for the future of their departments as part of the college-wide strategic plan and capital campaign.

- Assisted with the development of benchmark metrics for the nine areas of the strategic plan.

- Assisted with Board of Trustee functions:

- Board member engagement and recruitment

- Board member alignment with strategic goals

- Restructured the work of the IA Committee of the Board of Trustees and provided information concerning the role of advancement throughout all IA job functions.

- Meeting topics and format planning

- Created an Athletic Advisory Committee to achieve strategic/capital campaign goals.

- Increased giving in all areas of fundraising in the first year; exception - foundation giving.

- Assisted in securing grants of more than $\$ 100,000$ from the Mellon Foundation and the Hearst Foundation.

- Raised over $\$ 5,000,000$ in FY08 despite fallout from previous administration issues.

- Increased the donor pool by more than $33 \%$ in the first year.

- Created a comprehensive plan to meet annual fund goals of $\$ 2,000,000$ of repeatable funds.

- Developed the annual fund and stewardship efforts setting target goals and major gift donor identification processes.

- Worked with the Communications Team to develop a three-year comprehensive marketing/media placement plan for the college.

- Revamped the efforts of Alumni Relations to expand the reach of the college:

- Campus and regional focus group restructuring

- Presidential Inauguration planning

- Alumni Travel program 
- Secured several high profile speakers for Commencement(s) and Convocation including Coach Lloyd Carr (University of Michigan), David Brandon (CEO, Domino's Pizza/University of Michigan Athletic Director), and Bill McKibben (environmentalist).

- Identified major gift prospects and alignment with emerging strategic initiatives.

- Prepared and accompanied the President for major gift donor visits.

- Implemented CASE standards of accounting and receipting working with CASE consultant John Taylor and the Advancement Services Team.

- Provided leadership for the creation of a donor tracking system, next steps functions, wealth screening, and development officer reporting matrix using the Banner platform.

- Policy development for Institutional Advancement procedures including an evaluation system for IA staff. Worked to improve a wide variety of IA staff issues related to job performance, accountability, level of finish, work attendance, job responsibilities, etc.

- Created a Goals vs. Budget report that represented dollars raised (to date) measuring funds by type and category on a comparative year-to-date basis.

- Created a Financial Aid position to identify and coordinate the awarding of designated scholarships facilitating the disbursement of student support and the appropriate stewardship of donors.

- Developed a Stewardship Plan for donors.

- Planned and organized the Presidential Inauguration events to highlight Albion academic strengths, talents of students, and success of signature programs of the college to visiting scholars and dignitaries nationwide.

Concordia University-Ann Arbor, Michigan

2004 to 2007

Founded in 1963. Concordia is a 1,100-student private residential liberal arts institution associated with the Lutheran Church-Missouri Synod as an independent entity of the 10-member national Concordia University System. Concordia University offers undergraduate and graduate degrees in a variety of programs.

Vice President for Institutional Advancement, Marketing, and Institutional Research

Created an advancement model approach to fundraising for Concordia. Provided oversight for the offices of development, annual fund, alumni relations, church relations, community relations, marketing, special events, summer camps, and the cua $^{2}$ rts program. Responsible for organizing an institution-wide effort to advance the mission of the university including leading the planning, implementation, and metrics of the university-wide strategic plan. The planning process included the tactical, operational, master facility, project analysis, and contingency plans.

- Member of the President's Cabinet, the senior management team for the university.

- Led the Concordia University-Ann Arbor (CUAA) Strategic Plan process: 
- Organized focus groups of various constituencies to create the plan and provide a prioritization and vision for the future

- Facilitated implementation efforts on behalf of the university

- Created measurement metrics and benchmarks for strategic plan initiatives

- Worked with faculty to create a plan for the future of their departments as part of the university strategic plan and the forthcoming capital campaign

- Created a project analysis process and structure enabling the university to provide thorough research for new or revised initiatives and programs on campus

- Implemented and led the CUAA DREAM Team concept:

- Promoted a creative thinking and problem-solving environment for new programs, enhanced revenue, and efficiencies in existing programs

- Prioritized new program initiatives

- Provided tangible solutions to ideas, projects, or initiatives that sought to strengthen the university

- Facilitated the requisite analysis for new or revised programs

- Assisted with Board of Regents functions:

- Board member recruitment

- Board governance restructuring

- Meeting topics and format planning

- Worked with members of the Board of Regents to develop a debt reduction strategy for the university.

- Recruited a Health Education and Life Sciences (HEALS) Advisory Committee in preparation for the start of a Nursing program.

- Increased giving in the first two years by $58 \%$ and $71 \%$, respectively, as compared to FY04 giving levels.

- Raised $\$ 2,881,348$ in FY05

- Raised $\$ 4,436,857$ in FY06

- Increased the donor pool by more than $800 \%$.

- Made asks of $\$ 1,000,000$ or more resulting in several major gifts, pledges, and future commitments.

- Worked extensively with Board members and other key donors to secure major gifts.

- Prepared and accompanied the President for major gift solicitations.

- Developed the annual fund and thank you-thon efforts setting target goals and major gift donor identification processes.

- Provided leadership for the creation of a donor tracking system, next steps functions, wealth screening, and development officer reporting matrix using the PowerCampus (Sunguard) platform. 
- Revamped the efforts of the Office of Alumni Relations to expand the reach of the university:

- Campus and regional event development

- Homecoming/Family Weekend restructuring

- Alumni Travel program

- Alumni News and Notes (section of the Arborlight magazine published three times per year)

- Worked with the Office of Marketing to develop a three-year comprehensive marketing/media placement plan for the university.

- Created marketing partnerships with the Ohio and Indiana Districts of the Lutheran Church-Missouri Synod (LCMS) to assist those organizations with marketing strategies and design.

- Reorganized the format and focus of the Arborlight magazine.

- Served as Co-chair of the Athletic Advisory Committee

- Represented Concordia in the Ann Arbor community.

- Executive Director cua ${ }^{2}$ rts. Created and launched the cua ${ }^{2}$ rts (Concordia University Ann Arbor Arts), program bringing nationally and regionally recognized cultural offerings to campus in the visual arts, dance, music, theatre, literary forums, and other liberal arts lectures. Oversight for the Kreft Visual Arts Gallery.

Concordia College-New York, Bronxville, New York

2003 to 2004

A 500-student private liberal arts institution associated with the Lutheran Church-Missouri Synod as an independent entity of the 10-member national Concordia University System.

Vice President for Institutional Advancement Introduced an advancement model approach to fundraising for Concordia College-New York (CCNY). Provided oversight for the offices of development, annual fund, alumni relations, church relations, community relations, and served as the Secretary/Treasurer for CCNY Foundation.

- Member of the President's Council, the senior management team of the college.

- Raised $\$ 4,131,574$ in the first year on campus.

- Developed the annual appeals and phonathon efforts, setting target goals and major gift donor identification processes.

- Provided leadership for the creation of a donor tracking system, next steps functions, wealth screening, and development officer reporting matrix using the Banner platform.

- Developed an advisory board for the Osilas Art Gallery.

- Restructured and organized Homecoming/Parents Weekend activities. 
- Hosted the Hoops and Hearts winter alumni celebration.

- Provided leadership and oversight for new advancement publications:

- Concordia (College) New Yorker Magazine

- Concordia Current

- Compendium

- Taught an Introduction to Philanthropy course in the Accelerated Degree Program.

The University of Connecticut Foundation

2001 to 2003

The UConn Foundation works in support of the University of Connecticut with 127 employees and an operating budget of $\$ 11,000,000$. The University of Connecticut campuses enroll more than 28,000 students.

Assistant Vice President

Worked on all aspects of the $\$ 470$ million capital campaign including workflow management, prioritization, and metrics; major donor and alumni event planning; benchmarking studies, human resource functions, policy development, and assistance with the development of a fundraising strategic plan for the School of Fine Arts.

- Member of the Senior Management Team for the UConn Foundation.

- Capital Campaign planning, implementation, and measurement.

- Organized various events for the campaign including the celebratory kick-off event.

- Completed the strategic development plan for the School of Fine Arts.

- Assisted with Foundation Board of Directors planning and coordination.

- Assisted with planning for Donor Relations initiatives.

- Created and provided ongoing oversight for the Program Planning initiative on behalf of the Foundation, including prioritization of work projects, measurement functions, and status indicators.

- Part of the Change Management Team to restructure the staffing, work functions, and performance metrics for the Foundation.

- Assisted the Office of Human Resources with hiring and training initiatives for Foundation staff including the linkage between the program planning process and individual performance evaluation metrics.

- Participated in faculty/staff campaign training for various schools and departments of the university.

- Provided oversight for:

- Facility operations 
- Administrative support

- Special Events

- Donor Relations

- Performed benchmarking studies to measure:

- Management and structure

- Budget and ebusiness practices

- Worked on major policy committees within the Foundation:

- Privacy policy

- Performance evaluation processes

- Disbursement policy issues

- Served on campus committees:

- Campaign Operations Committee

- Football Traditions Task Force

o Football Stadium Committee

- Homecoming

- UConn Connects program (freshmen retention program)

The University of Connecticut Foundation/School of Fine Arts

2000 to 2001

The School of Fine Arts, with over 100 faculty and staff, offers undergraduate and graduate programs in art and art history, dramatic arts, and music. The School of Fine Arts houses the Ballard Institute and Museum of Puppetry, the Benton Museum of Art, and Jorgensen Auditorium.

Development Officer

Worked extensively with the new Dean to identify strategic fundraising initiatives and create a database of viable donor prospects to achieve goals. Created proposals, went on donor visits, made major gift asks, and accompanied and supported the Dean in several large gift solicitations.

- Served as a member of the School of Fine Arts Executive Committee.

- Worked closely with the Dean, raising more than $\$ 4,000,000$ in the first year.

- Created a new donor database of more than 275 donor prospects with accompanying wealth-screening information in the first year.

- Created a strategic development plan for the School of Fine Arts.

- Identified more than 100 new foundations and granting organizations for support of fine arts programs and initiatives.

- Organized the School of Fine Arts Phonathon.

- Began the cultivation process and laid the groundwork for numerous solicitations for projects in the School of Fine Arts. 
- Organized campus and regional donor cultivation events and School of Fine Arts functions.

- Hosted School of Fine Arts donor relations events and activities.

- Served on a variety of boards and committees associated with the School of Fine Arts:

- School of Fine Arts Vision Committee

- Benton Art Museum Board

- Ballard Institute and Museum of Puppetry Board

- Jorgensen Auditorium Art Deco Renovation Committee

- Band Support Committee

\section{Strategic Planning Leadership}

Brighton District Library, Brighton, Michigan

Library plan

2008 to present

Society for College and University Planners (SCUP)

2008 to present

Member

SCUP Planning Institute Certification, January 2010

Organizational Services, Inc.

Strategic Planning and Advancement Consulting

2008 to present

Albion Public Schools, Albion, Michigan

2008

District plan

Albion College, Albion, Michigan

2007 to 2008

College-wide planning

Concordia University-Ann Arbor, Michigan

2005 to 2007

University-wide planning

University of Connecticut Foundation, Storrs, Connecticut

2001 to 2003

Program Planning

University of Connecticut School of Fine Arts, Storrs, Connecticut

2000 to 2001

Fundraising plan

\section{Music Faculty}

The University of Louisville - School of Music

1997 to 2000

The School of Music is one of 11 colleges and schools at the University of Louisville. The campus has an enrollment of 21,000 undergraduate and graduate students university-wide.

Music Faculty

Served as a professor, band director, and music educator in the School of Music. 
- Conducted various ensembles in the School of Music:

- Marching Band

- Symphonic Band

- Community Band

- Responsible for band program administration.

- Raised funds for the band program (approx. $\$ 100,000$ per year)

- Taught courses in the School of Music:

- Eduprise Program (distance learning course development)

- Music Education

- Hosted music education events, music festivals, and workshops on campus.

- Organized numerous campus-wide and regional music events

- Served on School of Music committees:

- Music Education

- Wind and Percussion

o Recruitment

- Represented the university at various local and regional alumni events for recruitment purposes and actively participated in Admission Office recruiting activities, school visits, and campus events.

- Active guest conductor and clinician.

The University of Minnesota - School of Music

1991 to 1997

The School of Music is one of 17 colleges and professional schools at the University of Minnesota. The campus has an enrollment of 60,000 undergraduate and graduate students university-wide.

Music Faculty

Served as a professor, band director, and music educator in the School of Music. Provided leadership in different administrative capacities on behalf of the band program.

- Conducted ensembles in the School of Music:
- Marching Band
O Wind Ensemble
- Symphonic Band
- Chamber Winds
- Alumni Concert Band

- Responsible for band program administration.

- Taught courses in the School of Music:

- Undergraduate Conducting

- Graduate Conducting 
- Music Education

- Introduction to Music

- Bush Foundation for Diversity in Teaching Grant Recipient

- Hosted music education events and workshops on campus.

- Organized numerous campus and regional music events.

- Served on various committees:

- Music Education

- Recruitment

- Band facility development

- Represented the university at various local and regional alumni events for recruitment purposes and actively participated in Admission Office recruiting activities, school visits, and campus events.

- Active guest conductor and clinician.

The University of Wisconsin, River Falls - Department of Music

Winter 1997

The University of Wisconsin, River Falls is a regional institution as part of the University of Wisconsin

system with an enrollment of 6,000 students in four colleges.

Music Faculty/Leave Replacement Position

Served as a conductor and professor in the Department of Music, for several months, while continuing regular teaching responsibilities at the University of Minnesota.

- Provided assistance for music program administration.

- Conducted ensembles in the Department of Music:

- Symphonic Orchestra

- Symphonic Wind Ensemble

- Taught courses in the Department of Music:

o Conducting

- Music Education

The University of Arizona - School of Fine Arts

The School of Music is one of 17 colleges and schools at the University of Arizona. The campus has an enrollment of more than 36,000 undergraduate and graduate students university-wide.

Music Faculty

Served as a professor, band director, and music educator in the School of Music.

- Conducted ensembles in the School of Music:

o Marching Band 
- Wind Ensemble, Chamber Ensembles

- Symphonic Band

o Alumni Band

- Responsible for band program administration.

- Taught courses in the School of Music:

- Undergraduate Conducting

- Music Education

- Brass and Woodwind Methods

- Supervision of Student Teachers

- Hosted music education events, camps, and workshops on campus.

- Organized several campus-wide music events.

- Served on various committees:

- Music Education

- Recruitment

- Graduate Examining Committee

- Represented the university at various local and regional alumni events; participated in recruiting activities, school visits, and campus events.

- Active guest conductor and clinician.

The University of Michigan - School of Music

1980 to 1989

The School of Music is one of 12 colleges and schools at the University of Michigan. The campus has an enrollment of more than 40,000 undergraduate and graduate students university-wide.

Music Faculty

Served as a professor, band director, and music educator in the School of Music. Became the youngest director of a major college marching band at the age of 23 .

- Conducted ensembles in the School of Music.

- Marching Band

- Concert Band

- Athletic Bands

- Responsible for band program administration.

- Taught courses in the School of Music:

- Undergraduate Conducting

o Music Education

- Secured lead gift of $\$ 1,000,000$ for the Revelli Hall band facility addition.

- Raised funds for the band program (approx. $\$ 100,000$ annually).

- Hosted music education events, camps, and workshops on campus. 
- Organized numerous campus-wide, regional, national, and international music events.

- Served on various committees:

- Music Education

- Wind and Percussion

- Collage Concert

- Represented the university at various local, regional, and international alumni events.

- Guest speaker, Alumni Association of the University of Michigan trip to Europe

- Actively participated in recruiting activities, school visits, and campus events.

- Active guest conductor and clinician.

\section{Education}

The University of Louisville, Louisville, KY Ph.D., Higher Education Administration Anticipated completion date: May 2011

The University of Michigan, Ann Arbor, MI

$\begin{array}{lr}\text { MM, Music Education } & 1980\end{array}$

$\begin{array}{ll}\text { BM, Music Education } & 1978\end{array}$

\section{Present and Past Professional Affiliations}

- Society for College and University Planners (SCUP)

- SCUP Planning Institute Certification

- Association of Independent Colleges and Universities in New Jersey (AICUNJ)

- Council for Advancement and Support of Education (CASE)

- Association of Governing Boards (AGB)

- Morris County Chamber of Commerce

- Urban League of Morris County, Member

- Madison Area Cultural Alliance (MACA)

- Association of Lutheran Development Executives (ALDE)

- Concordia University System (CUS) Advancement Officers

- Thrivent Leadership Associates

- Association of Fundraising Professionals (AFP)

- For the Sake of the Church

- College Band Directors National Association (CBDNA)

- Music Educators National Conference (MENC)

- Kappa Kappa Psi (National Honorary Music Fraternity)

- Tau Beta Sigma (National Honorary Music Sorority) 


\section{Recent Professional Development}

- CASE V, Chicago, December 2010

- CASE Summit 2010 for Advancement Leaders, New York City, July 2010

- SCUP Planning Institute Certification, January 2010

- SCUP Step III Training Conference, Phoenix, AZ, January 2010

- Council of Independent Colleges presentation, CAO Institute, Santa Fe, NM, November 2009

- SCUP Step II Training Conference, Phoenix, AZ, January 2009

- SCUP Step I Training Conference, New Orleans, LA, November 2008

- CASE Summit 08 NYC, Summit for Advancement Leaders, New York City, NY, July 2008

- The Chronicle Executive Leadership Forum: Surviving and Thriving in 2012, Washington, DC, June 2008

- CASE Great Lakes Conference, Chicago IL, December 2007

- President, Indiana/Michigan Chapter, Association of Lutheran Development Executives

- Common Fund Trustee Luncheon, October 2006

- ALDE National Office, District Presidents Teleconference, August 2006

- CUS Vice Presidents for Advancement Meeting, Mequon, WI, August 2006

- Graduate, Thrivent Associates - Lutheran College and University Leadership Program, June 2006

- LCMS Michigan District Convention, June 2006

- Thrivent Beautification Project, May 2006

- Webinar - Creating Case Statements, May 2006

- Webinar - Making the Case for Lutheran Higher Education, March 2006

- Gonser Gerber Tinker Stuhr - Maximizing Impact of Advancement Programs, Chicago, August 2005

- Arts Alliance Conference, Lansing, MI, December 2004

- CUS Development Officers Meeting, St. Louis, August 2004

- LCMS National Convention - St. Louis, July 2004

- ALDE Chapter Workshop, Danbury, CT, May 2004

- For Sake of The Church Meeting, Bronxville, NY, April 2004

- LCMS Gift Planning Specialist Certificate Program, St. Louis, April 2004

- CASE District II Conference, Philadelphia, PA, February 2004

- ALDE National Conference, St. Louis, February 2004

- CASE Conference Capital Campaign Planning, Bentley College, 2003

- CASE Conference, Boston, 2003

- CASE Conference, Advancement Services, New Orleans, 2003

- Global Ethics Workshop, Camden, ME, 2003

- Lee Hecht Harrison - Leadership Development, Hartford, CT, 2002

- Proposal Writing Seminar, Hartford, CT, 2002

- Project Management Training, Hartford, CT, 2002

- Association of Fundraising Professionals Workshop, Meriden, CT, 2002

- UConn Advocates meeting, Hartford, 2002

- Institute for Charitable Giving Seminar, Boston, MA, 2001

- Association of Fundraising Professionals Seminar, Providence, RI, 2001

- Development Internship, Louisville Symphony Orchestra, 2000

- Eduprise Distance Learning Program, University of Louisville, 1999 - 2000 


\section{Selected Recent Presentations, Awards, Activity}

- Volunteer, Visiting Nurse Association of Somerset Hills Fundraising Event

- LCMS Mission Classic Golf Outing

O Chair, 2011

- Committee member 2010

- Presentation, Higher Education Leadership Seminar, University of Louisville, June 2010

- Council for Independent Colleges - Chief Academic Officers Institute presentation, "Insights from Chief Advancement Officers", November 2009

- Brighton District Library - fundraising plan development, September 2009 to present

- Brighton District Library - strategic planning facilitator, September 2008 to present

- Brighton District Library presentations, June/July 2008, July 2009, July 2010

- Presentation, Higher Education Leadership Seminar, University of Louisville, June 2009

- Albion College Board of Trustees presentation, February 2008

- Albion Public Schools, presentations, January - May 2008

- Albion College Board of Trustees presentation, October 2007

- Communication plan presentations, Indiana District LCMS Board, November - February 2007

- Recognition Award, University of Michigan Band Alumni, October 2006

- Host, Faithful Sowers (Planned Giving) Conference, October 2006

- Communication plan presentation, Ohio District LCMS Board, August 2006

- Presentation, Indiana-Michigan Regional ALDE Conference, June 2006

- Presentation, ALDE National Conference, Columbus, February 2006

- Presentation, Indiana-Michigan Regional ALDE Conference, June 2005

- Speaker, LWML Conference, Unionville, MI, May 2005

- Presentation, CASE Conference, Baltimore, January 2005

- Presentation, LCMS Atlantic District Workshop, March 2004

- Music Educators National Conference, Conductor, 2000

- Coordinator, Smart Music Technology Workshop, University of Louisville, 1999

- Presentation, College Band Directors Association, Green Bay, Wisconsin, 1996

- Presentation, Minnesota Music Educators Association, Minneapolis, 1996

- Recipient, University of Minnesota Bush Foundation for Diversity in Teaching, 1995 to 1996 